VAGNER CANDIDO DE SOUSA

Análise do comportamento eletroaeroelástico de uma seção típica para geração piezelétrica de energia 
VAGNER CANDIDO DE SOUSA

\section{Análise do comportamento eletroaeroelástico de uma seção típica para geração piezelétrica de energia}

Dissertação apresentada à Escola de Engenharia de São Carlos, da Universidade de São Paulo, como parte dos requisitos para obtenção do título de Mestre em Engenharia Mecânica

Área de Concentração: Aeronaves

Orientador: Prof. Dr. Carlos De Marqui Junior 
AUTORIZO A REPRODUÇÃO E DIVULGAÇÃO TOTAL OU PARCIAL DESTE TRABALHO, POR QUALQUER MEIO CONVENCIONAL OU ELETRÔNICO, PARA FINS DE ESTUDO E PESQUISA, DESDE QUE CITADA A FONTE.

Ficha catalográfica preparada pela Seção de Tratamento da Informação do Serviço de Biblioteca - EESC/USP

Sousa, Vagner Candido de.

S725a Análise do comportamento eletroaeroelástico de uma seção típica para geração piezelétrica de energia. / Vagner Candido de Sousa ; orientador Carlos De Marqui Júnior -- São Carlos, 2011.

Dissertação (Mestrado em Engenharia Mecânica com Área de Concentração em Aeronaves) -- Escola de Engenharia de São Carlos da Universidade de São Paulo, 2011.

1. Vibrações mecânicas. 2. Aeroelasticidade.

3. Piezeletricidade. 4. Geração de Energia. I. Título. 


\section{FOLHA DE JULGAMENTO}

Candidato: Engenheiro VAGNER CANDIDO DE SOUSA.

Título da dissertação: "Análise do comportamento eletroaeroelástico de uma seção típica para geração piezelétrica de energia".

Data da defesa: $13 / 02 / 2012$

\section{Comissão Julgadora:}

Prof. Dr. Carlos de Marqui Junior (Orientador)

(Escola de Engenharia de São Carlos/EESC)

Prof. Associado Flavio Donizete Marques

(Escola de Engenharia de São Carlos/EESC)

Prof. Dr. Mauricio Vicente Donadon

(Instituto Tecnológico de Aeronáutica)
Resultado:
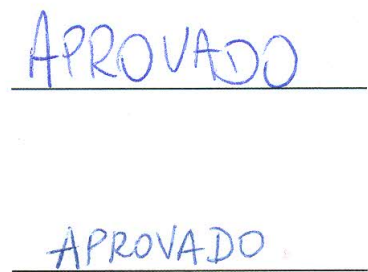

Coordenador do Programa de Pós-Graduação em Engenharia Mecânica:

Prof. Associado Marcelo Areias Trindade

Presidente da Comissão de Pós-Graduação:

Prof. Associado Paulo Cesar Lima Segantine 
À minha família. 


\section{AGRADECIMENTOS}

Ao meu orientador, Prof. Dr. Carlos De Marqui Junior, pela grande ajuda, atenção, paciência, por não desistir nos momentos em que tive mais dificuldades e pelas oportunidades que ainda virão.

À Escola de Engenharia de São Carlos, pela oportunidade.

Ao departamento de Engenharia Aeronáutica (alunos, professores e funcionários), pelo auxílio em assuntos aleatórios e pela amizade desenvolvida, em especial ao Wander e à Marcela, pela ajuda no início deste mestrado.

Ao Conselho Nacional de Desenvolvimento Científico e Tecnológico (CNPq), pelo apoio financeiro (processo número 155695/2010-0).

Ao pessoal das salas de pós-graduação (incluindo alunos de intercâmbio), pela companhia.

À minha família, em especial ao meu irmão Valdir, pelas oportunidades em São Carlos, que me trouxeram até aqui.

À Fernanda, pela paciência e apoio.

A todos que de alguma maneira contribuíram para com esta investigação. 
A vida virtuosa é aquela inspirada pelo amor e guiada pelo conhecimento.

Bertrand Russell 


\section{Resumo}

SOUSA, V. C. Análise do comportamento eletroaeroelástico de uma seção típica para geração piezelétrica de energia. 2011. 57f. Dissertação (Mestrado) - Escola de Engenharia de São Carlos, Universidade de São Paulo, São Carlos, 2011.

A conversão de vibrações aeroelásticas em eletricidade para a geração de pequenas quantidades de potência tem recebido cada vez mais atenção nos últimos anos. Além de aplicações em potencial para estruturas aeroespaciais, o objetivo é desenvolver configurações alternativas para a coleta de energia do escoamento e usá-las em sistemas eletrônicos sem fio. O uso de uma seção típica é uma abordagem conveniente para criar instabilidades e oscilações persistentes na coleta aeroelástica de energia. Este trabalho analisa as versões linear e não linear de dois geradores aeroelásticos de energia baseados em aerofólio que utilizam transdução piezelétrica: (1) com dois graus de liberdade (GDL) e (2) com três GDL. As equações governantes eletroaeroelásticas adimensionais são dadas em cada caso com uma carga resistiva no domínio elétrico para a previsão do comportamento do sistema. Primeiro, a interação entre a geração piezelétrica de potência e os comportamentos aeroelásticos linear e não linear de uma seção típica com 2-GDL é investigada para um conjunto de cargas resistivas. As previsões do modelo são comparadas com dados experimentais obtidos em ensaios em túnel de vento na condição de flutter. No segundo estudo de caso, uma não linearidade bilinear é adicionada ao GDL de rotação da seção típica. Mostra-se que oscilações não lineares em ciclo limite podem ser obtidas abaixo da velocidade linear de flutter. As simulações do modelo previram com sucesso os resultados experimentais. Finalmente, a combinação das não linearidades rigidez cúbica (do tipo que se torna mais rígida proporcionalmente ao cubo do deslocamento) e bilinear é considerada no GDL de rotação da seção típica. A resposta piezoaeroelástica não linear é investigada para diferentes valores da razão entre a rigidez não linear e a rigidez linear. A não linearidade bilinear reduz a velocidade em que oscilações persistentes aparecem enquanto que a rigidez cúbica contribui para com a obtenção de oscilações persistentes de amplitude aceitável em uma faixa mais ampla de velocidades do escoamento. Em seguida, os comportamentos piezoaeroelásticos linear e não linear de uma seção típica com 3-GDL são investigados. A não linearidade bilinear é adicionada ao GDL de rotação da superfície de controle. Mostra-se que oscilações não lineares em ciclo limite podem ser obtidas em uma faixa de velocidades do escoamento. No último caso, a não linearidade cúbica é modelada no GDL de rotação da seção típica (além da não linearidade bilinear na superfície de controle) e oscilações de amplitude limitada são obtidas em uma faixa de velocidades do escoamento. Não linearidades concentradas podem ser introduzidas em geradores aeroelásticos de energia (que utilizam transdução piezelétrica ou outro mecanismo transdutor) para melhoria do desempenho do sistema.

Palavras-chave: Vibrações mecânicas. Aeroelasticidade. Piezeletricidade. Geração de Energia. 


\section{Abstract}

SOUSA, V. C. Electroaeroelastic behavior analysis of a typical section for piezoelectric energy harvesting. 2011. 57f. Dissertação (Mestrado) - Escola de Engenharia de São Carlos, Universidade de São Paulo, São Carlos, 2011.

Converting aeroelastic vibrations into electricity for low power generation has received growing attention over the past few years. In addition to potential applications for aerospace structures, the goal is to develop alternative and scalable configurations for wind energy harvesting to use in wireless electronic systems. The use of a typical airfoil section is a convenient approach to create instabilities and persistent oscillations in aeroelastic energy harvesting. This work analyzes the linear and non linear versions of two airfoil-based aeroelastic energy harvesters using piezoelectric transduction: (1) with two degrees of freedom (DOF) and (2) with three DOF. The governing dimensionless electroaeroelastic equations are given in each case with a resistive load in the electrical domain for predicting the system behavior. First the interaction between piezoelectric power generation and linear and non linear aeroelastic behavior of a typical section with 2-DOF is investigated for a set of resistive loads. Model predictions are compared to experimental data obtained from the wind tunnel tests at the flutter boundary. In the second case study, free play nonlinearity is added to the pitch DOF and it is shown that nonlinear limitcycle oscillations can be obtained below the linear flutter speed. The experimental results are successfully predicted by the model simulations. Finally, the combination of cubic hardening stiffness and free play nonlinearities is considered in the pitch DOF. The nonlinear piezoaeroelastic response is investigated for different values of the nonlinear-to-linear stiffness ratio. The free play nonlinearity reduces the cut-in speed while the hardening stiffness helps in obtaining persistent oscillations of acceptable amplitude over a wider range of airflow speeds. Later the linear and non linear piezoaeroelastic behavior of a typical section with 3-DOF is investigated. Free play nonlinearity is added to the control surface DOF and it is shown that nonlinear limit-cycle oscillations can be obtained over a range of airflow speeds. In the last case cubic hardening nonlinearity is modeled in the pitch DOF (in addition to the free play in the control surface) and bounded oscillations are obtained for a range of airflow speeds. Concentrated nonlinearities can be introduced to aeroelastic energy harvesters (exploiting piezoelectric or other transduction mechanisms) for performance enhancement.

Keywords: Mechanical vibrations. Aeroelasticity. Piezoelectricity. Energy harvesting. 


\section{Lista de Figuras}

Figura - 1 Esquema de um gerador piezelétrico conectado ao circuito externo a) um gerador unimorph e b) um gerador piezelétrico bimorph .......... 23

Figura - 2 Comportamentos aeroelásticos a) super-crítico e b) sub-crítico

Figura - 3 Asa geradora e seção transversal da região com eletrodos embutidos, a) eletrodos contínuos e b) eletrodos segmentados (DE MARQUI; ERTURK; INMAN, 2010)

Figura - 4 Esquemático do conceito de operação do microgerador de potência proposto em Bibo, Li e Daqaq (2011)

Figura - 5 Esquemático da estrutura piezelétrica em forma de $\mathrm{T}$ proposta em Kwon (2010)

Figura - 6 Esquemático da estrutura proposta em Sirohi e Mahadik (2011)

Figura - 7 Esquemático do conceito de operação do gerador proposto em Zhu et al. (2010) a) esquemático do gerador e b) dispositivo experimental

Figura $-8 \quad$ Gerador proposto em Bryant e Garcia $(2011) \quad \ldots \ldots \ldots \ldots \ldots \ldots \ldots \ldots \ldots$

Figura - 9 Uma seção típica aeroelástica com 3-GDL (TANG; DOWELL, 2010) _.. 33

Figura - 10 Fotos do sistema experimental, a) molas de flexão e b) mola de torção $\ldots . .51$

Figura - 11 Fotos do sistema experimental: a) a seção típica posicionada no túnel de vento e b) uma piezocerâmica colada a uma das vigas de aço-mola $\ldots . .552$

Figura - 12 Análise de estabilidade por autovalores do sistema linear 2-GDL para a condição elétrica variando desde curto-circuito $\left(R_{l} \rightarrow 0\right)$ até circuito aberto $\left(R_{l} \rightarrow \infty\right)$

Figura - 13 Variação da potência adimensional produzida conforme a carga resistiva para o sistema linear 2-GDL e na fronteira de flutter

Figura - 14 Resposta no tempo (deslocamento linear adimensional) do sistema linear 
2-GDL para a carga resistiva ótima $\left(\lambda=1.7 \times 10^{8}\right.$ ou $\left.R_{l}=10^{5} \Omega\right)$ e na

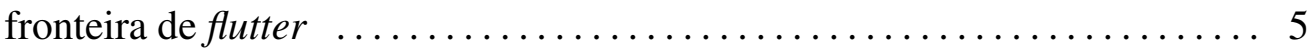

Figura - 15 Resposta no tempo (ângulo de rotação da seção típica) do sistema linear 2-GDL para a carga resistiva ótima $\left(\lambda=1.7 \times 10^{8}\right.$ ou $\left.R_{l}=10^{5} \Omega\right)$ e na fronteira de flutter ................................. 56

Figura - 16 Resposta no tempo (voltagem adimensional) do sistema linear 2-GDL para a carga resistiva ótima $\left(\lambda=1.7 \times 10^{8}\right.$ ou $\left.R_{l}=10^{5} \Omega\right)$ e na fronteira de flutter

Figura - 17 Momentos elásticos medidos experimentalmente para o sistema 2-GDL linear e não linear com mola bilinear no GDL de rotação (SOUSA et al., 2011)

Figura - 18 Variação da potência elétrica adimensional produzida conforme a carga resistiva adimensional para o sistema não linear 2-GDL

Figura - 19 Resposta no tempo (deslocamento linear adimensional) do sistema não linear 2-GDL com mola bilinear no GDL de rotação e para a carga resistiva ótima

Figura - 20 Resposta no tempo (rotação da seção típica) do sistema não linear com 2GDL com mola bilinear no GDL de rotação da seção típica para a carga resistiva ótima

Figura - 21 Resposta no tempo (voltagem adimensional) do sistema não linear 2-GDL com mola bilinear no GDL de rotação e para a carga resistiva ótima

Figura - 22 Variação da amplitude de deslocamento linear com a variação da velocidade do sistema 2-GDL com não linearidade combinada para cada razão de rigidez e na condição de curto-circuito

Figura - 23 Variação da amplitude de rotação com a variação da velocidade do sistema 2-GDL com não linearidade combinada para cada razão de rigidez e na condição de curto-circuito

Figura - 24 Variação da potência elétrica com o aumento da velocidade do escoamento para o sistema 2-GDL com não linearidade combinada e para cada carga resistiva $(\eta=100)$

Figura - 25 Variação da amplitude de deslocamento linear com o aumento da velocidade do sistema 2-GDL com não linearidade combinada e para cada carga 
resistiva $(\eta=100)$

Figura - 26 Variação da amplitude de rotação com o aumento da velocidade do sistema 2-GDL com não linearidade combinada e para cada carga resistiva $(\eta=$ 100)

Figura - 27 Variação da velocidade linear crítica em função da carga resistiva e do acoplamento eletromecânico

Figura - 28 Variação da potência elétrica adimensional em função da carga resistiva e do acoplamento eletromecânico

Figura - 29 Variação da velocidade linear de flutter com a carga resistiva e a capacitância equivalente

Figura - 30 Variação da potência elétrica adimensional com a carga resistiva e a capacitância equivalente

Figura - 31 Análise de estabilidade por autovalores para o sistema linear com 3-GDL nas condições de curto-circuito $\left(R_{l} \rightarrow 0\right)$ à circuito aberto $\left(R_{l} \rightarrow \infty\right) \ldots \ldots$

Figura - 32 Resposta no tempo (deslocamento linear) do sistema linear com 3-GDL para a carga resistiva ótima

Figura - 33 Resposta no tempo (rotação da seção típica) do sistema linear com 3-GDL para a carga resistiva ótima

Figura - 34 Resposta no tempo (rotação da superfície de controle) do sistema linear com

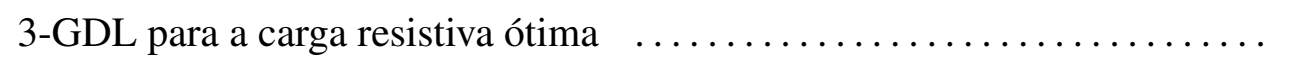

Figura - 35 Resposta no tempo (voltagem) do sistema linear com 3-GDL para a carga resistiva ótima

Figura - 36 Resposta no tempo (potência) do sistema linear com 3-GDL para a carga resistiva ótima

Figura - 37 Variação da potência elétrica adimensional convertida pelo sistema 3-GDL com mola bilinear na superfície de controle conforme a velocidade reduzida do escoamento e para a carga resistiva ótima

Figura - 38 Variação da amplitude de deslocamento linear com o aumento da velocidade para o sistema 3-GDL e não linearidades combinadas $\left(R_{l} \rightarrow 0\right)$ 
Figura - 39 Variação da amplitude de rotação da seção típica com aumento da velocidade para o sistema 3-GDL e não linearidades combinadas $\left(R_{l} \rightarrow 0\right) \ldots \ldots$

Figura - 40 Variação da amplitude de rotação da superfície de controle com aumento da velocidade para o sistema 3-GDL e não linearidades combinadas $\left(R_{l} \rightarrow 0\right) \quad 77$

Figura - 41 Variação da potência elétrica com o aumento de velocidade para o sistema 3-GDL com não linearidades combinadas e carga resistiva ótima . . . . . 77

Figura - 42 Comparação da conversão de potência elétrica entre os casos linear, bilinear e com não linearidade combinada para a seção típica 3-GDL 78 


\section{Lista de Tabelas}

Tabela $-1 \quad$ Parâmetros do sistema experimental com $2-$ GDL $\ldots \ldots \ldots \ldots \ldots \ldots .53$

Tabela - 2 Parâmetros adimensionais do modelo com 2-GDL $\ldots \ldots \ldots \ldots \ldots \ldots$

Tabela - 3 Parâmetros adimensionais do modelo com 3-GDL $\ldots \ldots \ldots \ldots \ldots \ldots . \ldots 9$ 


\section{Acrônimos}

2-GDL Dois graus de liberdade

3-GDL Três graus de liberdade

CG Centro de gravidade

EA Eixo de articulação (da superfície de controle)

EE Eixo elástico (do aerofólio)

EDO Equação diferencial ordinária

GDL Grau de liberdade

LCO Oscilação em ciclo limite (Limit Cycle Oscillation)

MAV Micro veículo aéreo (Micro-air Vehicle)

MFC Macro Fiber Composite

PVDF Fluoreto de polivinilideno

PZT Titanato zirconato de chumbo

SHM Sistema de verificação de integridade estrutural (Structural Health Monitoring)

UAV Veículo aéreo não-tripulado (Unmanned Aerial Vehicle) 


\section{Lista de Símbolos}

$h \quad$ Deslocamento linear da seção típica, p. 33

$\alpha \quad$ Ângulo de rotação da seção típica, p.33

$\beta \quad$ Ângulo de rotação da superfície de controle, p. 33

$b \quad$ Semicorda da seção típica, p. 33

$x_{\alpha} \quad$ Distância em semicordas entre o EE e o CG da seção típica, p. 33

$x_{\beta} \quad$ Distância em semicordas entre o EA e o CG da superfície de controle, p. 33

a Distância em semicordas do ponto médio da corda ao EE, p. 33

c Distância em semicordas do ponto médio da corda ao EA, p. 33

$k_{h} \quad$ Rigidez da mola do GDL de deslocamento linear (por unidade de comprimento), p. 33

$k_{\alpha} \quad$ Rigidez da mola do GDL de rotação da seção típica (por unidade de comprimento), p. 33

$k_{\beta} \quad$ Rigidez da mola do GDL de rotação da superfície de controle (por unidade de comprimento), p. 33

$\delta \quad$ Primeira variação de um funcional, p. 34

T Energia cinética total (por unidade de comprimento), p. 34

$U \quad$ Energia potencial total (por unidade de comprimento), p. 34

$W_{i e} \quad$ Energia elétrica interna (por unidade de comprimento), p. 34

$W_{n c e} \quad$ Componente do trabalho virtual devido à carga elétrica (por unidade de comprimento), p. 34

$W_{n c a} \quad$ Componente do trabalho virtual devido ao carregamento aerodinâmico (por unidade de comprimento), p. 34

$W_{s d} \quad$ Componente do trabalho virtual devido ao amortecimento estrutural (por unidade de comprimento), p. 34

$m \quad$ Massa da seção típica (por unidade de comprimento), p. 35 
$m_{f} \quad$ Massa das fixações (por unidade de comprimento), p. 35

$m_{\beta} \quad$ Massa da superfície de controle (por unidade de comprimento), p. 35

$I_{\alpha} \quad$ Momento de inércia da seção típica (por unidade de comprimento), p. 35

$I_{\beta} \quad$ Momento de inércia da superfície de controle (por unidade de comprimento), p. 35

$\theta \quad$ Termo de acoplamento eletromecânico, p. 35

$l \quad$ Envergadura da seção típica, p. 35

$v \quad$ Voltagem entre os terminais da carga resistiva, p. 35

$C_{p}^{e q} \quad$ Capacitância equivalente das camadas piezocerâmicas, p. 35

$Q \quad$ Carga elétrica (por unidade de comprimento), p. 35

$L \quad$ Força de sustentação (por unidade de comprimento), p. 35

$M_{\alpha} \quad$ Momento aerodinâmico da seção típica (por unidade de comprimento), p. 35

$M_{\beta} \quad$ Momento aerodinâmico da superfície de controle (por unidade de comprimento), p. 35

$d_{h} \quad$ Coeficiente de amortecimento do GDL de deslocamento linear (por unidade de comprimento), p. 35

$d_{\alpha} \quad$ Coeficiente de amortecimento do GDL de rotação da seção típica (por unidade de comprimento), p. 35

$d_{\beta} \quad$ Coeficiente de amortecimento do GDL de rotação da superfície de controle (por unidade de comprimento), p. 35

$q_{i} \quad$ Coordenada generalizada, p. 36

$\mathscr{Q}_{i} \quad$ Força não conservativa, p. 36

$R_{l} \quad$ Carga resistiva elétrica, p. 36

$v^{*} \quad$ Voltagem de referência para adimensionalização, p. 37

$r_{\alpha} \quad$ Raio de giração da seção típica, p. 37

$r_{\beta} \quad$ Raio de giração da superfície de controle, p.37

$\bar{h} \quad$ Deslocamento linear adimensional, p. 37

$\omega_{\alpha} \quad$ Frequência natural desacoplada de rotação da seção típica, p. 37 
$\omega_{\beta} \quad$ Frequência natural desacoplada de rotação da superfície de controle, p. 37

$\omega_{h} \quad$ Frequência natural desacoplada de deslocamento linear, p. 37

$\mu \quad$ Razão entre a massa total e a massa da seção típica, p. 37

$\bar{v} \quad$ Voltagem adimensional, p. 37

$\tau \quad$ Tempo adimensional, p. 37

$t \quad$ Tempo dimensional, p. 37

I Diferenciação no tempo adimensional, p. 38

$\xi_{\alpha} \quad$ Razão de amortecimento (por unidade de comprimento) no GDL de rotação da seção típica, p. 38

$\xi_{\beta} \quad$ Razão de amortecimento (por unidade de comprimento) no GDL da superfície de controle, p. 38

$\xi_{h} \quad$ Razão de amortecimento (por unidade de comprimento) no GDL de deslocamento linear, p. 38

$\eta_{\alpha} \quad$ Razão de frequências $\omega_{\alpha} / \omega_{h}$, p. 38

$\eta_{\beta} \quad$ Razão de frequências $\omega_{\beta} / \omega_{h}$, p. 38

$\psi \quad$ Capacitância adimensional, p. 38

$\chi \quad$ Acoplamento eletromecânico adimensional, p. 38

$\lambda \quad$ Carga resistiva adimensional, p. 38

$p^{*} \quad$ Potência elétrica adimensional, p. 38

$\bar{M}_{\alpha} \quad$ Momento aerodinâmico adimensional da seção típica, p. 38

$\bar{M}_{\beta} \quad$ Momento aerodinâmico adimensional da superfície de controle, p. 38

$\bar{L} \quad$ Força de sustentação adimensional, p. 38

I $\quad$ Matriz identidade, p. 39

$T \quad$ (superscrito) Vetor transposto, p. 39

$\Theta \quad$ Vetor de acoplamento eletromecânico, p.39

$\mathscr{F} \quad$ Carregamento aerodinâmico adimensional, p. 39

M Matriz estrutural de parâmetros inerciais adimensionais, p. 39

K Matriz estrutural de parâmetros adimensionais de rigidez, p.39 
B Matriz estrutural de parâmetros adimensionais de amortecimento, p. 39

$U \quad$ Velocidade do escoamento, p. 40

$\rho \quad$ Densidade do ar, p. 40

$T_{i} \quad$ Constantes de Theodorsen, p. 40

$C(\kappa) \quad$ Função Generalizada de Theodorsen, p. 40

$\varepsilon \quad$ Massa adicional virtual, p. 42

$x_{a_{i}} \quad$ Estados adicionais do modelo aerodinâmico, p. 42

$\mathbf{x}_{a} \quad$ Vetor de estados aerodinâmicos, p. 42

$\mathbf{S}_{i} \quad$ Vetores associados ao carregamento circulatório, p. 42

D Termos de acoplamento aerodinâmico-estrutural, p. 43

R Termos associados ao carregamento circulatório, p. 43

$\tilde{\mathbf{M}} \quad$ Matriz de parâmetros inerciais adimensionais, p. 43

K $\quad$ Matriz de parâmetros adimensionais de rigidez, p. 43

B $\quad$ Matriz de parâmetros adimensionais de amortecimento, p. 43

$\mathbf{M}_{n c}$ Contribuição do escoamento não circulatório à massa total, p. 43

$\mathbf{K}_{n c} \quad$ Contribuição do escoamento não circulatório à rigidez total, p. 43

$\mathbf{B}_{n c} \quad$ Contribuição do escoamento não circulatório ao amortecimento total, p. 43

$\tilde{\mathbf{E}}_{i} \quad$ Termos de acoplamento estrutural das equações aerodinâmicas, p. 43

$\tilde{\mathbf{F}}_{p} \quad$ Termos aerodinâmicos das equações adicionais, p. 43

D Acoplamento aerodinâmico-estrutural no tempo adimensional, p. 43

A Matriz de estados do sistema piezoaeroelástico linear, p. 44

$\hat{\mathbf{x}} \quad$ Vetor de estados adimensionais, p. 44

$\bar{f}_{\alpha b} \quad$ Momento elástico bilinear no GDL de rotação da seção típica, p. 45

$\bar{f}_{\alpha c} \quad$ Momento elástico cúbico no GDL de rotação da seção típica, p. 45

$\bar{f}_{\beta b} \quad$ Momento elástico bilinear no GDL de rotação da superfície de controle, p. 45

$\alpha_{s} \quad$ Fronteira da mola bilinear no GDL de rotação da seção típica, p. 45

$\eta_{c} \quad$ Razão de frequências $\omega_{\alpha c} / \omega_{h}$, p. 46 
$\omega_{\alpha c} \quad$ Frequência natural desacoplada de rotação da seção típica correspondente à mola cúbica, p. 46

$\beta_{s} \quad$ Fronteira da mola bilinear no GDL de rotação da superfície de controle, p. 46

a Matriz de estados da porção não linear do sistema piezoaeroelástico, p. 46

y Vetor constante associado aos estados não lineares, p. 47

$\gamma_{h} \quad$ Autovalor do GDL de deslocamento linear, p. 54

$u \quad$ Velocidade reduzida, p. 54

$u_{L F} \quad$ Velocidade linear de flutter (reduzida), p. 54

$\delta_{\alpha} \quad$ Região nominal de folga da mola bilinear de rotação da seção típica, p. 57

$\bar{u} \quad$ Razão entre a velocidade do escoamento e a velocidade linear de flutter, p. 62

$\delta_{\beta} \quad$ Região nominal de folga na mola bilinear de rotação da superfície de controle, p. 74

$\kappa \quad$ Razão entre a rigidez da mola cúbica e a rigidez da mola linear do GDL de rotação da seção típica, p. 75 


\section{Sumário}

1 Introdução 21

2 Revisão da Literatura 26

3 Modelo por Parâmetros Concentrados de uma Seção Típica Piezoaeroelástica 33

3.1 Modelo por Parâmetros Concentrados para uma Seção Típica Piezoaeroelástica 34

3.2 Representação das Equações de Movimento em Espaço de Estados . . . . . . . . 37

3.3 Modelo Aerodinâmico Não Estacionário para Movimentos Arbitrários . . . . . . 39

3.4 Modelo Piezoaeroelástico Não Linear . . . . . . . . . . . . . . . . . . . . . . . 44

3.4.1 Representação das Equações Não Lineares de Movimento em Espaço de Estados 46

3.5 Método de Hénon . . . . . . . . . . . . . . . . . . . . . . 47

3.5.1 Aplicação do Método de Hénon à Seção Típica Piezoaeroelástica Não Linear 49

4 Resultados $\quad 50$

$4.1 \quad$ Seção Típica com Dois Graus de Liberdade . . . . . . . . . . . . . . . . . . . 51

4.1.1 Análise do Comportamento Piezoaeroelástico Linear . . . . . . . . . . . . 54

4.1.2 Seção Típica Piezoaeroelástica com Não Linearidade Bilinear ～. . . . . . . . . 57

4.1.3 Seção Típica Piezoaeroelástica com Não Linearidade Combinada . . . . . . . . . 62

4.1.4 Análise da Influência de Parâmetros sobre o Comportamento Piezoaeroelástico

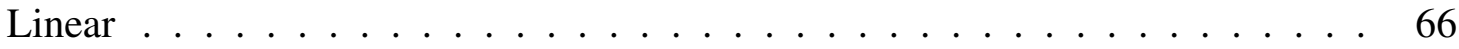

4.2 Seção Típica com Três Graus de Liberdade . . . . . . . . . . . . . . . . . . . . 69

4.2.1 Análise do Comportamento Piezoaeroelástico Linear . . . . . . . . . . . . . . . 69 
4.2.2 Caso Não Linear com Mola Bilinear no Grau de Liberdade de Rotação da Superfície de Controle . . . . . . . . . . . . . . . . . . . . . . . . 74

4.2.3 Caso Não Linear com Mola Cúbica no Grau de Liberdade de Rotação do Aerofólio e Mola Bilinear na Superfície de Controle . . . . . . . . . . . . . . . . 75

4.2.4 Análise Comparativa dos Casos Linear, Bilinear e com Não Linearidade Combinada para a Seção Típica com Três Graus de Liberdade . . . . . . . . . . . . . 78

5 Conclusões $\quad 79$

$5.1 \quad$ Conclusões deste trabalho . . . . . . . . . . . . . . . . . . . . . 79

5.2 Sugestões para trabalhos futuros $\ldots \ldots \ldots \ldots$. . . . . . . . . 81

$\begin{array}{ll}\text { Referências } & 82\end{array}$

APÊNDICE A - Equações de Lagrange para o Sistema Piezoaeroelástico $\quad 88$

APÊNDICE B - Submatrizes do Modelo Aerodinâmico 90

APÊNDICE C - Constantes de Theodorsen 92

$\begin{array}{ll}\text { Publicações decorrentes deste trabalho } & 93\end{array}$ 


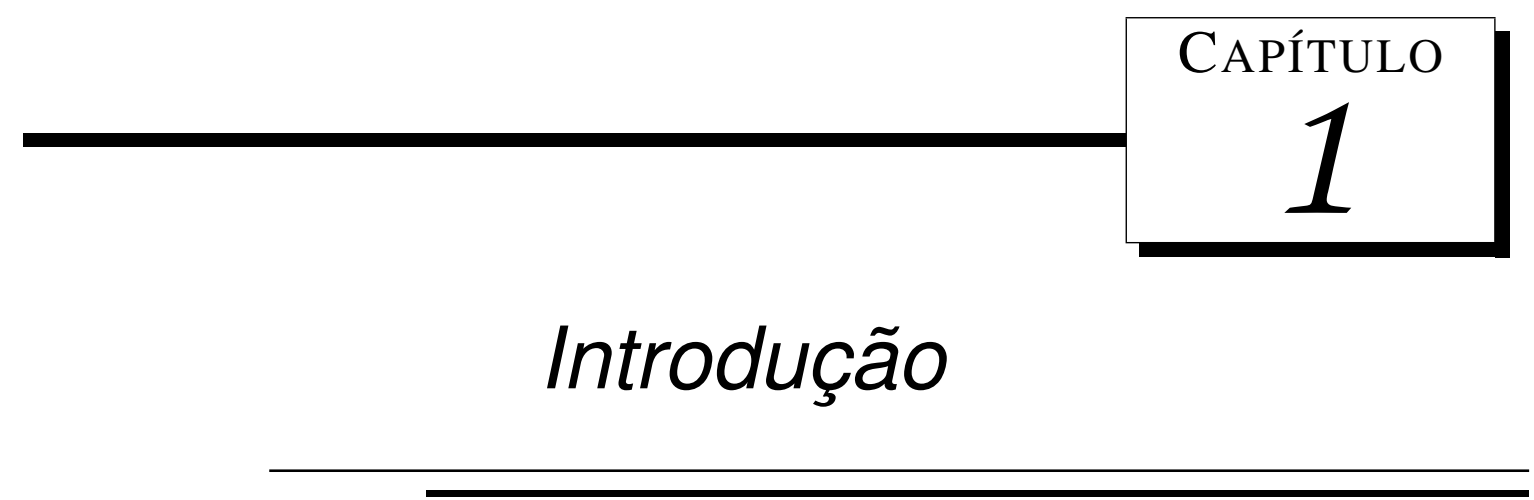

A conversão de energia de vibração disponível no ambiente em energia elétrica vem sendo investigada por vários grupos de pesquisa nos últimos anos. Este conceito (energy harvesting) é particularmente importante para sistemas remotamente operados e com fontes limitadas de energia. Incluem-se nesta categoria, por exemplo, sistemas de verificação de integridade estrutural (Structural Health Monitoring - SHM) instalados em regiões de difícil acesso (pontes, oleodutos e gasodutos, ou mesmo estruturas aeronáuticas, entre outros), satélites e veículos autônomos (como aeronaves UAVs - Unmanned Aerial Vehicles - e MAVs - Micro Air Vehicles - e veículos terrestres). Na maioria dos casos a substituição periódica de baterias do sistema (como nos sistemas de SHM) se faz necessária, em outros a vida útil do sistema ou a duração de uma missão (UAV e MAV) pode ser limitada pela duração de sua fonte de energia, que não pode ser substituída durante a operação. A possibilidade de alimentar componentes eletrônicos de baixo consumo destes sistemas, recarregar suas baterias ou em um caso extremo torná-los energeticamente autônomos é a principal motivação para a investigação da conversão, ou coleta, de energia de vibração existente no ambiente em eletricidade.

Williams e Yates (1996) apresentaram pela primeira vez na literatura a ideia de se converter vibrações em eletricidade. Um modelo por parâmetros concentrados para prever a potência elétrica gerada a partir da excitação de base e transdução eletromagnética foi discutido pelos autores. Os três mecanismos básicos para a conversão de vibrações em eletricidade apresentados são o piezelétrico (ROUNDY; WRIGHT; RABAEY, 2003; SODANO; INMAN; PARK, 2004; DUTOIT; WARDLE, 2006; ERTURK; INMAN, 2008), o eletromagnético (WILLIAMS; YATES, 1996; ARNOLD, 2007; GLYNNE-JONES et al., 2004; BEEBY; TUDOR; WHITE, 2006; MANN; SIMS, 2009) e o eletrostático (ROUNDY; WRIGHT; RABAEY, 2003; MITCHESON et al., 2004). As revisões apresentadas por Beeby, Tudor e White (2006) e de CookChennault, Thambi e Sastry (2008) incluem a maioria dos trabalhos experimentais da última década utilizando os três tipos de transdução. Entretanto, a transdução piezelétrica tem rece- 
bido mais atenção, o que se comprova com o numero de publicações utilizando este tipo de mecanismo. Quatro artigos de revisão publicados nos últimos anos (SODANO; INMAN; PARK, 2004; PRIYA, 2007; ANTON; SODANO, 2007; COOK-CHENNAULT; THAMBI; SASTRY, 2008) dão grande ênfase ao mecanismo piezelétrico para a conversão de vibrações em eletricidade. Vale ressaltar, entretanto, que mecanismos como o magnetoestritivo começam a ser investigados (WANG; YUAN, 2008; HU, 2010) como alternativa para sistemas de coleta de energia.

Os materiais piezelétricos têm a capacidade de intercâmbio entre energia elétrica e energia mecânica. $\mathrm{O}$ efeito piezelétrico direto é definido como a conversão de energia mecânica em energia elétrica. Já a conversão de energia elétrica em energia mecânica define o efeito piezelétrico inverso. Uma característica interessante desses materiais é a possibilidade de uso simultâneo dos efeitos piezelétricos direto e inverso. Ou seja, um mesmo material pode ser utilizado simultaneamente como sensor e atuador, permitindo, por exemplo, o estudo de controladores ativos-passivos, semi-passivos e outros (ZHAO, 2010).

Os geradores piezelétricos podem converter energia de vibrações mecânicas em energia elétrica a partir do efeito piezelétrico direto. As configurações mais simples destes geradores são investigadas na literatura por vigas ou placas metálicas engastadas, completa ou parcialmente cobertas por uma ou mais camadas de material piezelétrico e excitadas a partir do movimento de sua base, conforme observado na Fig. 1. Cada camada piezelétrica é completamente coberta em sua superfície superior e inferior por eletrodos contínuos e altamente condutivos que são conectados a um circuito gerador externo. No caso mais simplificado, e também usualmente encontrado na literatura, o domínio elétrico é representado por um elemento resistivo com o propósito de se estimar a potência elétrica obtida a partir das vibrações mecânicas do gerador. Em aplicações práticas, a ideia é acoplar o gerador à uma estrutura principal que será a fonte de excitação para o mesmo. Assim, a energia de vibração que originalmente seria desperdiçada poderá ser convertida em energia elétrica. Vale ressaltar que em alguns outros casos pode-se adicionar piezelétricos diretamente a uma estrutura com o objetivo de converter energia mecânica em elétrica.

Geralmente os geradores são dimensionados para que a frequência de ressonância de um de seus modos de vibrar possa ser excitada a partir de frequências das fontes de vibrações disponíveis no ambiente. A conversão mais eficiente se dá a partir do modo fundamental de vibrar da estrutura, primeiro modo de flexão. A distribuição de deformações ao longo de uma viga engastada para o modo fundamental explica tal fato. A presença de nós de deformação para modos mais elevados resulta em cancelamento da saída elétrica quando eletrodos contínuos são 


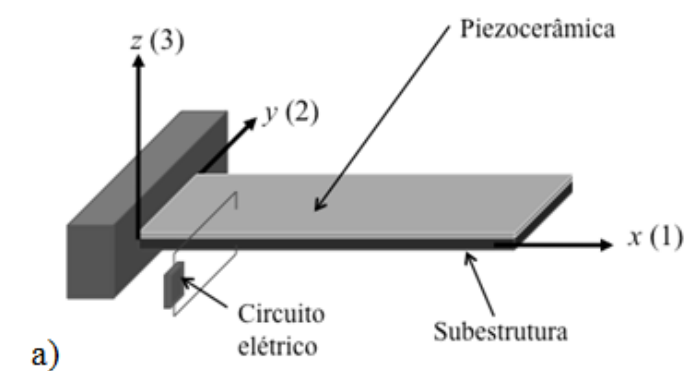

a)

Figura 1 - Esquema de um gerador piezelétrico conectado ao circuito externo a) um gerador unimorph e b) um gerador piezelétrico bimorph

utilizados.

Pesquisadores têm proposto diferentes modelos para se representar o comportamento eletromecânico de geradores piezelétricos. Um modelo confiável pode permitir o estudo de diferentes aspectos da geração de energia, como a previsão e a maximização das saídas elétricas a partir de entradas conhecidas. Os modelos variam desde representações por parâmetros concentrados (ROUNDY; WRIGHT; RABAEY, 2003; DUTOIT; WARDLE; KIM, 2005) a modelos aproximados de parâmetros distribuídos (SODANO; INMAN; PARK, 2004; DUTOIT; WARDLE; KIM, 2005; LU; LEE; LIM, 2004; CHEN; WANG; CHIEN, 2006). Alguns destes trabalhos incluem verificações experimentais e validações (DUTOIT; WARDLE, 2006; ERTURK; RENNO; INMAN, 2009). Erturk e Inman (2008) apresentaram a solução eletromecânica analítica de um gerador piezelétrico engastado para vibrações transversais baseado em hipóteses de viga Euler-Bernoulli.

Uma nova tendência tem aparecido recentemente na literatura, a conversão de energia a partir de estruturas elásticas excitadas por escoamentos. Por, exemplo, o flapping de polímeros piezelétricos (PVDF) quando sujeitos ao escoamento de ar é investigado para a geração de energia em Robbins et al. (2006). Em alguns estudos vigas elásticas cobertas com PVDF são posicionadas na esteira de um cilindro sujeito ao escoamento de ar (AKAYDIN; ELVIN; ANDREOPOULOS, 2010). A partir da interação entre a esteira de vórtices e a viga piezoelástica a energia do escoamento (ou parte dela) é convertida em energia elétrica. Apesar do reduzido acoplamento eletromecânico dos PVDFs (se comparado com as piezocerâmicas) a combinação de diversos dispositivos pode ser uma boa fonte alternativa de energia.

Estruturas elásticas sujeitas à ação de escoamentos apresentam um grande potencial para o estudo de novos métodos para a conversão de energia de vibração (excitadas pelo escoamento) em energia elétrica. O flutter é um fenômeno aeroelástico dinâmico onde uma superfície de sustentação apresenta oscilações autoexcitadas com amplitudes crescentes a partir de 
uma determinada velocidade do escoamento, conhecida como velocidade linear de flutter (BISPLINGHOFF; ASHLEY; HALFMAN, 1955). Oscilações que ocorrem em velocidades menores que a velocidade crítica são amortecidas com o passar do tempo. Em De Marqui et al. (2010) e De Marqui, Erturk e Inman (2010) são apresentados modelos piezoaeroelásticos para uma placa plana com piezocerâmicas embutidas para a conversão de energia do escoamento a partir de oscilações aeroelásticas. As análises realizadas a partir das simulações com os modelos lineares apresentados mostraram que a condição crítica de flutter é a mais interessante para a conversão piezelétrica de energia. Além disso, a geração piezelétrica de energia quando realizada nos sistemas aeroelásticos (tornando-os piezoaeroelásticos) tem como consequência, além da existência de uma saída elétrica (energia elétrica gerada), a modificação do comportamento aeroelástico da estrutura. Verifica-se que de acordo com os elementos utilizados no circuito gerador elétrico a estabilidade em torno da condição de flutter pode ser modificada.

Conceitos semelhantes foram também investigados e identificados para uma seção típica linear e eletromecanicamente acoplada com dois graus de liberdade (2-GDL) em Erturk et al. (2010). Apresentam-se um modelo numérico piezoaeroelástico no domínio da frequência e sua verificação experimental, assumindo o acoplamento eletromecânico em um dos GDL e um circuito gerador composto por um resistor. Além de gerar uma potência elétrica em torno de 10,7 mW na velocidade linear de flutter da resistência ótima, verificou-se também uma variação de 5,5\% na velocidade de flutter para esta resistência quando comparada com a velocidade de flutter em curto circuito $\left(R_{l} \rightarrow 0\right)$. Outros autores apresentaram recentemente sistemas excitados por escoamento para a conversão eletromecânica de energia, como Kwon (2010), Lallart e Guyomar (2010), Peng e Zhu (2009), Zhu (2011), Giacomello e Porfiri (2011) entre outros, mostrando o recente interesse e avanço das pesquisas na área.

Em Erturk et al. (2010) discute-se a possibilidade de conversão piezoaeroelástica de energia a partir de um sistema aeroelástico não linear. Sistemas aeroelásticos não lineares podem apresentar comportamento super-crítico ou sub-crítico, como mostrado na Fig. 2 (DOWELL; TANG, 2002). No caso super-crítico (Fig. 2a) são observadas oscilações em ciclo limite (LCOs) somente em velocidades maiores que a velocidade linear de flutter. No caso sub-crítico (Fig. 2b) LCOs ocorrem em velocidades menores que a velocidade linear de flutter.

Apesar de ser o caso mais crítico para aeronaves, o comportamento sub-crítico é o mais interessante para a geração piezelétrica de energia. O sistema apresentará oscilações persistentes (em alguns casos com grandes amplitudes) em uma faixa mais ampla de velocidades, favorecendo a conversão eletromecânica de energia e tornando os geradores mais atrativos e de implementação prática mais viável. Abdelkefi, Nayfeh e Hajj (2011), Dunnmon et al. (2011), 


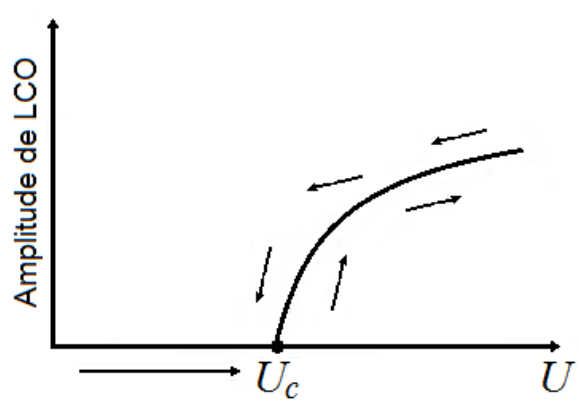

a)

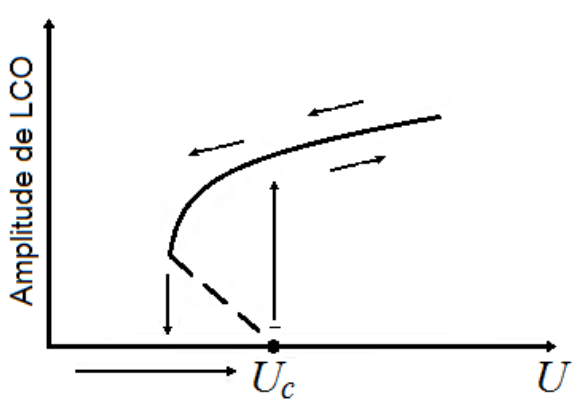

b)

Figura 2 - Comportamentos aeroelásticos a) super-crítico e b) sub-crítico

Bryant e Garcia (2011) e Sousa et al. (2011) são exemplos de investigações recentes de sistemas piezoaeroelásticos não lineares.

Assim, o objetivo deste trabalho é a investigação da interação entre a conversão piezelétrica de energia e o comportamento de uma seção típica aeroelástica (eletromecanicamente acoplada). Inicialmente uma seção típica com 2-GDL será estudada para o caso linear e para o caso não linear. Posteriormente uma seção típica com três graus de liberdade (3-GDL) será investigada para o caso linear e não linear. Em ambos os casos (2-GDL ou 3-GDL), não linearidades estruturais concentradas serão consideradas em algum dos GDLs do sistema. Um modelo por parâmetros concentrados será apresentado para o caso mais geral aqui considerado (sistema com 3-GDL e não linearidades concentradas). Os casos com 2-GDL, e ou casos lineares, são representados com o mesmo modelo por parâmetros concentrados, porém, excluindo termos ou equações convenientemente. As equações resultantes serão resolvidas em espaço de estados para a simulação dos geradores piezoaeroelásticos. Um modelo aerodinâmico não estacionário, uma aproximação da função de Theodorsen através da função de Wagner e sua representação em espaço de estados, é utilizado para todos os estudos de casos aqui considerados. Verificações experimentais do modelo por parâmetros concentrados serão apresentadas para o caso com 2-GDL linear e também não linear. 


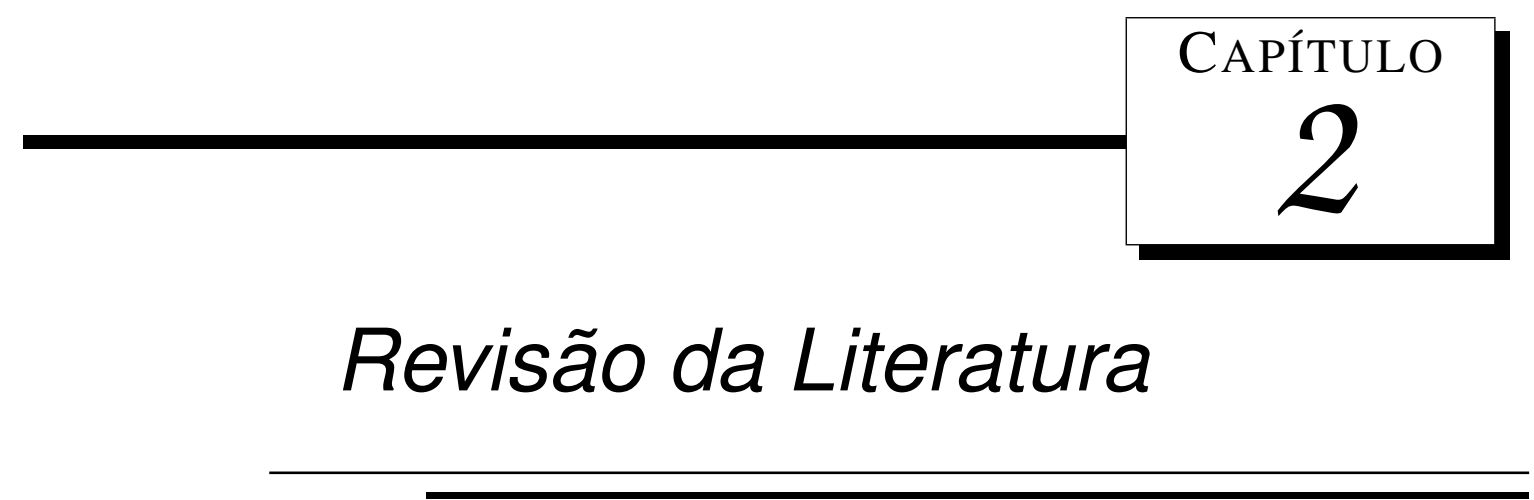

O desenvolvimento de pesquisas para a conversão de energia disponível no ambiente em energia elétrica tem crescido nos últimos anos tanto no meio acadêmico quanto industrial (BEEBY; TUDOR; WHITE, 2006; ANTON; SODANO, 2007; COOK-CHENNAULT; THAMBI; SASTRY, 2008). O conceito de geração de energia (energy harvesting) é particularmente útil para sistemas remotamente operados e com fontes limitadas de energia. A motivação está relacionada com a redução do nível de consumo de alguns componentes eletrônicos, como redes de sensores sem fio utilizados em sistemas de monitoramento de integridade estrutural, e a utilização da energia de vibração disponível no ambiente para a alimentação dos mesmos. Sistemas autossuficientes energeticamente que utilizam a energia coletada do ambiente implicam na redução de tarefas de manutenção periódica para a substituição de baterias. Além disso, poderá existir a redução do uso de baterias, que normalmente exigem um procedimento de descarte adequado (nem sempre realizado) devido aos componentes poluentes nelas utilizados.

A maioria das pesquisas que visam a coleta de energia mecânica focam na transformação de vibrações em eletricidade utilizando uma das formas de transdução descritas anteriormente (eletromagnética, eletrostática e piezelétrica). Como descrito anteriormente, os geradores piezelétricos podem obter energia elétrica a partir de vibrações através do efeito piezelétrico direto. Estes geradores têm sido estudados como alternativas eficientes e de baixo custo para se gerar energia. Pesquisadores têm proposto modelos para se representar o comportamento eletromecânico de geradores piezelétricos, que variam desde representações por parâmetros concentrados (ROUNDY; WRIGHT; RABAEY, 2003; DUTOIT; WARDLE; KIM, 2005) a modelos aproximados de parâmetros distribuídos (SODANO; INMAN; PARK, 2004; DUTOIT; WARDLE; KIM, 2005; LU; LEE; LIM, 2004; CHEN; WANG; CHIEN, 2006). Alguns destes trabalhos incluem verificações experimentais e validações (DUTOIT; WARDLE, 2006; ERTURK; RENNO; INMAN, 2009). 
Outra forma de energia disponível na vizinhança de sensores e de sistemas localizados em áreas remotas é a energia do vento. Alguns autores apresentam moinhos de vento, ou mini geradores eólicos, com o intuito de se coletar energia do vento (PRIYA et al., 2005; MYERS et al., 2007; RANCOURT; TABESH; FRECHETTE, 2007; XU et al., 2010). Em alguns trabalhos o efeito piezelétrico direto é utilizado para a transdução eletromecânica (PRIYA et al., 2005; MYERS et al., 2007) enquanto em outros a indução eletromagnética é utilizada (RANCOURT; TABESH; FRECHETTE, 2007).

Outras configurações de sistemas para a coleta de energia a partir do escoamento de ar podem ser encontradas na literatura recente. Alguns autores investigam a conversão de oscilações aeroelásticas em eletricidade apresentando diferentes configurações. Em um trabalho experimental, energia foi coletada a partir de oscilações induzidas pelo escoamento sobre placas metálicas arqueadas (simulando um aerofólio fino) e cobertas por fibras piezocerâmicas em compósito - Macro Fiber Composite (MFC) (ERTURK et al., 2008).

O problema piezoaeroelástico de coleta de energia a partir do escoamento utilizando placas planas engastadas com piezocerâmicas embutidas é estudado por De Marqui, Erturk e Inman (2010) e De Marqui et al. (2011). No primeiro artigo um modelo por elementos finitos eletromecanicamente acoplado é associado com um modelo aerodinâmico não estacionário de malha de vórtices. Uma carga resistiva é considerada no domínio elétrico. As piezocerâmicas são ligadas em série à carga resistiva do circuito elétrico gerador e duas configurações de eletrodos são testadas, como apresentado nas Figs. 3a e 3b. As simulações no domínio do tempo mostraram que a condição crítica de flutter é a mais interessante para a conversão piezelétrica de energia. Um outro aspecto interessante estudado é que a segmentação de eletrodos apresentada possibilitou se evitar o cancelamento da saída elétrica convertida a partir de movimentos de torção. Como as oscilações na condição de flutter resultam do acoplamento de modos de flexão com modos de torção, tal configuração apresentou melhor acoplamento eletromecânico e, consequentemente, maior efeito shunt damping.

No segundo artigo comentado (De Marqui et al., 2011) apresenta-se a formulação piezoaeroelástico no domínio da frequência. O modelo em elementos finitos eletromecanicamente acoplado é associado ao método de malha de dipólos. Funções resposta em frequência piezoaeroelásticas também foram definidas associando-se o problema de excitação de base com excitação aerodinâmica. Outro fato interessante é a apresentação de um método prático para a determinação de elementos ótimos do circuito gerador. Foram estudados o caso de um resistor no domínio elétrico e de um circuito ressonante (resistivo-indutivo em série).

Em Bryant e Garcia (2011) uma seção típica com 2-GDL e piezoaeroelasticamente aco- 


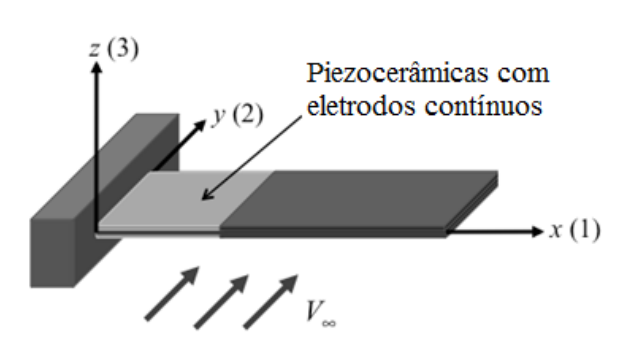

a)

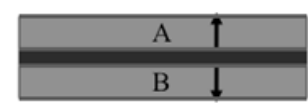

b)
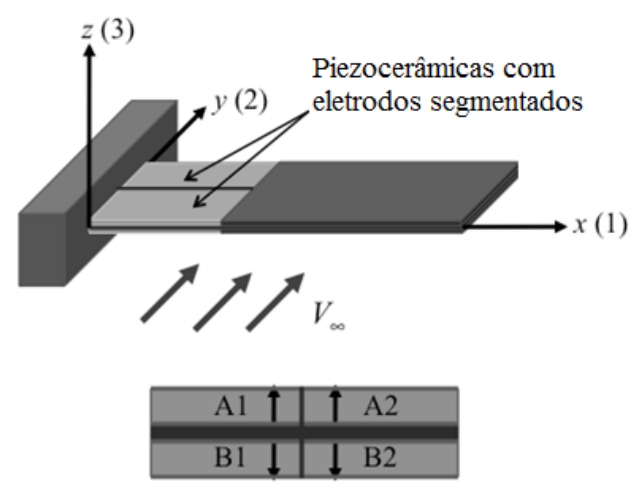

Figura 3 - Asa geradora e seção transversal da região com eletrodos embutidos, a) eletrodos contínuos e b) eletrodos segmentados (DE MARQUI; ERTURK; INMAN, 2010)

plada é utilizada para a conversão de energia do escoamento em energia elétrica. Os autores utilizam a teoria de Peters (1985) para a determinação do carregamento aerodinâmico não estacionário. Um esquema de chaveamento no domínio elétrico do problema é apresentado com o intuito de maximizar a energia gerada. Em Erturk et al. (2010) um modelo por parâmetros concentrados para uma seção típica com 2-GDL e piezocerâmicas no GDL de deslocamento linear é validado experimentalmente. O modelo aerodinâmico de Theodorsen (1935) é utilizado na formulação apresentada. A conversão de energia na fronteira de flutter e também a variação do comportamento aeroelástico do sistema (velocidade linear de flutter) com a conversão piezelétrica de energia são discutidos.

Alternativas às configurações baseadas em aerofólios e placas sujeitas ao escoamento também são encontradas na literatura. Bibo, Li e Daqaq (2011) se basearam no princípio de funcionamento de órgãos musicais para projetar um micro gerador piezelétrico. Um órgão musical produz diferentes tons a partir de oscilações de hastes submetidas ao escoamento de ar. Oscilações autoexcitadas induzidas pelo escoamento em uma viga piezelétrica engastada em uma cavidade são utilizadas para a conversão de energia. Um esquema do gerador é apresentado na Fig. 4.

Em Akaydin, Elvin e Andreopoulos (2010), uma viga eletromecanicamente acoplada composta de uma subestrutura de Mylar coberta por uma camada de PVDF é posicionada na esteira de um cilindro. A coincidência entre a frequência predominante no escoamento pós-cilindro e a frequência de ressonância do primeiro modo de vibrar da viga geradora maximiza a saída elétrica da mesma. As dimensões da viga e seu posicionamento na esteira do cilindro também são investigados para a maximização da potência elétrica. Outros autores como Schmidt (1992), Allen e Smits (2001), Taylor et al. (2001), Pobering e Schwesinger (2004) e Robbins et al. (2006) exploraram conceitos similares para a geração piezelétrica de energia. Em Tang, Paidoussis e 


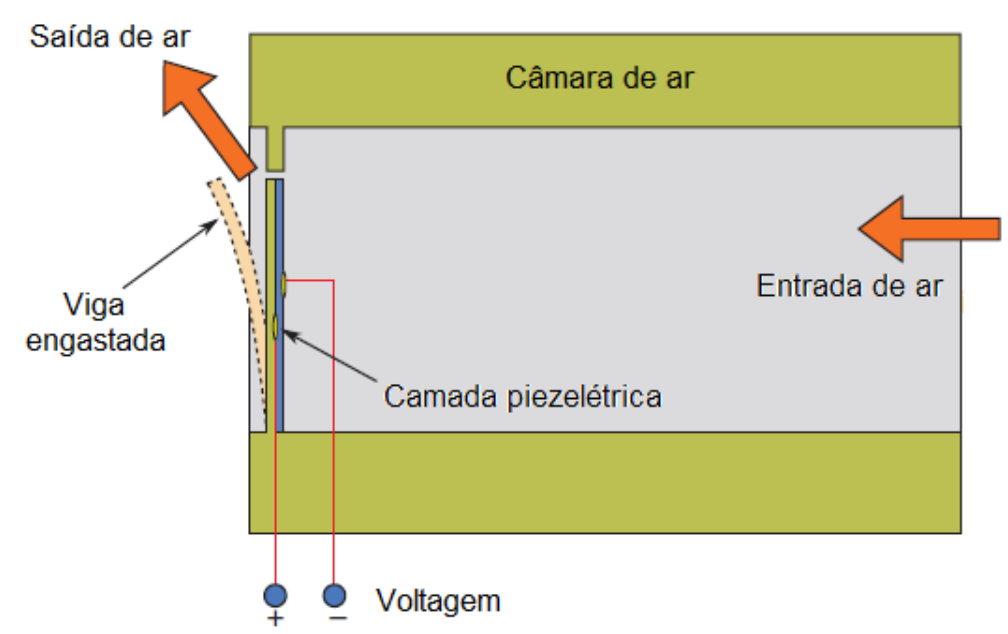

Figura 4 - Esquemático do conceito de operação do microgerador de potência proposto em Bibo, Li e Daqaq (2011)

Jiang (2009) é realizado um estudo com vigas engastadas sujeitas ao escoamento axial. Uma análise da energia transferida do fluido para a estrutura quando na condição de oscilações autossustentadas é apresentada. A conversão piezelétrica de energia a partir de LCOs de vigas eletromecânicas engastadas e sujeitas ao escoamento axial também é discutia por Dunnmon et al. (2011).

Kwon (2010) propõe o gerador piezelétrico mostrado na Fig. 5. Uma viga em T com piezelétricos colados na região do engaste é submetida ao escoamento axialmente. Um protótipo $\left(100 \times 60 \times 30 \mathrm{~mm}^{3}\right)$ foi testado em túnel de vento, apresentando oscilações persistentes a partir de $4 \mathrm{~m} / \mathrm{s}$. Algumas das vantagens do dispositivo apresentado são a simplicidade construtiva, baixo custo e a possibilidade de investigação de geradores em escalada reduzida.

Sirohi e Mahadik (2011) se baseiam no fenômeno galloping para o projeto de um gerador piezelétrico de energia a partir do escoamento de ar. Uma barra de seção transversal triangular é engastada a um par de vigas elásticas também engastadas, como mostrado na Fig. 6. Sobre as vigas são coladas piezocerâmicas para a conversão de oscilações mecânicas em eletricidade. Um modelo numérico eletromecânico é apresentado e a aerodinâmica é representada por um modelo quasi-estático, apesar da natureza não estacionária do problema.

A indução eletromagnética também é utilizada para a conversão de energia do escoamento em energia elétrica. Zhu et al. (2010) apresentam um gerador onde um aerofólio é conectado a uma viga elástica engastada, conforme a Fig. 7a. Na Fig. 7b verifica-se que o imã está vinculado ao aerofólio e a bobina ao sistema estacionário. Quando o aerofólio é submetido ao escoamento ocorre a deflexão do sistema. A presença de um corpo rombudo, conforme indicado na figura, causa um desbalanceamento nas forças resultantes no sistema, resultando 


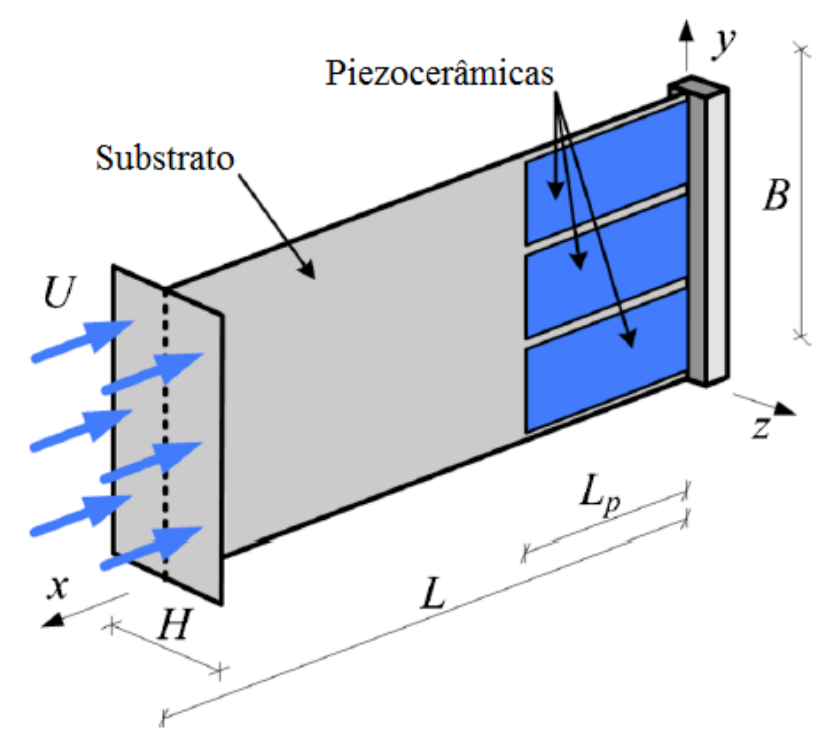

Figura 5 - Esquemático da estrutura piezelétrica em forma de T proposta em Kwon (2010)

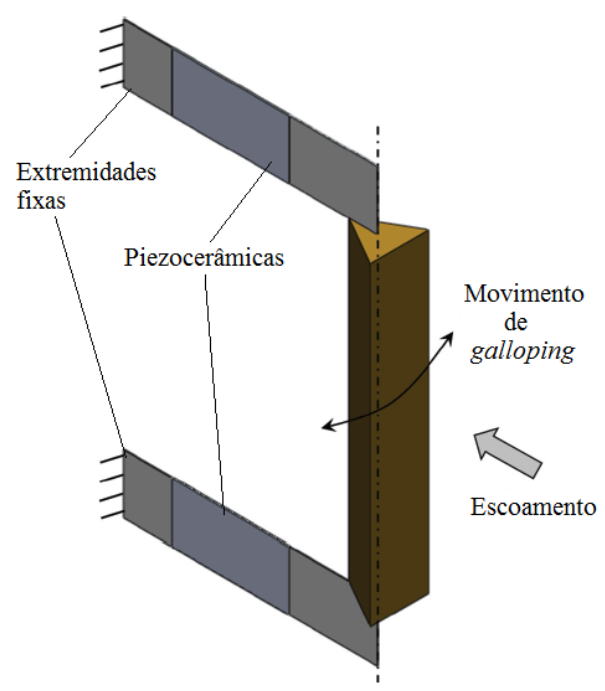

Figura 6 - Esquemático da estrutura proposta em Sirohi e Mahadik (2011)

na oscilação persistente e conversão de energia. Os autores mostram que sem a presença do corpo rombudo, o sistema aerofólio e viga elástica simplesmente sofreria, mesmo em baixas velocidades, divergência (ou uma deformação estática).

Algumas pesquisas recentes discutem os benefícios da inclusão de não linearidades em sistemas aeroelásticos (DOWELL; EDWARDS; STRGANAC, 2003) para a conversão piezelétrica de energia. A possibilidade de ocorrência de oscilações persistentes em faixas de velocidades do escoamento, permitindo assim a conversão de energia não somente em uma velocidade específica (como nos casos piezoaeroelásticos lineares), e também a ocorrência de grandes oscilações (em alguns casos) é a principal motivação. 
a)

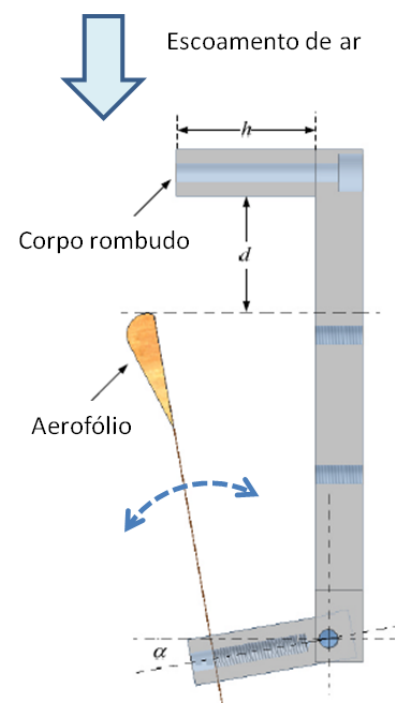

b)

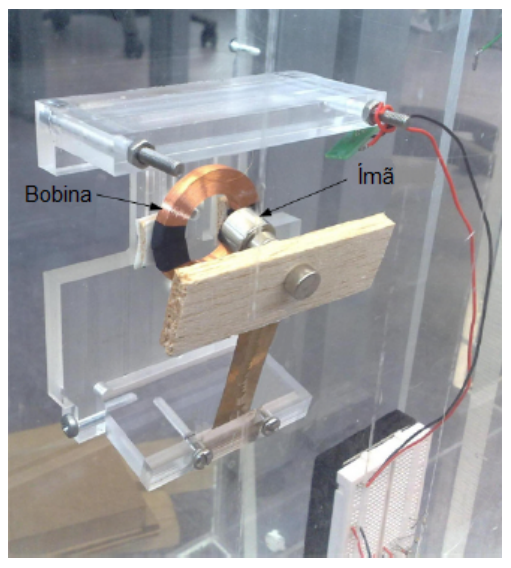

Figura 7 - Esquemático do conceito de operação do gerador proposto em Zhu et al. (2010) a) esquemático do gerador e b) dispositivo experimental

Dunnmon et al. (2011) modelam e apresentam um protótipo experimental de um gerador piezoaeroelástico de energia não linear. Uma viga elástica engastada e com piezocerâmicas coladas na região da raiz é submetida ao escoamento axial. Um modelo eletroelástico não linear é apresentado e associado ao método de malha de vórtices para a determinação do carregamento aerodinâmico não estacionário. Métricas para o cálculo da eficiência e caracterização de sistemas piezoaeroelásticos são apresentadas.

O gerador piezoaeroelástico da Fig. 8 foi proposto por Bryant e Garcia (2011). O aerofólio é vinculado à extremidade livre de uma viga elástica engastada, possuindo também o GDL de rotação em torno do seu bordo de ataque. Piezocerâmicas são coladas na região da raiz da viga para a conversão de energia do escoamento em eletricidade. Um modelo semi-empírico não linear que leva em conta o estol dinâmico no flape quando sujeito a grandes deflexões é apresentado. Ensaios em túnel de vento são realizados e os resultados experimentais são utilizados para a determinação de parâmetros empíricos do modelo aerodinâmico. A potência elétrica gerada e a frequência de flutter são investigadas em função do ângulo de incidência do escoamento.

Sousa e De Marqui (2011) apresentam um modelo não linear por parâmetros concentrados de uma seção típica eletroaeroelástica com 3-GDL. Os parâmetros aeroelásticos apresentados em Tang, Dowell e Virgin (1998) são utilizados (acoplamento eletromecânico é inserido no GDL de deslocamento linear). A velocidade linear de flutter é $24 \mathrm{~m} / \mathrm{s}$ (para a condição de curtocircuito). Ao se introduzir uma mola bilinear na superfície de controle LCOs de amplitudes aceitáveis foram identificadas para velocidades entre $18 \%$ e $94 \%$ da velocidade linear de $f l u t$ - 


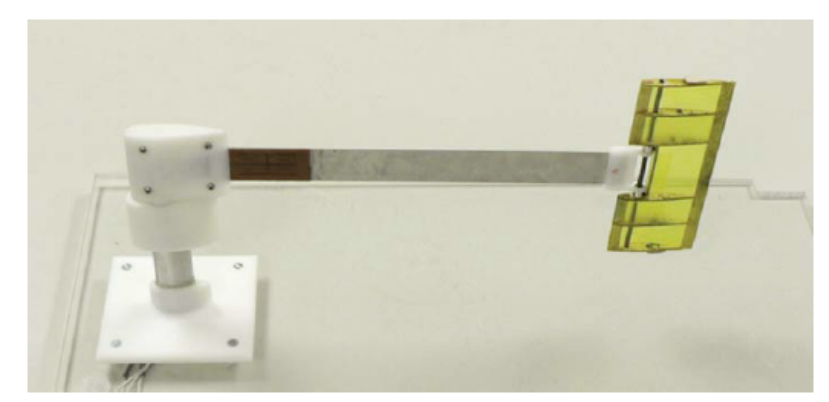

Figura 8 - Gerador proposto em Bryant e Garcia (2011)

ter. Assim, há uma ampla faixa de velocidades na qual ocorre geração persistente de energia. Fica claro também a relação entre a potência elétrica gerada e o GDL que apresenta instabilidade. Como o acoplamento eletromecânico foi inserido no GDL de deslocamento linear, a saída elétrica é maximizada quando o mesmo apresenta instabilidades e maiores amplitudes de oscilação.

Abdelkefi, Nayfeh e Hajj (2011) investigam a influência de não linearidades estruturais e aerodinâmicas no comportamento dinâmico de uma seção típica piezoaeroelástica com 2-GDL. Molas não lineares são consideradas nos dois GDL e o acoplamento piezelétrico é considerado no GDL de deslocamento linear. As simulações numéricas são realizadas com o objetivo de se determinar o efeito da variação da carga resistiva do domínio elétrico e também o efeito da variação dos coeficientes das molas do sistema nas LCOs encontradas em cada GDL do sistema e na saída elétrica do sistema. Os resultados mostram que o efeito da resistência elétrica sobre a velocidade linear de flutter é desprezível se comparado ao efeito dos coeficientes das molas, em conformidade com outros estudos prévios (ERTURK et al., 2010).

Como se observa na revisão aqui apresentada, poucos grupos de pesquisa têm investigado numérica e experimentalmente a interação entre a geração piezelétrica de energia e o comportamento aeroelástico linear e não linear de uma seção típica eletroaeroelasticamente acoplada. Assim, justificam-se os objetivos deste trabalho apresentados no capítulo anterior e espera-se que as investigações aqui realizadas possam contribuir para a área de pesquisa. 


\section{Modelo por Parâmetros Concentrados de uma Seção Típica Piezoaeroelástica}

A Fig. 9 mostra uma seção típica aeroelástica com 3-GDL, sendo $h$ o deslocamento linear da seção típica, medido no eixo elástico (EE) a partir da posição de equilíbrio estático quando não há escoamento e positivo para baixo; $\alpha$ o ângulo de rotação em torno do ponto de referência medido em relação à direção do escoamento e $\beta$ o ângulo de rotação da superfície de controle a partir da linha de corda da seção típica, ambos positivos no sentido horário. Ainda, $b$ é a semicorda da seção típica, $x_{\alpha}$ é a distância em semicordas entre o EE e o centro de gravidade (CG) da seção típica, $x_{\beta}$ é a distância (em semicordas) entre o eixo de articulação (EA) e o CG da superfície de controle, $a$ e $c$ são as distâncias (em semicordas) do ponto médio da corda ao EE e ao EA, respectivamente. Os termos $k_{h}, k_{\alpha}$ e $k_{\beta}$ são as rigidezes lineares das molas por unidade de comprimento nos GDLs de deslocamento linear, rotação da seção típica e rotação da superfície de controle, respectivamente.

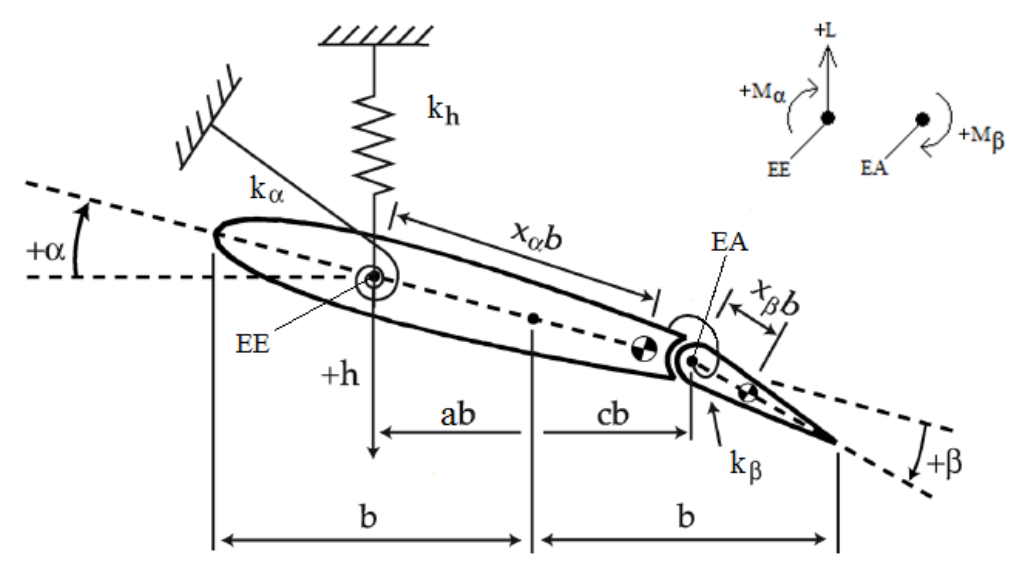

Figura 9 - Uma seção típica aeroelástica com 3-GDL (TANG; DOWELL, 2010)

A seção típica aeroelástica será estudada neste trabalho considerando-se o caso com 2- 
GDL e 3-GDL. Em ambos, entretanto, modificações serão impostas. Uma delas é modelar as não linearidades concentradas em alguns dos GDL do sistema. Outra é a adição de acoplamento piezelétrico ao GDL de deslocamento linear $(h)$. Consequentemente, um GDL elétrico é adicionado ao problema.

Devido ao acoplamento piezelétrico, este trabalho referir-se-á à seção típica da Fig. 9 por seção típica piezoaeroelástica. A seção seguinte determinará as equações de movimento para a seção típica com 3-GDL piezeletricamente acoplada a partir da equação de Lagrange. Ainda, fica implícito que, se uma seção típica com 2-GDL é considerada, deve-se eliminar a equação de momento da superfície de controle do modelo, assim como os termos de acoplamento com outros GDLs (que serão apresentados posteriormente).

\subsection{Modelo por Parâmetros Concentrados para uma Seção Típica Piezoaeroelástica}

Erturk e Inman (2011) equacionam o problema de uma seção típica com 2-GDL piezeletricamente acoplada. Eles partem do Princípio de Hamilton para um sistema eletroaeroelástico para determinar as equações piezoaeroelásticas de Lagrange e, por fim, determinam as equações de movimento para uma seção típica piezoaeroelástica. Neste trabalho, o mesmo método é aplicado a uma seção típica com 3-GDL piezeletricamente acoplada.

O Princípio de Hamilton extendido para um sistema eletroaeroelástico (ERTURK; INMAN, 2011) é apresentado como,

$$
\int_{t_{1}}^{t_{2}}\left(\delta T-\delta U+\delta W_{i e}+\delta W_{n c e}+\delta W_{n c a}+\delta W_{s d}\right) d t=0
$$

onde $\delta$ denota a primeira variação de um funcional. Logo, $\delta T, \delta U$ e $\delta W_{i e}$ representam, respectivamente, a primeira variação da energia cinética total, da energia potencial total e da energia elétrica interna, todas por unidade de comprimento. Os termos $\delta W_{n c e}, \delta W_{n c a}$ e $\delta W_{s d}$ correspondem às componentes não-conservativas do trabalho virtual devido à carga elétrica, às cargas aerodinâmicas e ao amortecimento estrutural. Estas grandezas são definidas por unidade de comprimento (na direção da envergadura e no plano da página) para o problema bidimensional tratado neste trabalho.

A energia cinética total do sistema por unidade de comprimento é

$$
T=\frac{1}{2}\left(m \dot{h}^{2}+2 m x_{\alpha} b \dot{h} \dot{\alpha}+2 m_{\beta} x_{\beta} b \dot{h} \dot{\beta}+m_{f} \dot{h}^{2}+I_{\alpha} \dot{\alpha}^{2}+I_{\beta} \dot{\beta}^{2}\right)
$$


onde $m$ é a massa do aerofólio por unidade de comprimento e $m_{f}$ é uma massa adicional (por unidade de comprimento) presente no sistema experimental e que também se desloca durante movimentos lineares. Esta massa será melhor descrita posteriormente. Ainda, $m_{\beta}$ é a massa da superfície de controle por unidade de comprimento, $I_{\alpha}$ é o momento de inércia da seção típica em relação ao eixo elástico e $I_{\beta}$ é o momento de inércia da superfície de controle em relação ao seu eixo de articulação, ambos por unidade de comprimento. Cada ponto acima das variáveis $h$, $\alpha$ e $\beta$ representa diferenciação no tempo; $h, \alpha$ e $\beta$, quando subscritos, indicam o GDL ao qual um parâmetro se aplica.

A energia potencial total por unidade de comprimento é definida,

$$
U=\frac{1}{2}\left(k_{h} h^{2}+k_{\alpha} \alpha^{2}+k_{\beta} \beta^{2}-\frac{\theta}{l} h v\right)
$$

onde $\theta$ é o termo de acoplamento eletromecânico, $l$ é a envergadura da seção típica e $v$ é a voltagem entre os terminais de uma carga resistiva presente no domínio elétrico do sistema.

A energia elétrica interna do sistema é

$$
W_{i e}=\frac{1}{2}\left(\frac{C_{p}^{e q}}{l} v^{2}+\frac{\theta}{l} v h\right)
$$

sendo que $C_{p}^{e q}$ é a capacitância equivalente das camadas piezocerâmicas.

As componentes não-conservativas do trabalho virtual devido à carga elétrica, às cargas aerodinâmicas e ao amortecimento estrutural são dadas, respectivamente, como,

$$
\begin{gathered}
\delta W_{n c e}=\frac{Q}{l} \delta v \\
\delta W_{n c a}=-L \delta h+M_{\alpha} \delta \alpha+M_{\beta} \delta \beta \\
\delta W_{s d}=-d_{h} \dot{h} \delta h-d_{\alpha} \dot{\alpha} \delta \alpha-d_{\beta} \dot{\beta} \delta \beta
\end{gathered}
$$

onde $Q$ é a carga elétrica, $L$ é a força de sustentação por unidade de comprimento (positiva para cima), $M_{\alpha}$ e $M_{\beta}$ são os momentos aerodinâmicos por unidade de comprimento de rotação da seção típica em relação ao EE da seção típica e de rotação em torno do EA da superfície de controle, respectivamente. Ainda, na Eq. (3.7), $d_{h}, d_{\alpha}$ e $d_{\beta}$ representam, nesta ordem, os coeficientes de amortecimento por unidade de comprimento dos GDLs de deslocamento linear, rotação da seção típica e rotação da superfície de controle.

As equações de Lagrange para o sistema piezoaeroelástico são (Apêndice A),

$$
\frac{d}{d t}\left(\frac{\partial T}{\partial \dot{q}_{i}}\right)-\frac{\partial T}{\partial q_{i}}+\frac{\partial U}{\partial q_{i}}-\frac{\partial W_{i e}}{\partial q_{i}}=\mathscr{Q}_{i} \quad(i=1, \ldots, n)
$$


onde $q_{i}$ representa cada coordenada generalizada discreta de um sistema holonômico. Similarmente, $\mathscr{Q}_{i}$ representa forças não conservativas. Esta equação é uma especialização do princípio do trabalho virtual conveniente para descrever sistemas dinâmicos.

Aplicando as equações de Lagrange, Eq. (3.8), à seção típica com 3-GDL piezeletricamente acoplada resulta,

$$
\begin{gathered}
\frac{d}{d t}\left(\frac{\partial T}{\partial \dot{\alpha}}\right)-\frac{\partial T}{\partial \alpha}+\frac{\partial U}{\partial \alpha}-\frac{\partial W_{i e}}{\partial \alpha}=M_{\alpha}-d_{\alpha} \dot{\alpha} \\
\frac{d}{d t}\left(\frac{\partial T}{\partial \dot{\beta}}\right)-\frac{\partial T}{\partial \beta}+\frac{\partial U}{\partial \beta}-\frac{\partial W_{i e}}{\partial \beta}=M_{\beta}-d_{\beta} \dot{\beta} \\
\frac{d}{d t}\left(\frac{\partial T}{\partial \dot{h}}\right)-\frac{\partial T}{\partial h}+\frac{\partial U}{\partial h}-\frac{\partial W_{i e}}{\partial h}=-L-d_{h} \dot{h} \\
\frac{d}{d t}\left(\frac{\partial T}{\partial \dot{v}}\right)-\frac{\partial T}{\partial v}+\frac{\partial U}{\partial v}-\frac{\partial W_{i e}}{\partial v}=\frac{Q}{l}
\end{gathered}
$$

e substituindo os termos $T, U, W_{i e}, \delta W_{n c e}, \delta W_{n c a}$ e $\delta W_{s d}$ (definidos nas Eqs. (3.2) a (3.7)) nas Eqs. (3.9) a (3.12), resulta nas equações que representam um sistema dinâmico piezoaeroelástico,

$$
\begin{gathered}
I_{\alpha} \ddot{\alpha}+\left(I_{\beta}+(c-a) m_{\beta} x_{\beta} b^{2}\right) \ddot{\beta}+m x_{\alpha} b \ddot{h}+d_{\alpha} \dot{\alpha}+k_{\alpha} \alpha=M_{\alpha} \\
\left(I_{\beta}+(c-a) m_{\beta} x_{\beta} b^{2}\right) \ddot{\alpha}+I_{\beta} \ddot{\beta}+m_{\beta} x_{\beta} b \ddot{h}+d_{\beta} \dot{\beta}+k_{\beta} \beta=M_{\beta} \\
m x_{\alpha} b \ddot{\alpha}+m_{\beta} x_{\beta} b \ddot{\beta}+\left(m+m_{f}\right) \ddot{h}+d_{h} \dot{h}+k_{h} h-\frac{\theta}{l} v=-L \\
C_{p}^{e q} \dot{v}+\frac{v}{R_{l}}+\theta \dot{h}=0
\end{gathered}
$$

onde $R_{l}$ é a carga resistiva considerada no domínio elétrico. É importante observar que a Eq. (3.16) foi derivada no tempo para que relação $\dot{Q}=v / R_{l}$ pudesse ser utilizada.

As Eqs. (3.13) a (3.16) constituem um modelo representativo de um sistema piezoaeroelástico. Os termos do lado esquerdo destas equações são, em sua maioria, usualmente encontrados em equações aeroelásticas, com excessão dos termos eletromecânicos. Entretanto, assumindo que todos serão conhecidos, a simulação do sistema ainda vai depender da definição de um modelo aerodinâmico não-estacionário para a determinação de $M_{\alpha}, M_{\beta}$ e $L$, o que será apresentado posteriormente. 


\subsection{Representação das Equações de Movimento em Espaço de Estados}

Ao reescrever as equações de movimento, Eqs. (3.13) a (3.16), de maneira adimensional pode-se estabelecer relações de similaridade entre modelos em escalas diferentes (reduzida ou ampliada) (BISPLINGHOFF; ASHLEY; HALFMAN, 1955). Além disso, ao considerar modelos adimensionais, é possível analisar uma classe de sistemas ao invés de apenas um sistema em particular (HEMATI, 1995).

Os parâmetros-chave para a adimensionalização das Eqs. (3.13) a (3.16) são a massa de referência por unidade de comprimento $m$ (massa da seção típica e superfície de controle, se houver) e a semicorda da seção típica $b$. Para introduzir os parâmetros adimensionais definidos por Theodorsen (1935), as equações de momento, Eqs. (3.13) e (3.14), são multiplicadas por $1 /\left(m b^{2}\right)$ e a equação de sustentação, Eq. (3.15), é multiplicada por $1 /(m b)$. A equação elétrica, Eq. (3.16), por sua vez, é multiplicada por $v^{*} /\left(m b^{2} l\right)$, sendo que $v^{*}$ corresponde à 1 Volt. Este tratamento leva às equações de movimento expressas em termos de parâmetros piezoaeroelásticos adimensionais,

$$
\begin{gathered}
r_{\alpha}^{2} \ddot{\alpha}+\left(r_{\beta}^{2}+(c-a) x_{\beta}\right) \ddot{\beta}+x_{\alpha} \ddot{\bar{h}}+\frac{d_{\alpha}}{m b^{2}} \dot{\alpha}+r_{\alpha}^{2} \omega_{\alpha}^{2} \alpha=\frac{M_{\alpha}}{m b^{2}} \\
\left(r_{\beta}^{2}+(c-a) x_{\beta}\right) \ddot{\alpha}+r_{\beta}^{2} \ddot{\beta}+x_{\beta} \ddot{\bar{h}}+\frac{d_{\beta}}{m b^{2}} \dot{\beta}+r_{\beta}^{2} \omega_{\beta}^{2} \beta=\frac{M_{\beta}}{m b^{2}} \\
x_{\alpha} \ddot{\alpha}+x_{\beta} \ddot{\beta}+\mu \ddot{\bar{h}}+\frac{d_{h}}{m} \dot{\bar{h}}+\omega_{h}^{2} \bar{h}-\frac{\theta v^{*}}{m b l} v=-\frac{L}{m b} \\
\frac{C_{p}^{e q} v^{* 3}}{m b^{2} l} \dot{\bar{v}}+\frac{v^{* 2}}{m b^{2} l R_{l}} \bar{v}+\frac{\theta v^{*}}{m b l} \dot{\bar{h}}=0
\end{gathered}
$$

onde $r_{\alpha}$ é o raio de giração da seção típica dividido por $b$ e $r_{\beta}$ é o raio de giração da superfície de controle dividido por $b$ (THEODORSEN, 1935), $\bar{h}=h / b$ é o deslocamento linear adimensional, $\omega_{\alpha}, \omega_{\beta}$ e $\omega_{h}$ são as frequências naturais desacopladas de cada GDL, respectivamente, $\mu$ é a razão entre a massa total e a massa da seção típica e $\bar{v}=v / v^{*}$ é a voltagem adimensional.

Para completar a adimensionalização, se admite também um tempo adimensional,

$$
\tau=\omega_{h} t
$$

onde $\tau$ é o tempo adimensional e $t$ é o tempo dimensional.

As diferenciações de uma grandeza no tempo dimensional e no tempo adimensional satis- 
fazem a relação,

$$
\frac{d}{d t}=\omega_{h} \frac{d}{d \tau}
$$

ou, da mesma maneira,

$$
\dot{x}=\omega_{h} x^{\prime}
$$

para uma variável arbitrária $x$ dependendente do tempo $(\alpha, \beta, h$ ou $v$ neste problema em particular) e, para a segunda derivada,

$$
\ddot{x}=\omega_{h}^{2} x^{\prime \prime}
$$

onde o símbolo / denota diferenciação no tempo adimensional.

Assim sendo, as Eqs. (3.13) a (3.15) também são multiplicadas por $1 / \omega_{h}^{2}$, e a Eq. (3.16) é multiplicada por $1 / \omega_{h}^{3}$, o que completa o procedimento de adimensionalização, restando, apenas, adotar uma notação adequada. As equações de movimento expressas de maneira adimensional são dadas,

$$
\begin{gathered}
r_{\alpha}^{2} \alpha^{\prime \prime}+\left(r_{\beta}^{2}+(c-a) x_{\beta}\right) \beta^{\prime \prime}+x_{\alpha} \bar{h}^{\prime \prime}+\xi_{\alpha} \alpha^{\prime}+\eta_{\alpha}^{2} r_{\alpha}^{2} \alpha=\bar{M}_{\alpha} \\
\left(r_{\beta}^{2}+(c-a) x_{\beta}\right) \alpha^{\prime \prime}+r_{\beta}^{2} \beta^{\prime \prime}+x_{\beta} \bar{h}^{\prime \prime}+\xi_{\beta} \beta^{\prime}+\eta_{\beta}^{2} r_{\beta}^{2} \beta=\bar{M}_{\beta} \\
x_{\alpha} \alpha^{\prime \prime}+x_{\beta} \beta^{\prime \prime}+\mu \bar{h}^{\prime \prime}+\xi_{h} \bar{h}^{\prime}+\bar{h}-\chi \bar{v}=-\bar{L} \\
\psi \bar{v}^{\prime}+\frac{1}{\lambda} \bar{v}+\chi \bar{h}^{\prime}=0
\end{gathered}
$$

onde $\xi_{\alpha}=d_{\alpha} /\left(m b^{2} \omega_{h}\right), \xi_{\beta}=d_{\beta} /\left(m b^{2} \omega_{h}\right)$ e $\xi_{h}=d_{h} /\left(m \omega_{h}\right)$ são as razões de amortecimento nos respectivos GDLs (por unidade de comprimento), $\eta_{\alpha}$ é a razão $\omega_{\alpha} / \omega_{h}$ e $\eta_{\beta}$ é a razão $\omega_{\beta} / \omega_{h}$

Similarmente ao domínio estrutural, atribuem-se parâmetros adimensionais para as grandezas elétricas do problema. A capacitância adimensional é definida por $\psi=C_{p}^{e q} v^{* 3} /\left(m b^{2} l \omega_{h}^{2}\right)$, ao passo que $\chi=\theta v^{*} /\left(m b l \omega_{h}^{2}\right)$ representa o acoplamento eletromecânico adimensional. Definese a carga resistiva adimensional por $\lambda=m b^{2} l \omega_{h}^{3} R_{l} / v^{* 2}$, e a potência elétrica adimensional é, portanto, expressa por $p^{*}=\bar{v}^{2} / \lambda$.

Os termos $\bar{M}_{\alpha}, \bar{M}_{\beta}$ e $\bar{L}$ representam o carregamento aerodinâmico expresso de maneira adimensional, isto é, $\bar{M}_{\alpha}=M_{\alpha} /\left(m b^{2} \omega_{h}^{2}\right), \bar{M}_{\beta}=M_{\beta} /\left(m b^{2} \omega_{h}^{2}\right)$ e $\bar{L}=L /\left(m b \omega_{h}^{2}\right)$.

A representação das Eqs. (3.21) a (3.24) em espaço de estados é dada,

$$
\left[\begin{array}{ccc}
\mathbf{I} & \mathbf{0} & \mathbf{0} \\
\mathbf{0} & \mathbf{M} & \mathbf{0} \\
\mathbf{0} & \mathbf{0} & \psi
\end{array}\right]\left\{\begin{array}{c}
\mathbf{x}^{\prime} \\
\mathbf{x}^{\prime \prime} \\
\bar{v}^{\prime}
\end{array}\right\}+\left[\begin{array}{ccc}
\mathbf{0} & -\mathbf{I} & \mathbf{0} \\
\mathbf{K} & \mathbf{B} & -\Theta^{T} \\
\mathbf{0} & \Theta & 1 / \lambda
\end{array}\right]\left\{\begin{array}{c}
\mathbf{x} \\
\mathbf{x}^{\prime} \\
\bar{v}
\end{array}\right\}=\left\{\begin{array}{c}
\mathbf{0} \\
\mathscr{F} \\
0
\end{array}\right\}
$$


onde I representa a matriz identidade de dimensão $2 \times 2$ ou $3 \times 3$, conforme o aerofólio possua 2GDL ou 3-GDL, respectivamente. O vetor $\mathbf{x}=\left\{\begin{array}{lll}\alpha & \beta & \bar{h}\end{array}\right\}^{T}$ representa os estados estruturais ( $T$ superscrito indica transposto), $\Theta=\left\{\begin{array}{lll}0 & 0 & \chi\end{array}\right\}$ é o vetor de acoplamento eletromecânico e $\mathscr{F}=\left\{\begin{array}{lll}\bar{M}_{\alpha} & \bar{M}_{\beta} & \bar{L}\end{array}\right\}^{T}$ representa o carregamento aerodinâmico expresso em função de grandezas adimensionais. As matrizes $\mathbf{M}, \mathbf{K}$ e $\mathbf{B}$ representam as contribuições inerciais, de rigidez e de amortecimento ao domínio estrutural do sistema, respectivamente. Estas matrizes são apresentadas a seguir.

$$
\begin{aligned}
& \mathbf{M}=\left[\begin{array}{ccc}
r_{\alpha}^{2} & r_{\beta}^{2}+(c-a) x_{\beta} & x_{\alpha} \\
r_{\beta}^{2}+(c-a) x_{\beta} & r_{\beta}^{2} & x_{\beta} \\
x_{\alpha} & x_{\beta} & \mu
\end{array}\right] \\
& \mathbf{K}=\left[\begin{array}{ccc}
r_{\alpha}^{2} \eta_{\alpha}^{2} & 0 & 0 \\
0 & r_{\beta}^{2} \eta_{\beta}^{2} & 0 \\
0 & 0 & 1
\end{array}\right] \\
& \mathbf{B}=\left[\begin{array}{ccc}
\xi_{\alpha} & 0 & 0 \\
0 & \xi_{\beta} & 0 \\
0 & 0 & \xi_{h}
\end{array}\right]
\end{aligned}
$$

A seção seguinte apresenta um modelo aerodinâmico não estacionário baseado na teoria potencial para implementar o carregamento $\mathscr{F}$.

\subsection{Modelo Aerodinâmico Não Estacionário para Movimen- tos Arbitrários}

Este trabalho admite escoamentos incompressíveis bidimensionais em regime subsônico. Admite também pequenos ângulos de ataque sem separação.

Theodorsen (1935) trata o potencial de velocidade devido ao escoamento em torno da seção típica como não circulatório e circulatório, e obtém estas duas classes de potenciais mapeando (por uma transformação conformal de Joukowski) um círculo de raio $b / 2$ sobre a projeção da seção típica. A contribuição não circulatória do potencial satisfaz a condição de contorno dependente do tempo ao longo da seção típica distribuindo fontes e sumidouros (doublets) nas superfícies superior e inferior. A contribuição circulatória do potencial é obtida distribuindo-se um padrão de vórtices sobre o aerofólio e ao longo da esteira (idealmente até o infinito) de maneira que a condição de Kutta (pressão e velocidade no bordo de fuga sejam finitas e contínuas) seja satisfeita sem violar as condições de contorno (EDWARDS, 1977; ALIGHANBARI, 
1995).

Após derivar os potenciais de velocidade para cada GDL, Theodorsen (1935) aplica o Teorema de Bernoulli para escoamentos não estacionários e calcula as pressões locais atuantes no aerofólio. Integrando estas pressões, obtém os esforços aerodinâmicos mostrados nas Eqs. (3.29) a (3.31), que correspondem aos momentos aerodinâmicos (nos GDLs de rotação da seção típica e rotação da superfície de controle) e à força de sustentação. Estas expressões incluem as contribuições não circulatória e circulatória e são,

$$
\begin{gathered}
M_{\alpha}=-\rho b^{2}\left[\begin{array}{l}
\pi\left(\frac{1}{2}-a\right) U b \dot{\alpha}+\pi b^{2}\left(\frac{1}{8}+a^{2}\right) \ddot{\alpha}+ \\
\left(T_{4}+T_{10}\right) U^{2} \beta+ \\
\left(T_{1}-T_{8}-(c-a) T_{4}+\frac{1}{2} T_{11}\right) U b \dot{\beta}- \\
\left(T_{7}+(c-a) T_{1}\right) b^{2} \ddot{\beta}-\dot{\alpha} \pi b \ddot{h}
\end{array}\right]+2 \rho U b^{2} \pi\left(a+\frac{1}{2}\right) C(\kappa) f(t) \\
M_{\beta}=-\rho b^{2}\left[\begin{array}{c}
\left\{-2 T_{9}-T_{1}+T_{4}\left(a-\frac{1}{2}\right)\right\} U b \dot{\alpha}+ \\
2 T_{13} b^{2} \ddot{\alpha}+\frac{1}{\pi} U^{2} \beta\left(T_{5}-T_{4} T_{10}\right)- \\
\frac{1}{2 \pi} U b \dot{\beta} T_{4} T_{11}-\frac{1}{\pi} T_{3} b^{2} \ddot{\beta}-T_{1} b \ddot{h}
\end{array}\right]-\rho U b^{2} T_{12} C(\kappa) f(t) \\
L=-\rho b^{2}\left(U \pi \dot{\alpha}+\pi \ddot{h}-\pi b a \ddot{\alpha}-U T_{4} \dot{\beta}-T_{1} b \ddot{\beta}\right)-2 \pi \rho U b C(\kappa) f(t)
\end{gathered}
$$

onde $U$ é a velocidade do escoamento, $\rho$ é a densidade do ar, $T_{i}$ são as constantes de Theodorsen (1935), $C(\kappa)$ é a função Generalizada de Theodorsen e $f(t)$ é definido a seguir.

$$
f(t)=U \alpha+\dot{h}+b\left(\frac{1}{2}-a\right) \dot{\alpha}+\frac{1}{\pi} T_{10} U \beta+b \frac{1}{2 \pi} T_{11} \dot{\beta}
$$

A contribuição não circulatória do carregamento aerodinâmico defindo nas Eqs. (3.29) a (3.31) depende apenas da posição do eixo elástico da seção típica e da posição do eixo de articulação da superfície de controle. A contribuição circulatória depende de uma função transcendental conhecida como função Generalizada de Theodorsen, usualmente indicada por $C(\kappa)$ e expressa em sua forma exata na Eq. (3.32) (THEODORSEN, 1935).

$$
C(\kappa)=\frac{\int_{1}^{\infty} \frac{x_{0}}{\sqrt{x_{0}^{2}-1}} e^{-i k x_{0} d x_{0}}}{\int_{1}^{\infty} \frac{x_{0}+1}{\sqrt{x_{0}^{2}-1}} e^{-i k x_{0} d x_{0}}}
$$

Esta é uma função complexa que representa os efeitos do desprendimento de vórtices no bordo de fuga da seção típica (PENG; ZHU, 2009) e que dependente somente da frequência reduzida $\kappa=\omega b / U$. A resposta, portanto, é limitada à movimentos harmônicos (ALIGHANBARI, 1995; CONNER, 1996). 
Conforme mencionado por Alighanbari (1995), na presença de não linearidades estruturais um aerofólio pode realizar movimentos arbitrários. Neste caso, as expressões para $M_{\alpha}$, $M_{\beta}$ e $L$ descritas nas Eqs. (3.29) a (3.31) não se aplicam e o modelo original de Theodorsen deve ser modificado para lidar adequadamente com movimentos não-harmônicos, que podem eventualmente ser caóticos. Uma maneira de adaptar o operador de Theodorsen, $C(\kappa)$, para a representação de movimentos arbitrários é descrita a seguir.

O carregamento aerodinâmico não estacionário e harmônico é tabulado para vários valores de $\kappa$. No entanto, assumir que o movimento da seção típica começa em $t=0$ (e não em $t=-\infty$ ) permite expressar o carregamento em função da variável de Laplace $(s)$ e da variável "reduzida" de Laplace $(\bar{s}=s b / U)$. Dessa maneira, é possível obter uma expressão de carregamento na qual a contribuição circulatória é decomposta em uma porção racional (cuja transformada pode ser expressa como uma razão de polinômios em $s$ ) e outra não-racional. Visto que somente a parte racional é relevante para a análise de flutter, aproximá-la por uma função racional em $s$ permite obter expressões de carregamento para valores arbitrários de $s$. Tais expressões são, então, transformadas para o domínio do tempo e incluídas no modelo como EDOs adicionais (EDWARDS; ASHLEY; BREAKWELL, 1979). Edwards (1977) mostra detalhadamente estes procedimentos.

Para obter uma função (análoga à de Theodorsen) em termos da variável de Laplace ( $s$ ), são necessários alguns passos adicionais envolvendo a função indicial de Wagner, $\phi(\tau)$, em que $\tau$ é o tempo adimensional. Em Alighanbari (1995) há uma discussão detalhada sobre como Wagner determina expressões para carregamentos aerodinâmicos não estacionários correspondentes a movimentos arbitrários de aerofólio. A Eq. (3.33) mostra a função indicial de Wagner em sua forma exata, em termos de funções Bessel modificadas de primeira ordem $\left(I_{i}\right)$ e segunda ordem $\left(K_{i}\right)$ (ALIGHANBARI, 1995; FUNG, 1955).

$$
\phi(\tau)=1-\int_{0}^{\infty} \frac{1}{\left(K_{o}-K_{1}\right)^{2}+\pi^{2}\left(I_{0}-I_{1}\right)^{2}} e^{-x \kappa} x^{-2} d x
$$

Considerando a dificuldade em incluir a função de Wagner no modelo numérico, aproximações são feitas (BISPLINGHOFF; ASHLEY; HALFMAN, 1955). Neste trabalho, a aproximação exponencial de Jones (1938) para a função indicial de Wagner é utilizada para representar o carregamento aerodinâmico não estacionário correspondente à movimentos arbitrários de aerofólio.

Jones (1938) menciona que a Eq. (3.34) reproduz quase que exatamente a curva obtida pela função de Wagner. Em seguida, Jones (1939) mostra graficamente tal correspondência para 
diferentes valores de razão de aspecto (inclusive razão infinita). Portanto,

$$
\phi(s) \approx C_{0}+C_{1} e^{C_{3} s}+C_{2} e^{C_{4} s}
$$

onde os coeficientes são $C_{0}=2 \varepsilon, C_{1}=-0.33 \varepsilon, C_{2}=-0.67 \varepsilon, C_{3}=-0.0455$ e $C_{4}=-0.3$, sendo que $\varepsilon$ representa a massa adicional virtual. Para um aerofólio de razão de aspecto infinita, $\varepsilon=\pi$. A variável $s$ refere-se à semicorda como unidade, isto é, $s=U t / b$ corresponde à distância percorrida em semicordas (THEODORSEN, 1935; JONES, 1938).

A Eq. (3.34), aplicada a uma seção típica e normalizada por $2 \pi$, resulta na Eq. (3.35). Esta última é uma forma mais comum na literatura.

$$
\phi(s) \approx 1-0.165 e^{-0.0455 s}-0.335 e^{-0.3 s}
$$

O carregamento circulatório associado à função de Theodorsen, $C(\kappa) f(t)$ nas Eqs. (3.29) a (3.31), pode ser substituído pela formulação de Duhamel no domínio do tempo ao assumir a função aproximadora (Eq. (3.35) ) como uma função indicial de admitância (analogamente à análise de circuitos). A função indicial de carregamento resulta de uma entrada degrau no ângulo de ataque de um aerofólio que parte do repouso imediatamente para uma velocidade finita e constante. Desta maneira, obtém-se o carregamento correspondente a um deslocamento arbitrário de aerofólio. A integral de Duhamel é então reescrita em uma forma equivalente fazendo-se integração por partes. Em seguida, utilizam-se os polinômios de Padé para substituir o termo integral, difícil de ser representado no espaço de estados, por uma equação diferencial ordinária (EDO) de segunda ordem. Este tratamento resulta na Eq. (3.36) (EDWARDS, 1977; ALIGHANBARI, 1995; TRICKEY, 2000; LI; XIANG, 2010),

$$
C(\kappa) f(t) \approx\left(C_{0}+C_{1}+C_{2}\right) f(t)+C_{3} C_{4}\left(C_{1}+C_{2}\right) x_{a_{1}}+\left(C_{1} C_{3}+C_{2} C_{4}\right) \dot{x}_{a_{2}}
$$

em que dois estados aerodinâmicos $\left(x_{a_{1}}\right.$ e $\left.x_{a_{2}}\right)$ são então incluídos no modelo. A Eq. (3.37) define estes estados em função do tempo dimensional,

$$
\dot{\mathbf{x}}_{a}=\left(\frac{U}{b}\right) \mathbf{S}_{1} \mathbf{x}+\mathbf{S}_{2} \dot{\mathbf{x}}+\left[\begin{array}{ll}
-C_{3} C_{4}\left(\frac{U^{2}}{b}\right) & \left(C_{3}+C_{4}\right)\left(\frac{U}{b}\right)
\end{array}\right] \mathbf{x}_{a}
$$

onde $\mathbf{x}_{a}=\left\{\begin{array}{ll}x_{a_{1}} & x_{a_{2}}\end{array}\right\}^{T}$ representa os dois estados adicionais referentes à aproximação do carregamento aerodinâmico não estacionário. Os vetores $\mathbf{S}_{1}$ e $\mathbf{S}_{2}$ estão associados ao carregamento circulatório e são apresentados no Apêndice B.

Consequentemente, dois termos são acrescentados às equações de movimento. Estes termos 
realizam a troca de informações entre o carregamento aerodinâmico e o domínio estrutural do problema. A Eq. (3.38) define estes termos (na forma matricial),

$$
\mathbf{D}=\mathbf{R S}_{3}
$$

onde $\mathbf{R}$ e $\mathbf{S}_{3}$ também estão associados ao carregamento circulatório e são dados no Apêndice B.

Tomam-se as devidas diferenciações nas Eq. (3.37) e (3.38) em relação ao tempo adimensional $\tau$. Por fim, a Eq. (3.39) representa o sistema piezoaeroelástico resultante em espaço de estados. Inclui as equações de movimento piezeletricamente acopladas e o carregamento aerodinâmico aproximado por estados aumentados.

$$
\left[\begin{array}{cccc}
\mathbf{I} & \mathbf{0} & \mathbf{0} & \mathbf{0} \\
\mathbf{0} & \tilde{\mathbf{M}} & \mathbf{0} & \mathbf{0} \\
\mathbf{0} & \mathbf{0} & \tilde{\mathbf{I}} & \mathbf{0} \\
\mathbf{0} & \mathbf{0} & \mathbf{0} & \psi
\end{array}\right]\left\{\begin{array}{c}
\mathbf{x}^{\prime} \\
\mathbf{x}^{\prime \prime} \\
\mathbf{x}^{\prime}{ }_{a} \\
\bar{v}^{\prime}
\end{array}\right\}=\left[\begin{array}{cccc}
\mathbf{0} & \mathbf{I} & \mathbf{0} & \mathbf{0} \\
-\tilde{\mathbf{K}} & -\tilde{\mathbf{B}} & \tilde{\mathbf{D}} & \Theta^{T} \\
\tilde{\mathbf{E}}_{1} & \tilde{\mathbf{E}}_{2} & \tilde{\mathbf{F}}_{p} & \mathbf{0} \\
\mathbf{0} & -\Theta & \mathbf{0} & -1 / \lambda
\end{array}\right]\left\{\begin{array}{c}
\mathbf{x} \\
\mathbf{x}^{\prime} \\
\mathbf{x}_{a} \\
\bar{v}
\end{array}\right\}
$$

onde $\tilde{\mathbf{M}}$ é a matriz de grandezas inerciais e $\tilde{\mathbf{K}}$ e $\tilde{\mathbf{B}}$ representam os efeitos de rigidez e amortecimento, respectivamente. Estas matrizes são adimensionais e compostas por contribuições estruturais e aerodinâmicas. Edwards (1977), Edwards, Ashley e Breakwell (1979), Conner (1996), Trickey (2000) e Li e Xiang (2010) apresentam estas matrizes expressas em função do tempo dimensional $t$. A seguir, estas mesmas matrizes são apresentadas no domínio do tempo adimensional $\tau$,

$$
\begin{gathered}
\tilde{\mathbf{M}}=\mathbf{M}-\frac{\rho b^{2}}{m} \mathbf{M}_{n c} \\
\tilde{\mathbf{K}}=\mathbf{K}-\frac{\rho b^{2}}{m}\left(\frac{U}{\omega_{h} b}\right)^{2}\left(\mathbf{K}_{n c}+\frac{1}{2} \mathbf{R S}_{1}\right) \\
\tilde{\mathbf{B}}=\mathbf{B}-\frac{\rho b^{2}}{m}\left(\frac{U}{\omega_{h} b}\right)\left(\mathbf{B}_{n c}+\frac{1}{2} \mathbf{R S}_{2}\right)
\end{gathered}
$$

onde as componentes da aerodinâmica não circulatória são definidas por $\mathbf{M}_{n c}, \mathbf{K}_{n c}$ e $\mathbf{B}_{n c}$, e as componentes circulatórias estão relacionadas aos vetores $\mathbf{R}, \mathbf{S}_{1}$ e $\mathbf{S}_{2}$. As matrizes $\tilde{\mathbf{E}}_{1}$, $\tilde{\mathbf{E}}_{2}$ e $\tilde{\mathbf{F}}_{p}$ (na Eq. (3.39)) constituem as duas equações diferenciais adicionais devido ao modelo aproximado de aerodinâmica não estacionária; $\tilde{\mathbf{D}}$ é a matriz $\mathbf{D}$ no tempo adimensional. Todas essas submatrizes aerodinâmicas são apresentadas no Apêndice B. Elas são geométricas e são definidas em função das constantes de Theodorsen (1935). Estas constantes são apresentadas no Apêndice $\mathrm{C}$ e dependem apenas das posições adimensionais do EE da seção típica e do EA da superfície de controle. 
A Eq. (3.39) pode ser representada de maneira compacta,

$$
\hat{\mathbf{x}}^{\prime}=\mathbf{A} \hat{\mathbf{x}}
$$

onde A é a matriz de estados do sistema piezoaeroelástico linear,

$$
\mathbf{A}=\left[\begin{array}{cccc}
\mathbf{0} & \mathbf{I} & \mathbf{0} & \mathbf{0} \\
-\tilde{\mathbf{M}}^{-1} \tilde{\mathbf{K}} & -\tilde{\mathbf{M}}^{-1} \tilde{\mathbf{B}} & \tilde{\mathbf{M}}^{-1} \tilde{\mathbf{D}} & \tilde{\mathbf{M}}^{-1} \Theta^{T} \\
\tilde{\mathbf{I}}^{-1} \tilde{\mathbf{E}}_{1} & \tilde{\mathbf{I}}^{-1} \tilde{\mathbf{E}}_{2} & \tilde{\mathbf{I}}^{-1} \tilde{\mathbf{F}}_{p} & \mathbf{0} \\
\mathbf{0} & -(1 / \psi) \Theta & \mathbf{0} & -1 /(\psi \lambda)
\end{array}\right]
$$

e $\hat{\mathbf{x}}=\left\{\begin{array}{llll}\mathbf{x} & \mathbf{x}^{\prime} & \mathbf{x}_{a} & \bar{v}\end{array}\right\}^{T}$ é o vetor de estados do sistema piezoaeroelástico linear expresso em função de grandezas adimensionais; $\mathbf{x}$ e $\bar{v}$ representam as respostas estrutural e elétrica, respectivamente, e $\mathbf{x}_{a}$ representa os estados aerodinâmicos.

Edwards, Ashley e Breakwell (1979) compararam soluções aproximadas por estados adicionais com soluções exatas e concluiram que tais aproximações produzem resultados equivalentes para propósitos de engenharia. Baseado em tal constatação, o mesmo modelo foi adotado neste trabalho para representar o carregamento aerodinâmico não estacionário relacionado a movimentos arbitrários de aerofólio.

\subsection{Modelo Piezoaeroelástico Não Linear}

Um dos objetivos deste trabalho é investigar o efeito de não linearidades estruturais na resposta aeroelástica da seção típica eletromecanicamente acoplada. Sabendo que na presença de não linearidades LCOs podem ocorrer em velocidades menores que a velocidade linear de flutter (tipo sub-crítico), a motivação principal é obter geração persistente de energia elétrica em um amplo envelope de operação (SOUSA et al., 2011).

Na presença de não linearidades estruturais os movimentos podem ser arbitrários, pois afetam também, além da velocidade linear de flutter, as características do movimento. A região de folga induz o aparecimento de LCOs sub-críticas (ALIGHANBARI, 1995; LEE; PRICE; WONG, 1999). Do ponto de vista estrutural, isto é um inconveniente associado à depreciação precoce da estrutura. No entanto, não linearidades são intrínsecas a qualquer sistema real. Do ponto de vista de coleta de energia representa uma fonte adicional e persistente de potência elétrica, que pode alimentar sistemas eletrônicos de baixo consumo embarcados em aeronaves de pequeno porte. 
Neste trabalho, a não linearidade bilinear pode ocorrer na mola de rotação da seção típica ou na mola da superfície de controle e a não linearidade cúbica ocorre somente no GDL de rotação da seção típica. Outras considerações podem ser feitas dependendo do escopo da investigação. Alighanbari (1995), por exemplo, também considerou mola bilinear no GDL de translação. Ainda no mesmo trabalho, constatou tendência mais acentuada à movimentos caóticos quando molas bilineares são introduzidas simultaneamente no GDL de rotação da seção típica e na superfície de controle. Combinar as não linearidades pode permitir que o gerador se beneficie tanto de LCOs em baixas velocidades quanto de oscilações de maiores amplitudes em velocidades elevadas, caracterizando um gerador piezoaeroelástico broadband (em termos de velocidade).

As equações de movimento do sistema piezoaeroelástico (Eqs. (3.21) a (3.24)) são apresentadas como,

$$
\begin{gathered}
r_{\alpha}^{2} \alpha^{\prime \prime}+\left(r_{\beta}^{2}+(c-a) x_{\beta}\right) \beta^{\prime \prime}+x_{\alpha} \bar{h}^{\prime \prime}+\xi_{\alpha} \alpha^{\prime}+\eta_{\alpha}^{2} r_{\alpha}^{2} \alpha+\bar{f}_{\alpha b}(\alpha)+\bar{f}_{\alpha c}(\alpha)=\bar{M}_{\alpha} \\
\left(r_{\beta}^{2}+(c-a) x_{\beta}\right) \alpha^{\prime \prime}+r_{\beta}^{2} \beta^{\prime \prime}+x_{\beta} \bar{h}^{\prime \prime}+\xi_{\beta} \beta^{\prime}+\eta_{\beta}^{2} r_{\beta}^{2} \beta+\bar{f}_{\beta b}(\beta)=\bar{M}_{\beta} \\
x_{\alpha} \alpha^{\prime \prime}+x_{\beta} \beta^{\prime \prime}+\mu \bar{h}^{\prime \prime}+\xi_{h} \bar{h}^{\prime}+\bar{h}-\chi \bar{v}=-\bar{L} \\
\psi \bar{v}^{\prime}+\frac{1}{\lambda} \bar{v}+\chi \bar{h}^{\prime}=0
\end{gathered}
$$

onde $\bar{f}_{\alpha b}(\alpha)$ é o momento elástico exercido pela mola bilinear no GDL de rotação da seção típica e $\bar{f}_{\alpha c}(\alpha)$ é o momento elástico exercido pela mola cúbica. Ainda, $\bar{f}_{\beta b}(\beta)$ é o momento elástico exercido pela mola bilinear no GDL de rotação da superfície de controle. Além disso, fica implícito que se alguma não linearidade não está sendo considerada no problema, o termo correspondente é nulo. Se todos são nulos, tem-se, obviamente, o caso linear.

O termo bilinear $\bar{f}_{\alpha b}(\alpha)$ é,

$$
\bar{f}_{\alpha b}(\alpha)= \begin{cases}-\eta_{\alpha}^{2} r_{\alpha}^{2} \alpha_{s} & \alpha>\alpha_{s} \\ 0 & -\alpha_{s} \leq \alpha \leq \alpha_{s} \\ \eta_{\alpha}^{2} r_{\alpha}^{2} \alpha_{s} & \alpha<-\alpha_{s}\end{cases}
$$

sendo que $\alpha_{s}$ é o ângulo de rotação da seção típica (em radianos) onde a mola (deste mesmo GDL) passa a exercer momento elástico. Logo, o momento elástico é nulo quando $-\alpha_{s} \leq \alpha \leq$ $\alpha_{s}$. 
O termo cúbico $\bar{f}_{\alpha c}(\alpha)$ é,

$$
\bar{f}_{\alpha c}(\alpha)= \begin{cases}\eta_{c}^{2} r_{\alpha}^{2}\left(\alpha-\alpha_{s}\right)^{3} & \alpha>\alpha_{s} \\ 0 & -\alpha_{s} \leq \alpha \leq \alpha_{s} \\ \eta_{c}^{2} r_{\alpha}^{2}\left(\alpha+\alpha_{s}\right)^{3} & \alpha<-\alpha_{s}\end{cases}
$$

onde $\eta_{c}=\omega_{\alpha c} / \omega_{h}$ é a razão entre a frequência natural desacoplada de rotação da seção típica correspondente à mola cúbica $\left(\omega_{\alpha c}\right)$ e a frequência natural desacoplada de deslocamento linear.

Ainda,

$$
\bar{f}_{\beta b}(\beta)= \begin{cases}-\eta_{\beta}^{2} r_{\beta}^{2} \beta_{s} & \beta>\beta_{s} \\ 0 & -\beta_{s} \leq \beta \leq \beta_{s} \\ \eta_{\beta}^{2} r_{\beta}^{2} \beta_{s} & \beta<-\beta_{s}\end{cases}
$$

onde $\beta_{s}$ é o ângulo de rotação da superfície de controle onde a rigidez da mola bilinear (deste mesmo GDL) muda.

Portanto, as Eqs. (3.45) e (3.46) podem ser ajustadas para atender modelos lineares ou não lineares. As não linearidades podem ocorrer de maneira isolada ou podem ser combinadas no mesmo GDL ou em GDL diferentes.

A seguir, as não linearidades serão incluídas na representação em espaço de estados.

\subsubsection{Representação das Equações Não Lineares de Movimento em Es- paço de Estados}

A Eq. (3.52) mostra o sistema piezoaeroelástico não linear representado em espaço de estados. Esta é a forma mais completa das equações de movimento e inclui o acoplamento eletromecânico, os estados adicionais associados ao carregamento aerodinâmico para movimento arbitrário e todas as não linearidades possíveis neste trabalho,

$$
\hat{\mathbf{x}}^{\prime}=\mathbf{A} \hat{\mathbf{x}}+\mathbf{a y}
$$

sendo que a representação em espaço de estados foi estruturada em duas partes - uma parte referente ao sistema linear e outra referente à contribuição das não linearidades; A é a matriz de estados da porção linear do sistema piezoaeroelástico (definido anteriormente) e a é a matriz de 
estados da porção não linear do sistema,

$$
\mathbf{a}=\left[\begin{array}{cccc}
\mathbf{0} & \mathbf{0} & \mathbf{0} & \mathbf{0} \\
-\tilde{\mathbf{M}}^{-1} \mathbf{K}_{n l} & \mathbf{0} & \mathbf{0} & \mathbf{0} \\
\mathbf{0} & \mathbf{0} & \mathbf{0} & \mathbf{0} \\
\mathbf{0} & \mathbf{0} & \mathbf{0} & 0
\end{array}\right]
$$

onde a submatriz $\mathbf{K}_{n l}$ introduz as não linearidades anteriormente descritas,

$$
\mathbf{K}_{n l}=\left[\begin{array}{ccc}
\bar{f}_{\alpha b}(\alpha) & \bar{f}_{\alpha c}(\alpha) & 0 \\
0 & 0 & \bar{f}_{\beta b}(\beta) \\
0 & 0 & 0
\end{array}\right]
$$

e o vetor y é um vetor constante, definido a seguir,

$$
\mathbf{y}=\left\{\begin{array}{lllllllll}
1 & 1 & 1 & 0 & 0 & 0 & 0 & 0 & 0
\end{array}\right\}^{T}
$$

A próxima seção descreve um método para minimizar o erro acumulado durante a resolução numérica de sistemas com não linearidade do tipo bilinear (que foi incluído no modelo). $\mathrm{O}$ capítulo seguinte apresentará os estudos de casos.

\subsection{Método de Hénon}

O modelo numérico (Eq. (3.52)) é resolvido no domínio do tempo. O método utilizado é o Runge-Kutta de quarta ordem. Este método é amplamente difundido na literatura (THORBY, 2008) e propicia soluções com boa precisão. No entanto, as não linearidades (molas bilineares) devem ser consideradas para que as previsões do modelo representem os resultados experimentais de maneira satisfatória.

Conner (1996) analisou alternativas às soluções "linearizadas" e observou que a simplicidade em se adotar um algorítmo de "força-bruta" (apenas substituir parâmetros do sistema após uma descontinuidade ser encontrada) pode levar a resultados incorretos. Para comparação, também analisou o método da bisecção e mostrou que a precisão da solução depende de um número considerável de iterações adicionais (dependendo da tolerância aceitável), o que pode tornar este método ineficiente.

Como alternativa, o método apresentado por Hénon (1982) pode ser utilizado para minimizar o erro acumulado durante a resolução numérica de sistemas não lineares que podem ser 
representados por uma combinação de modelos lineares.

O método de Hénon encontra a intersecção da trajetória de um atrator com uma superfície de seção de Poincaré em apenas um passo de integração numérica. Para aplicar o método, um sistema de $N$ equações diferenciais simultâneas,

$$
\begin{gathered}
\frac{d x_{1}}{d t}=f_{1}\left(x_{1}, \ldots, x_{N}\right) \\
\vdots \\
\frac{d x_{N}}{d t}=f_{N}\left(x_{1}, \ldots, x_{N}\right)
\end{gathered}
$$

é rearranjado de maneira que seja possível integrá-lo para um dado valor de variável de estado. Segundo Hénon (1982), é necessário apenas que o método de integração numérica escolhido permita passos independentes de tempo, como o Runge-Kutta. Assim, é possível especificar com antecedência a mudança de uma variável dependente (do tempo) durante uma iteração da resolução numérica, tornando-a temporariamente independente. Logo, pode-se obter um ponto de integração exatamente sobre a superfície de seção de Poincaré apenas escolhendo o passo de integração apropriado.

Para mudar a variável independente, Hénon (1982) diferencia o sistema em termos da variável de interesse, dividindo cada equação do sistema pela equação que contém a variável dependente que se deseja especificar a variação (com antecedência) e faz o inverso desta última,

$$
\begin{gathered}
\frac{d x_{1}}{d x_{N}}=\frac{f_{1}}{f_{N}}\left(x_{1}, \ldots, x_{N}\right) \\
\vdots \\
\frac{d t}{d x_{N}}=\frac{1}{f_{N}}\left(x_{1}, \ldots, x_{N}\right)
\end{gathered}
$$

supondo que $d x_{N} / d t$ seja a equação correspondente à uma variável de estado descontínua arbitrária. Ainda, $d x_{i} / d x_{N}$ representa a variação de cada variável de estado do sistema em relação à variável descontínua e $d t / d x_{N}$ representa a variação do tempo em relação à variável descontínua.

O sistema da Eq. (3.56) é resolvido normalmente até que uma variável intercepte uma descontinuidade (conhecida), quando calcula-se a distância ultrapassada. O valor negativo desta distância é usado como passo de integração para a resolução do sistema da Eq. (3.57) (durante apenas uma iteração). Dessa maneira, o último ponto de integração (estado do sistema) no tempo pode ser substituído por este novo ponto, exatamente onde e quando os parâmetros do sistema mudam. A resolução no tempo prossegue normalmente até um novo cruzamento por uma descontinuidade, quando o método se repete. Assim, o erro acumulado a cada ultrapassagem é minimizado. 


\subsubsection{Aplicação do Método de Hénon à Seção Típica Piezoaeroelástica Não Linear}

Conner (1996) adaptou o método de Hénon para resolver sistemas com não linearidades estruturais do tipo bilinear. De maneira semelhante, neste trabalho dois sistemas similares à Eq. (3.57) são formulados. Em um deles, a equação não linear $d x_{N} / d t$ é a equação de momento de arfagem dada na Eq. (3.45). No outro, a equação não linear $d x_{N} / d t$ é a equação de momento da superfície de controle, Eq. (3.46). Ainda, $d x_{i} / d t$ representa cada uma das equações lineares restantes no sistema.

Durante a resolução da Eq. (3.52), $\alpha$ ou $\beta$ (dependendo do GDL onde a mola bilinear é considerada) é monitorada. Quando a variável não linear intercepta uma fronteira ( $\alpha_{s}$ ou $\left.\beta_{s}\right)$, a ultrapassagem é calculada e o sistema modificado, Eq. (3.57), é resolvido para o valor negativo desta distância. Este procedimento resulta no estado que o sistema teria se o último ponto de integração no tempo coincidisse com o ponto de transição entre as diferentes regiões lineares da mola bilinear. O estado obtido resolvendo a Eq. (3.57) "de volta no espaço” substitui, então, o último ponto de integração no tempo. Ainda, neste momento, a rigidez da mola bilinear muda conforme a relação dada na Eq. (3.49) ou na Eq. (3.51), e a resolução da Eq. (3.52) prossegue normalmente. Cada vez que a rigidez de uma mola bilinear muda, este procedimento é repetido.

O capítulo seguinte apresenta os resultados deste trabalho. 


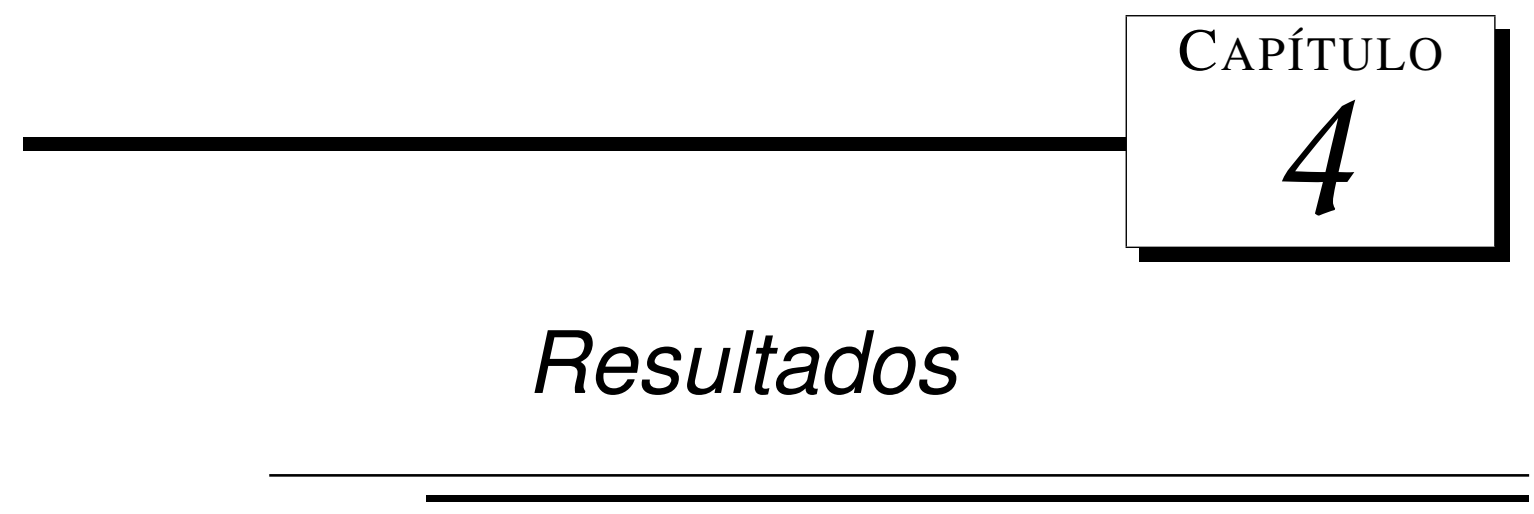

Conforme discutido anteriormente, duas configurações de geradores piezoaeroelásticos são consideradas neste trabalho, uma seção típica com 2-GDL (deslocamento linear e deslocamento angular) e outra com 3-GDL (deslocamento linear, deslocamento angular e posição da superfície de controle). Nas duas configurações o acoplamento eletromecânico é inserido em um dos GDL do sistema e um resistor é considerado no domínio elétrico do problema. Os estudos de caso aqui apresentados referem-se à condição linear de cada gerador e posteriormente à condição não linear.

Inicialmente a configuração com 2-GDL é investigada. A primeira análise visa a verificação da influência de diferentes parâmetros adimensionais (capacitância equivalente, acoplamento eletromecânico e resistência) sobre o comportamento piezoaeroelástico linear do sistema (velocidade de flutter e potência elétrica gerada). Posteriormente, o modelo numérico linear é verificado a partir de resultados experimentais para diferentes condições de contorno elétricas (desde curto circuito $\left(R_{l} \rightarrow 0\right)$ até circuito aberto $\left(R_{l} \rightarrow \infty\right)$ ). A seguir os casos não lineares são apresentados para o sistema com 2-GDL. Inicialmente, uma não linearidade concentrada do tipo bilinear é modelada no GDL de deslocamento angular. Os resultados numéricos são verificados a partir de resultados experimentais para diferentes condições de contorno elétricas. A seguir, uma não linearidade combinada (bilinear + cúbica) é modela no mesmo GDL e o comportamento do sistema avaliado para uma ampla faixa de velocidades e razões de rigidez.

Por fim, o gerador com 3-GDL é investigado. O comportamento eletroaeroelástico linear e não linear é investigado numericamente desde a condição de curto circuito até circuito aberto. A inclusão de não linearidades concentradas para a obtenção de oscilações persistentes em uma faixa ampla de velocidades (e a consequente saída elétrica) também é discutida. 


\subsection{Seção Típica com Dois Graus de Liberdade}

O comportamento piezoaeroelástico de um gerador com 2-GDL é investigado para o caso linear e para casos não lineares nesta seção. Em alguns desses casos, o modelo numérico aqui utilizado é verificado a partir de resultados experimentais. Para isso, um modelo experimental de uma seção típica já utilizada em outras pesquisas do grupo foi adaptada para o caso piezoaeroelástico. Assim, uma breve descrição do sistema experimental é apresentada para tornar claro pontos posteriores do texto.

O sistema aeroelástico experimental utilizado nos ensaios experimentais é baseado no projeto de Conner (1996). O modelo apresentado nas fotos da Fig. 10 é constituído por um aerofólio rígido conectado a elementos elásticos que permitem oscilações em dois graus de liberdade: deslocamento linear e deslocamento angular. Um eixo de alumínio passa pelo ponto de $1 / 4$ da corda da seção típica. Esse eixo é vinculado a duas placas de aço em cada uma de suas extremidades através de uma sistema de rolamentos e flanges. Em cada uma dessas placas (uma superior e outra inferior), estão engastadas duas vigas de aço mola. A outra extremidades dessas quatro vigas estão engastadas em um sistema inercial. Assim, esse conjunto de vigas confere a rigidez ao GDL de deslocamento linear. A foto da Fig. 10a mostra um par de vigas vinculadas à placa inferior. A rigidez do GDL de rotação é obtida com um fio mola. Este fio atravessa o eixo a $1 / 4$ da corda e é apoiado em cantoneiras instaladas na placa superior. A foto da Fig. 10b mostra o sistema com o fio mola. Detalhes sobre o sistema podem ser encontrados em Tavares (2009).

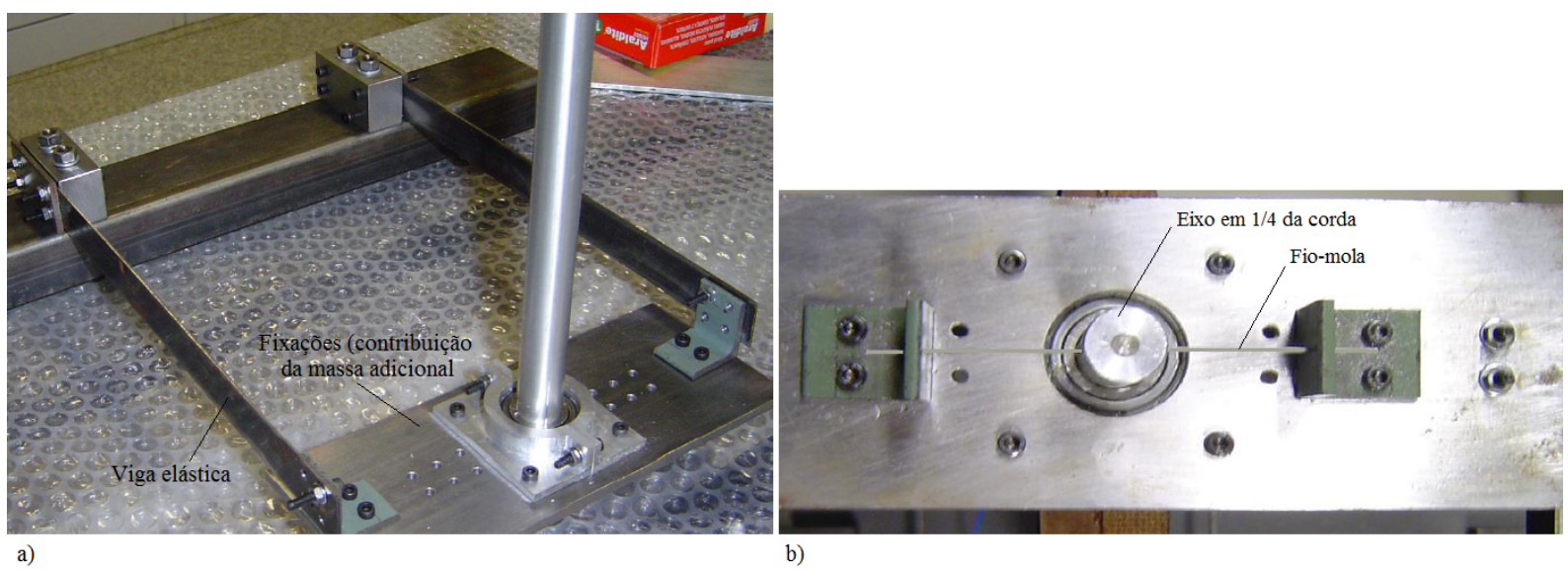

Figura 10 - Fotos do sistema experimental, a) molas de flexão e b) mola de torção

O acoplamento eletromecânico é inserido no sistema através da colagem de cerâmicas piezelétricas (QP-10N - Mide Technology Corp.) na raiz de duas das vigas que conferem rigidez ao sistema. Estas piezocerâmicas são ligadas em paralelo e os eletrodos aos terminais de um 
resistor, com o objetivo de se estimar a potência elétrica gerada. As fotos da Fig. 11 mostram o sistema experimental no túnel de vento (Fig. 11a) e as piezocerâmicas (Fig. 11b). Nos casos experimentais lineares e não lineares deste trabalho considera-se um conjunto de resistores variando desde uma condição próxima ao curto-circuito a até próxima ao circuito aberto $\left(R_{l}=10^{2}, 10^{3}, 10^{4}, 10^{5}\right.$ e $\left.10^{6} \Omega\right)$.

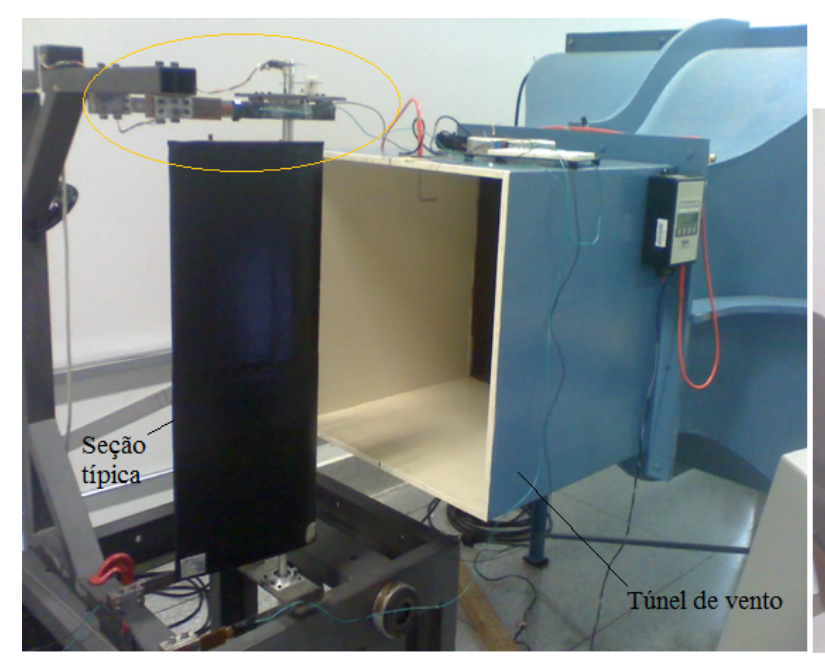

a)

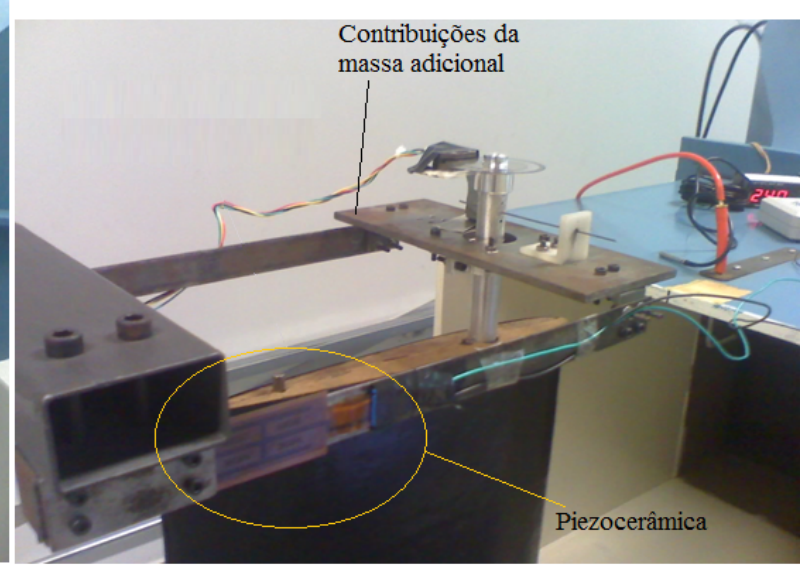

b)

Figura 11 - Fotos do sistema experimental: a) a seção típica posicionada no túnel de vento e b) uma piezocerâmica colada a uma das vigas de aço-mola

Durante os ensaios em túnel de vento os dados foram coletados utilizando-se um sistema dSPACE DS1104. Para a medição do deslocamento linear $(h)$ foi utilizado um strain gage colado em uma das vigas que conferem rigidez ao GDL de deslocamento linear. Um esquema de $1 / 4$ de ponte foi utilizado em um sistema HBM MGC Plus. A saída foi calibrada para fornecer o deslocamento no GDL de deslocamento linear em metros. Um encoder US Digital modelo HEDS-9000-T00 foi instalado no eixo que passa a $1 / 4$ da corda da seção típica, fornecendo assim a posição angular do sistema. Os eletrodos dos piezelétricos foram conectados aos terminais de resistores e o sinal de voltagem coletado no sistema dSPACE.

Um conjunto de parâmetros aeroelásticos e eletromecânicos é necessário para a realização das simulações. Todos os parâmetros aeroelásticos foram determinados experimentalmente. Os parâmetros eletromecânicos, capacitância equivalente e acoplamento eletromecânico, foram determinados com o modelo analítico de Erturk e Inman (2008). A Tab. 1 apresenta os parâmetros de interesse.

A partir dos parâmetros piezoaeroelásticos listados na Tab. 1, calculam-se as grandezas adimensionais apresentadas na Tab. 2. As adimensionalizações apresentadas no Capítulo 3 foram aqui utilizadas. 
Tabela 1 - Parâmetros do sistema experimental com 2-GDL

\begin{tabular}{ccc}
\hline \hline Parâmetro & Valor & Unidade \\
\hline$l$ & $5 \times 10^{-1}$ & $\mathrm{~m}$ \\
$b$ & $1.25 \times 10^{-1}$ & $\mathrm{~m}$ \\
$a$ & $-5 \times 10^{-1}$ & - \\
$x_{\alpha} b$ & $3.2 \times 10^{-2}$ & $\mathrm{~m}$ \\
$m$ & 1.542 & $\mathrm{~kg} / \mathrm{m}$ \\
$m_{f}$ & 2.548 & $\mathrm{~kg} / \mathrm{m}$ \\
$I_{\alpha}$ & $7.2 \times 10^{-3}$ & $\mathrm{~kg} \cdot \mathrm{m}$ \\
$k_{\alpha}$ & 5.08 & $\mathrm{~N} / \mathrm{rad}$ \\
$k_{h}$ & $4.2 \times 10^{3}$ & $\mathrm{~N} / \mathrm{m}^{2}$ \\
$d_{\alpha}$ & $6.35 \times 10^{-2}$ & $\mathrm{~N} \cdot \mathrm{s} / \mathrm{rad}$ \\
$d_{h}$ & 1.8146 & $\mathrm{~N} \cdot \mathrm{s} / \mathrm{m}^{2}$ \\
$\theta$ & $1.55 \times 10^{-3}$ & $\mathrm{~N} / \mathrm{V}$ \\
$C_{p}^{e q}$ & $1.2 \times 10^{-7}$ & $\mathrm{~F}$ \\
$R_{l}$ & $10^{2}$ & $\Omega$ \\
\hline
\end{tabular}

Tabela 2 - Parâmetros adimensionais do modelo com 2-GDL

\begin{tabular}{cc}
\hline \hline Parâmetro & Valor \\
\hline$a$ & $-5 \times 10^{-1}$ \\
$\mu$ & 2.594 \\
$x_{\alpha}$ & $2.5448 \times 10^{-1}$ \\
$r_{\alpha}$ & 4.373 \\
$\eta_{\alpha}$ & $5.1 \times 10^{-1}$ \\
$\xi_{\alpha}$ & $4.3 \times 10^{-2}$ \\
$\xi_{h}$ & $1.5 \times 10^{-2}$ \\
$\chi$ & $5.905 \times 10^{-6}$ \\
$\psi$ & $3.657 \times 10^{-9}$ \\
$\lambda$ & $1.713 \times 10^{5}$ \\
\hline
\end{tabular}




\subsubsection{Análise do Comportamento Piezoaeroelástico Linear}

Nesta seção o modelo piezoaeroelástico linear é verificado a partir de resultados experimentais. O comportamento aeroelástico linear da seção típica com 2-GDL é investigado numérica e experimentalmente na fronteira de flutter para o conjunto de resistores elétricos considerados neste trabalho. Os parâmetros utilizados nas simulações são os apresentados na Tab. 1.

A Fig. 12 mostra a variação da parte real do autovalor (associada ao amortecimento do sistema) do GDL de deslocamento linear $\left(\gamma_{h}\right)$ com o aumento da velocidade (reduzida) do escoamento, $u=U /\left(\omega_{h} b\right)$, e diferentes resistores. Apenas os autovalores do GDL que se torna instável são mostrados para facilitar a visualização da velocidade linear de flutter $\left(u_{L F}\right)$. Constata-se a ocorrência de flutter quando a parte real de um autovalor aeroelástico intercepta o limiar de estabilidade neutra. Nota-se também que, embora próximas, há uma velocidade crítica particular para cada carga resistiva considerada. Na condição de curto-circuito o modelo prevê a velocidade de flutter de $11.6 \mathrm{~m} / \mathrm{s}$ enquanto que na condição próxima ao circuito aberto a velocidade prevista é de $11.9 \mathrm{~m} / \mathrm{s}$. Esta variação é explicada pelo efeito shunt damping resistivo da geração piezelétrica de energia. É importante ressaltar que a velocidade de flutter determinada experimentalmente é de $12 \mathrm{~m} / \mathrm{s}$ para a condição de curto-circuito. A variação da velocidade de flutter para diferentes resistores não pôde ser medida experimentalmente.

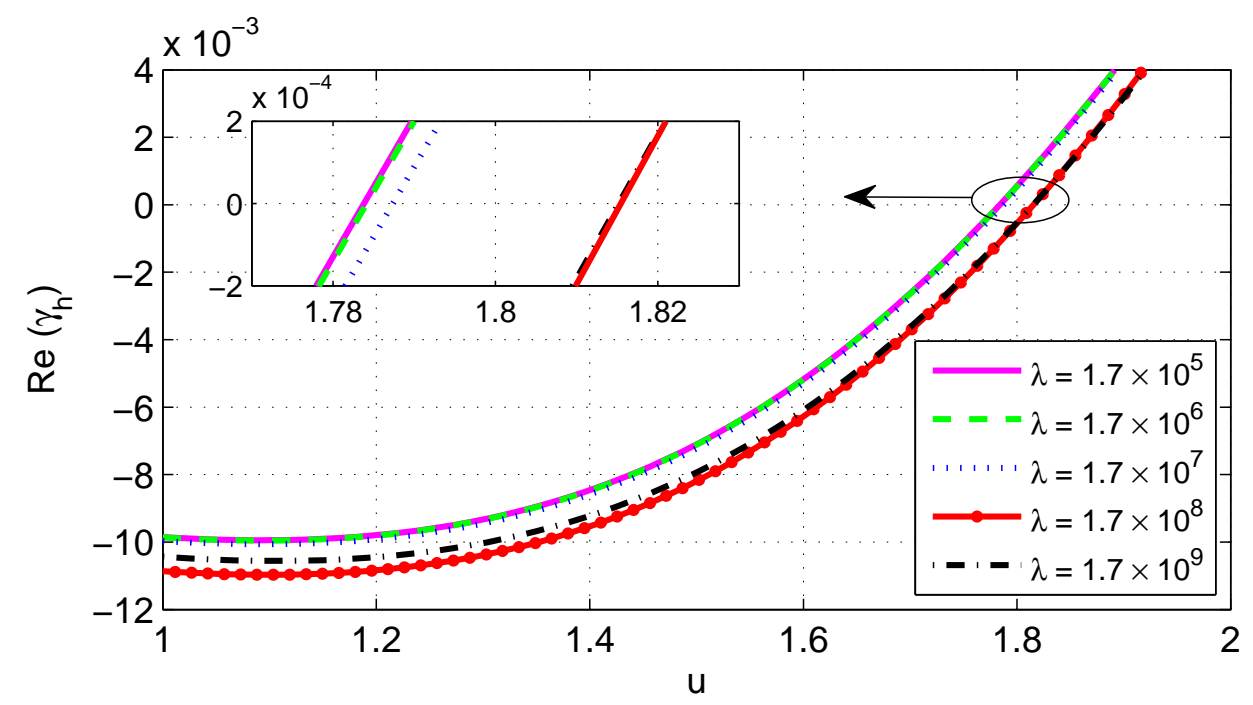

Figura 12 - Análise de estabilidade por autovalores do sistema linear 2-GDL para a condição elétrica variando desde curto-circuito $\left(R_{l} \rightarrow 0\right)$ até circuito aberto $\left(R_{l} \rightarrow \infty\right)$

Simulações no domínio do tempo foram realizadas considerando-se a velocidade linear de flutter determinada para cada resistor (Fig. 12). Conforme o modelo em espaço de estados apresentado no Capítulo 3, obtém-se em cada caso a variação dos estados mecânicos (deslocamento linear e deslocamento angular) e estado elétrico (voltagem) ao longo do tempo para a veloci- 
dade considerada na simulação. A partir do sinal de voltagem e conhecendo-se a resistência utilizada determina-se a potência elétrica gerada.

A variação da potência elétrica adimensional (determinada numérica e experimentalmente) com a variação da carga resistiva para cada velocidade de flutter é apresentada na Fig. 13. Os resultados numéricos foram obtidos para diversos valores de resistências elétricas, conferindo um caráter contínuo para a curva. Entretanto, os valores experimentais foram obtidos para os resistores $10^{2}, 10^{3}, 10^{4}, 10^{5}$ e $10^{6} \Omega$. Pode-se verificar na figura que o modelo numérico prevê adequadamente a saída elétrica medida experimentalmente. Observa-se também que a resistência ótima experimental (entre as consideradas nos testes) que fornece a potência máxima é $10^{5} \Omega\left(\lambda=1.7 \times 10^{8}\right)$. Entretanto, a partir das simulações, pôde-se determinar a resistência ótima (global) como sendo $\lambda=4.3 \times 10^{8}$.

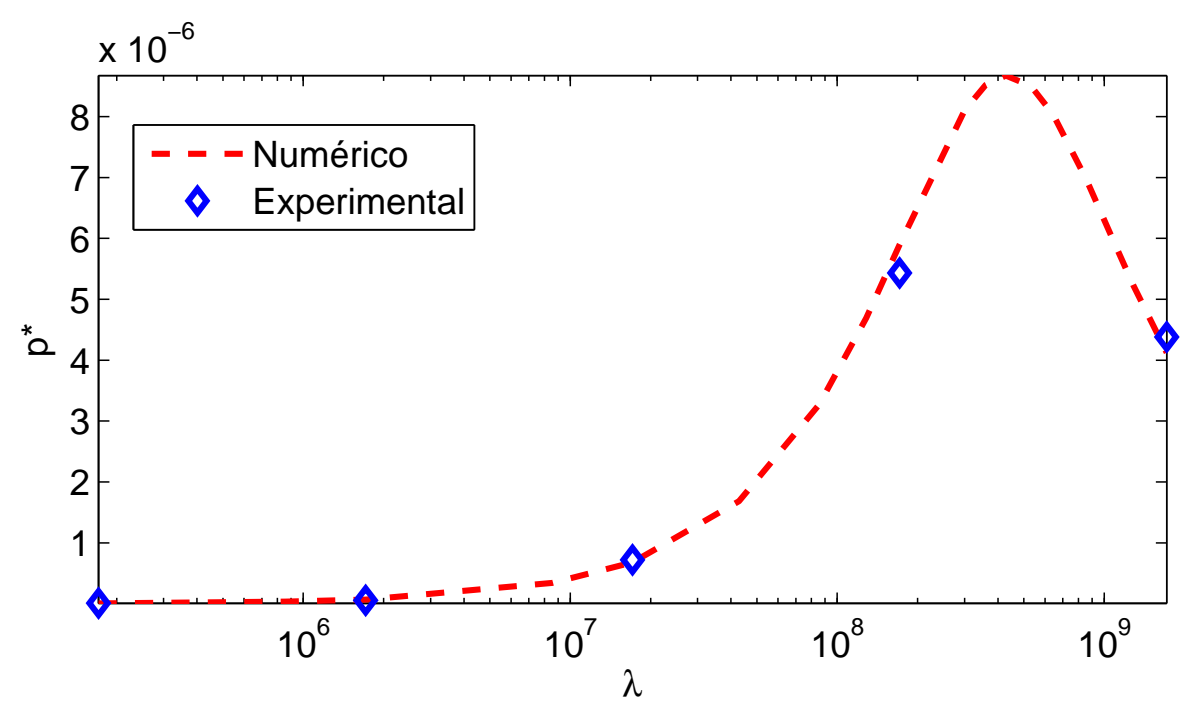

Figura 13 - Variação da potência adimensional produzida conforme a carga resistiva para o sistema linear 2-GDL e na fronteira de flutter

Apresenta-se a seguir a história no tempo dos estados mecânicos e elétrico obtidos na velocidade de flutter da resistência ótima. É importante destacar que os resultados experimentais foram medidos em velocidades próximas à velocidade crítica. Estas respostas sempre apresentam um pequeno aumento ou redução da amplitude das oscilações ao longo do tempo. As Figs. 14 a 16 apresentam as respostas numéricas e experimentais para os deslocamento linear e angular e para a voltagem. Verifica-se que o modelo prevê adequadamente as amplitudes e frequências do sistema. 


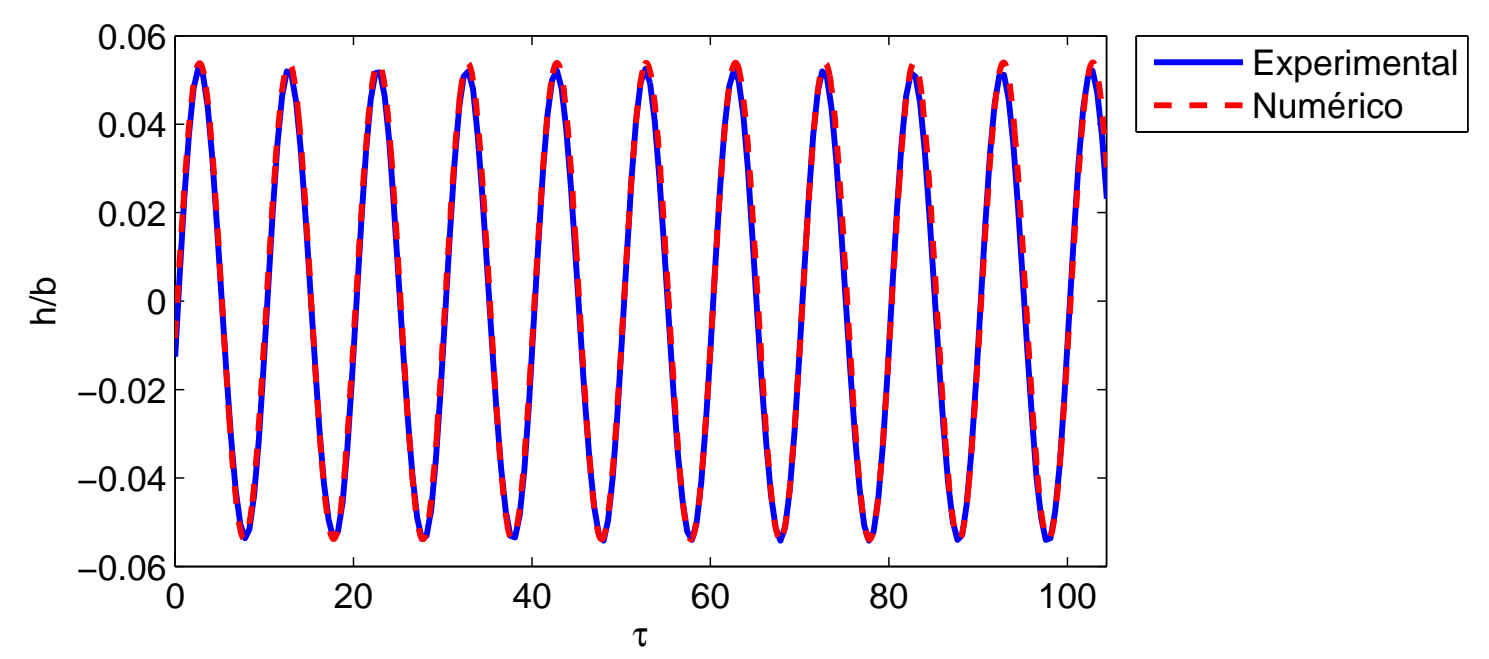

Figura 14 - Resposta no tempo (deslocamento linear adimensional) do sistema linear 2-GDL para a carga resistiva ótima $\left(\lambda=1.7 \times 10^{8}\right.$ ou $\left.R_{l}=10^{5} \Omega\right)$ e na fronteira de flutter

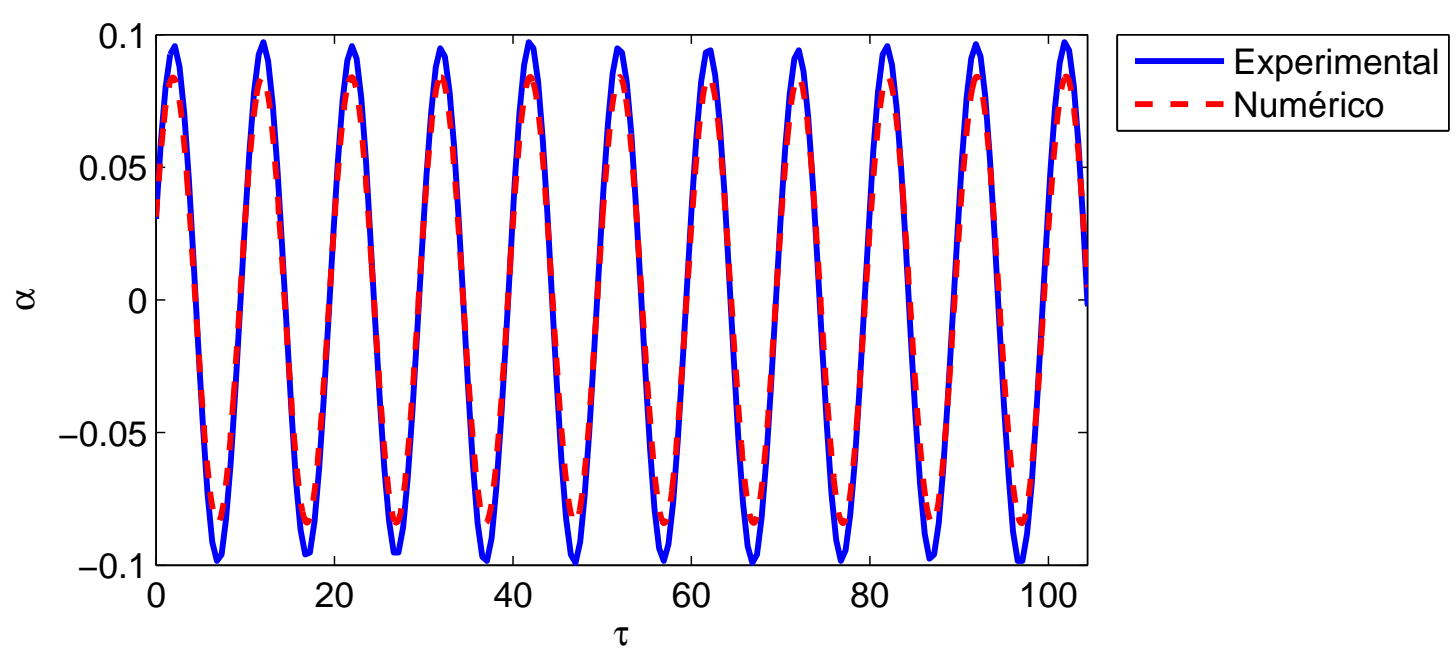

Figura 15 - Resposta no tempo (ângulo de rotação da seção típica) do sistema linear 2-GDL para a carga resistiva ótima $\left(\lambda=1.7 \times 10^{8}\right.$ ou $\left.R_{l}=10^{5} \Omega\right)$ e na fronteira de flutter

Apesar dos resultados apresentados mostrarem que o modelo numérico representa apropriadamente o comportamento piezoaeroelástico do sistema com 2-GDL, o envelope de operação desta configuração de gerador é limitado. Frente a tal restrição, serão apresentadas nas próximas seções investigações com configurações onde não linearidades estruturais concentradas são modeladas em um dos GDL do sistema. Espera-se assim ampliar a faixa de velocidades de operação do sistema. 


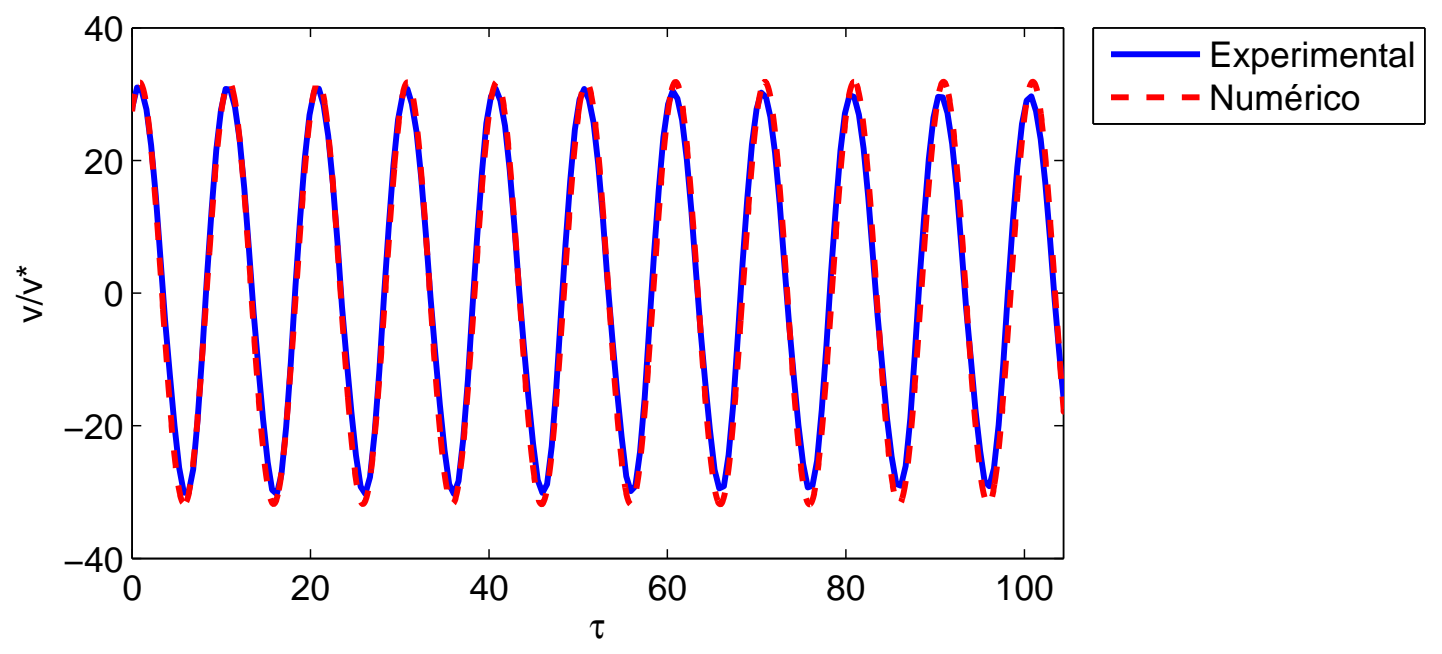

Figura 16 - Resposta no tempo (voltagem adimensional) do sistema linear 2-GDL para a carga resistiva ótima $\left(\lambda=1.7 \times 10^{8}\right.$ ou $\left.R_{l}=10^{5} \Omega\right)$ e na fronteira de flutter

\subsubsection{Seção Típica Piezoaeroelástica com Não Linearidade Bilinear}

Neste estudo de caso, uma não linearidade estrutural concentrada é modelada no GDL de rotação da seção típica. Assim, a mola torsional linear do estudo de caso anterior é substituída por uma mola bilinear. A solução das equações do movimento do sistema levam em consideração o método de Hénon (1982) para lidar com as descontinuidades do momento elástico angular devido à presença da mola bilinear.

Os resultados das simulações são verificados a partir de resultados experimentais. No sistema experimental, o mesmo fio mola utilizado no caso linear é responsável por atribuir a rigidez ao GDL de rotação. No caso linear o fio estava apoiado em um furo circular, de mesmo diâmetro do fio mola, na cantoneira posicionada na placa superior. Para a representação de uma mola bilinear, uma nova cantoneira foi instalada no sistema e agora um furo do tipo oblongo garante a descontinuidade no sistema.

O momento bilinear é simétrico e os limites são $\alpha_{s}= \pm 1.4 \pi / 180$ radianos. $\left(\delta_{\alpha}=2.8 \pi / 180\right.$ radianos é a faixa nominal de deslocamento no GDL de rotação da seção típica para a qual a mola não excerce momento elástico). Além destes limites, a rigidez da mola é a mesma do caso linear. A Fig. 17 mostra os momentos elásticos experimentais linear e bilinear (SOUSA et al., 2011). Observa-se, claramente, que há uma faixa de deslocamentos angulares para os quais o momento elástico correspondente no GDL de rotação da seção típica é nulo.

Diferente do caso linear, um sistema dinâmico não linear é altamente sensível às condições iniciais que lhe são impostas (NAYFEH; BALACHANDRAN, 1995; OTT, 1993). Assim 


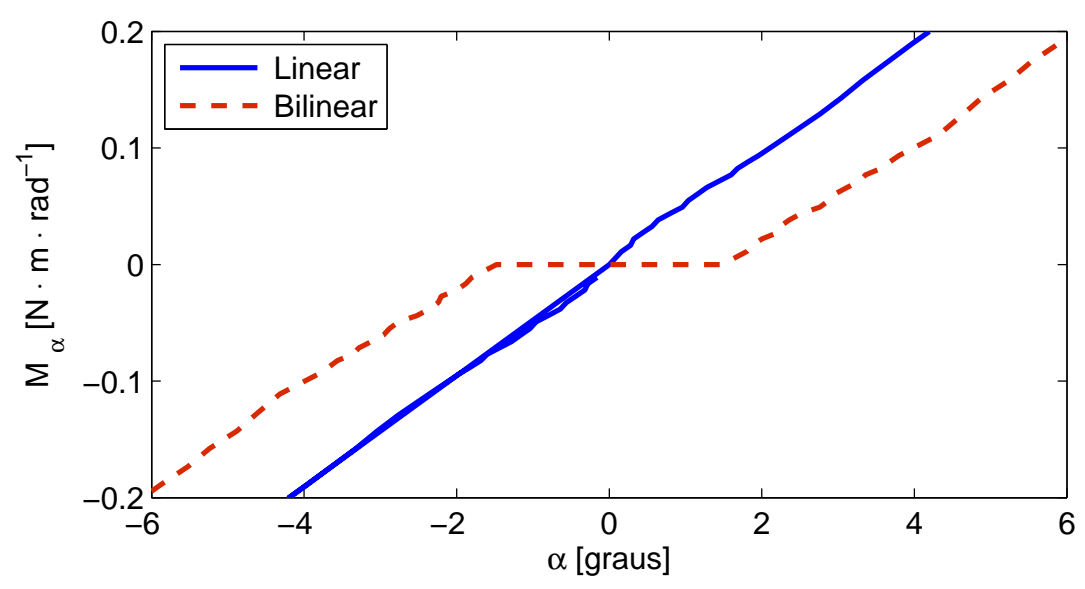

Figura 17 - Momentos elásticos medidos experimentalmente para o sistema 2-GDL linear e não linear com mola bilinear no GDL de rotação (SOUSA et al., 2011)

sendo, conforme Tang, Dowell e Virgin (1998), uma das formas de se determinar as velocidades em que LCOs ocorrem é por integração no tempo e estas podem ser particulares para cada perturbação inicial aplicada ao sistema. Em um sistema linear eletromecanicamente acoplado, a carga resistiva considerada altera a velocidade na qual oscilações autosustentadas aparecem (SOUSA; DE MARQUI, 2011). Entretanto, as LCOs são um fenômeno fortemente não linear e o efeito de shunt damping em relação aos exibidos pelo sistema linear é menos influente. Tal afirmação é bastante evidente em uma seção típica eletroaeroelástica como a aqui estudada, onde não linearidades concentradas são modeladas em um GDL e o acoplamento eletromecânico (acoplamento mais fraco do sistema) é assumido em outro. Assim, as velocidades em que LCOs são inicialmente identificadas não variam com a variação da carga resistiva considerada no domínio elétrico do problema (SOUSA et al., 2011).

Durante a aquisição das respostas experimentais, perturbações iniciais de aproximadamente 8\% da semicorda foram aplicadas no GDL de deslocamento linear (ou $10 \mathrm{~mm}$ para o sistema descrito na Tab. 1). A velocidade adimensional do escoamento na qual a primeira LCO foi constatada é 1.53 para a condição de curto-circuito (ou $10.0 \mathrm{~m} / \mathrm{s}$ ). A velocidade prevista pelo modelo é 1.58 (ou $10.3 \mathrm{~m} / \mathrm{s}$ ). A potência adimensional produzida experimentalmente pela carga resistiva ótima $\left(\lambda=1.7 \times 10^{8}\right.$ ou $R_{l}=10^{5} \Omega$ ) é $1.6 \times 10^{-5}$ (ou $27.5 \mathrm{~mW}$ ) e a prevista pelo modelo é $1.7 \times 10^{-5}$ (ou $28.6 \mathrm{~mW}$ ). A velocidade do escoamento na qual observa-se a primeira LCO é $16 \%$ menor que a velocidade linear crítica. Entretanto, as oscilações são persistentes e permanecem com amplitudes aceitáveis para velocidades até próximas da velocidade linear de flutter (até $u \approx 1.8$ ), quando o movimento passa a ser divergente.

A variação da potência com a carga resistiva é apresentada na Fig. 18. Observa-se a pre- 
sença da carga resistiva ótima que fornece a máxima potência elétrica. É importante salientar que, apesar das oscilações persistentes ocorrerem em uma faixa restrita de velocidades (assim como no caso linear), a potência gerada com a resistência ótima no caso bilinear é $300 \%$ da potência do caso linear.

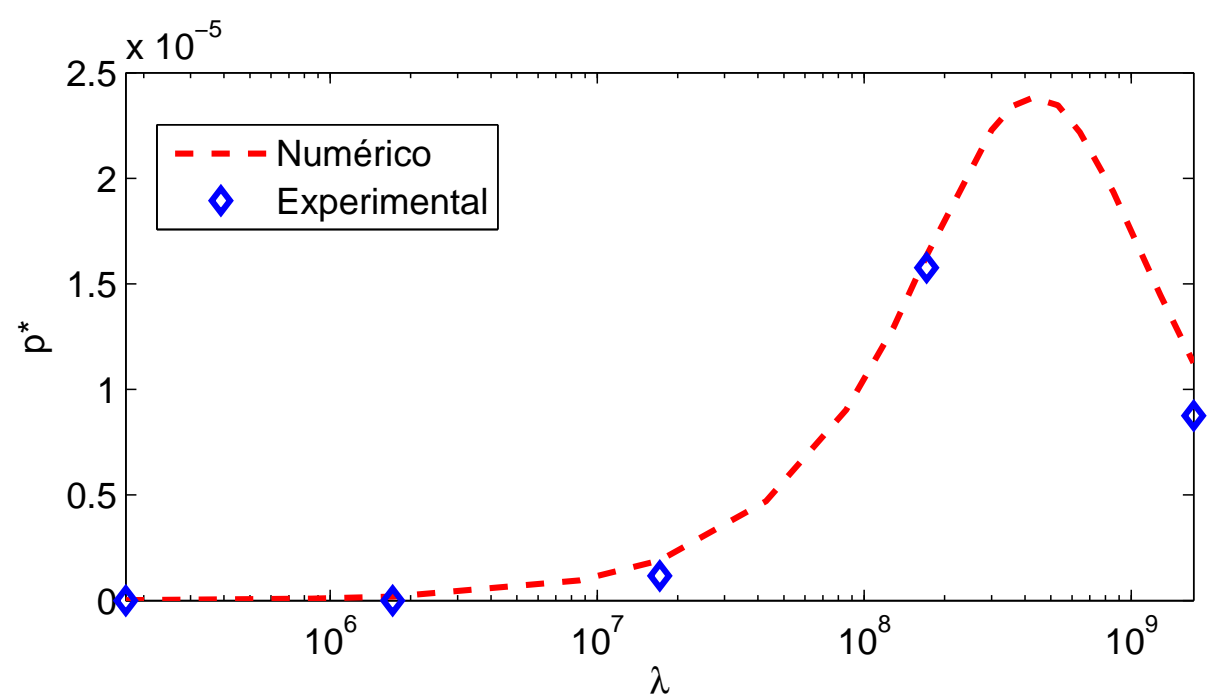

Figura 18 - Variação da potência elétrica adimensional produzida conforme a carga resistiva adimensional para o sistema não linear 2-GDL

Outro ponto que merece destaque é que a velocidade de LCO é pouco afetada pela variação da resistência no circuito gerador (ou pelo efeito shunt damping resistivo), tanto experimental quanto numericamente. Isso é explicado pelo fato de que o acoplamento eletromecânico é pouco evidente, ou seja, seu efeito em termos de amortecimento é da mesma ordem que o amortecimento mecânico. Além disso, no caso aqui estudado, o acoplamento piezelétrico é considerado no GDL de deslocamento linear, enquanto a não linearidade concentrada é modelada no GDL de rotação.

As Fig. 19 a 21 mostram as respostas no tempo obtidas numérica e experimentalmente para a carga ótima $\lambda=1.7 \times 10^{8}$ (ou $R_{l}=10^{5} \Omega$ ). Verifica-se que o modelo também é capaz de prever adequadamente tanto as amplitudes quanto a frequência para o caso não linear.

Como já destacado, apesar de as oscilações persistentes ocorrerem em velocidade mais baixa do que no caso linear elas ainda ocorrem em uma faixa restrita de velocidades. Desta forma, a próxima seção tratará de um caso com não linearidade combinada (bilinear + cúbica) com o intuito de preservar a redução de velocidade onde LCOs iniciam (em relação ao caso linear) e ainda tentar limitar o aumento de amplitudes (mecânicas) com o aumento de velocidade do escoamento. 


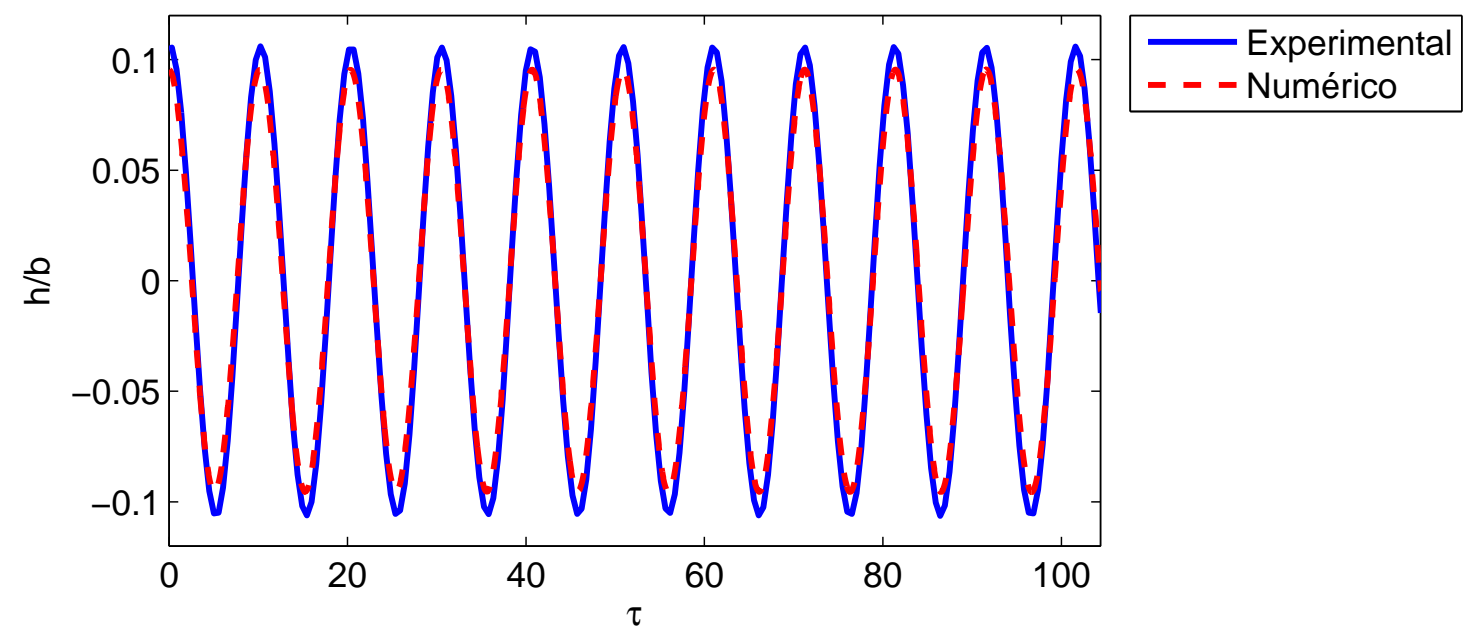

Figura 19 - Resposta no tempo (deslocamento linear adimensional) do sistema não linear 2GDL com mola bilinear no GDL de rotação e para a carga resistiva ótima

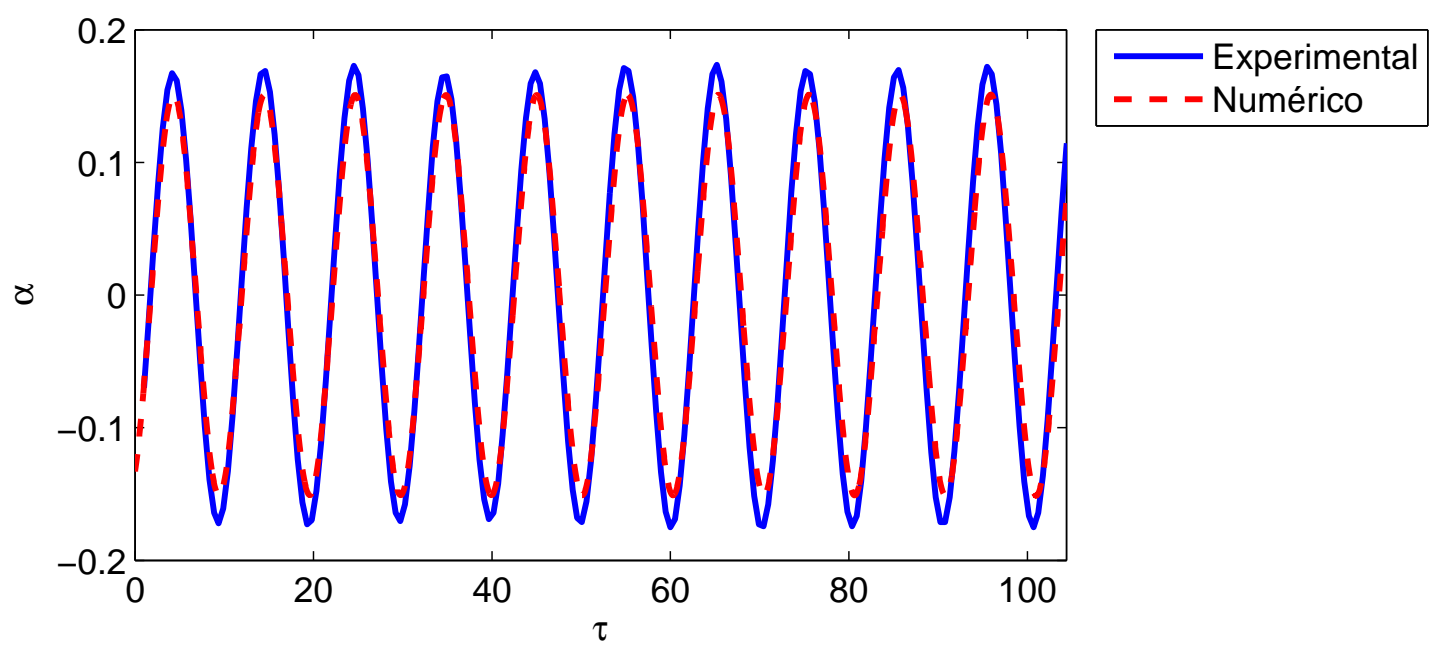

Figura 20 - Resposta no tempo (rotação da seção típica) do sistema não linear com 2-GDL com mola bilinear no GDL de rotação da seção típica para a carga resistiva ótima 


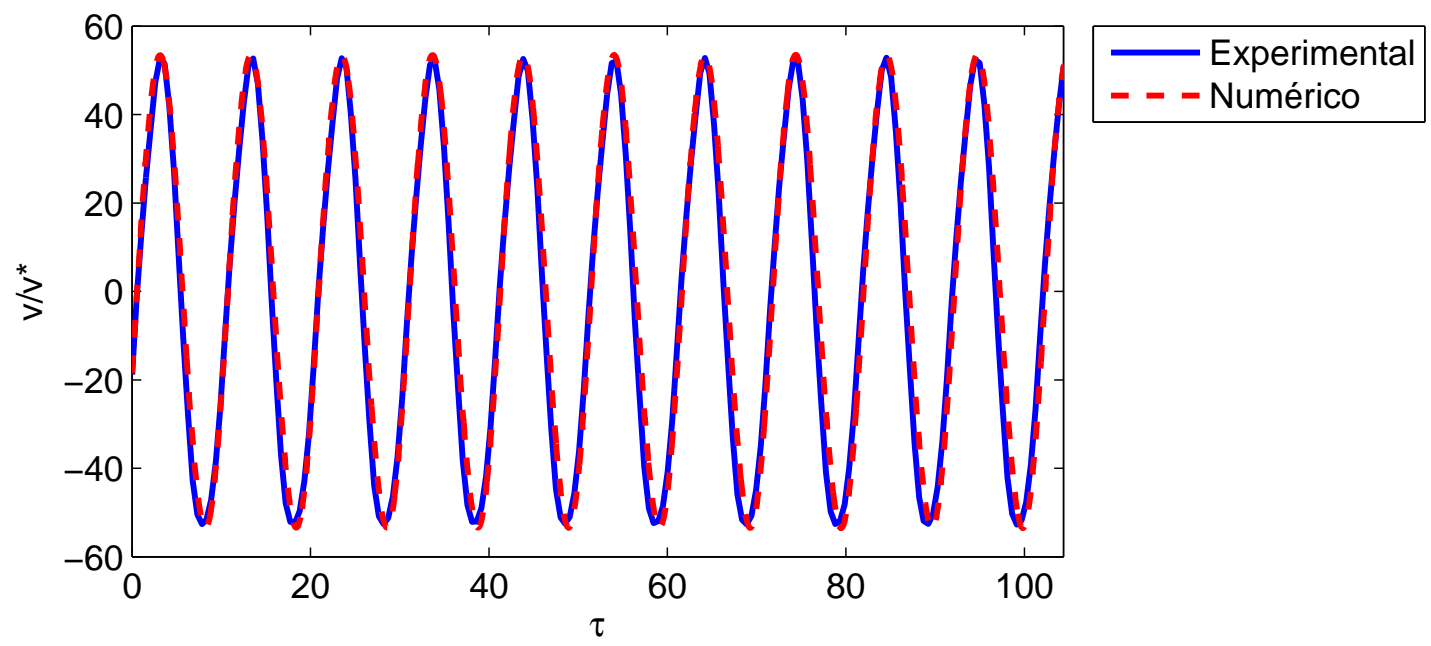

Figura 21 - Resposta no tempo (voltagem adimensional) do sistema não linear 2-GDL com mola bilinear no GDL de rotação e para a carga resistiva ótima 


\subsubsection{Seção Típica Piezoaeroelástica com Não Linearidade Combinada}

Após a verificação do modelo numérico eletroaeroelástico para o caso linear e para o caso bilinear, a configuração com não linearidade combinada (bilinear e cúbica) é apresentada nesta seção. Assim, o sistema continua com uma região de folga onde o momento elástico é nulo (como no caso anterior), entretanto, fora destes limites o momento elástico varia segundo um polinômio de terceiro grau. Duas possibilidades podem ocorrer, ou o aumento da rigidez elástica com o aumento do ângulo de ataque (hardening), ou sua redução (softening) com o aumento do ângulo de ataque. O primeiro caso é utilizado neste trabalho e o intuito é se limitar dentro de valores aceitáveis a amplitude de oscilações persistentes com o aumento da velocidade de escoamento, podendo assim realizar a coleta de energia em uma faixa ampla de velocidades.

Conforme a Eq. (3.21) verifica-se a presença de um termo de rigidez linear $k_{\alpha}$ e rigidez não linear $k_{n \alpha}$ quando se considera a não linearidade combinada. O comportamento eletroaeroelástico do sistema é aqui investigado para diferentes razões $\eta=k_{\alpha c} / k_{\alpha}$ e para uma faixa de velocidades variando entre $90 \%$ e $150 \%$ da velocidade linear de flutter (ou faixa de velocidades adimensionais $\bar{u}=U / U_{L F}$ entre 0.9 e 1.5). As Figs. 22 e 23 mostram, respectivamente, a variação da amplitude de deslocamento linear e de rotação com o aumento da velocidade para diferentes razões de rigidez na condição de curto-circuito. As amplitudes são sensíveis à variação de razão de rigidez. Observa-se que as amplitudes aumentam com o aumento da velocidade do escoamento e que diminuem com o aumento da razão de rigidez em toda a faixa de velocidades investigada. Na prática, a razão de rigidez pode ser aumentada com a adição de molas não lineares para ampliar a faixa de velocidades em que oscilações persistentes e com amplitudes aceitáveis ocorrem quando a não linearidade bilinear também está presente.

A Fig. 24 mostra a variação da potência elétrica gerada com o aumento da velocidade de escoamento para $\eta=100$ e para cinco valores de resistências elétricas. A potência elétrica aumenta com o aumento da velocidade de escoamento para qualquer resistor considerado no circuito externo. Entretanto, para qualquer velocidade na faixa considerada, quando o valor da resistência aumenta de $10^{2} \Omega\left(\lambda=1.7 \times 10^{5}\right)$ até $10^{5} \Omega\left(\lambda=1.7 \times 10^{8}\right)$ a potência elétrica aumenta. Quando a resistência de $10^{6} \Omega\left(\lambda=1.7 \times 10^{9}\right)$ é considerada, a potência elétrica gerada diminui. Assim, entre as resistências testadas, $R_{l}=10^{5} \Omega$ é a resistência ótima em toda a faixa de velocidades. A potência máxima teórica de $120 \mathrm{~mW}\left(p^{*}=7 \times 10^{-5}\right)$ é gerada na velocidade de $18 \mathrm{~m} / \mathrm{s}$ (razão de velocidades $\bar{u}=1.5$ ou velocidade reduzida $u=2.76$ ). As Figs. 25 e 26 mostram a variação de amplitudes de deslocamento linear e angular para a faixa de resistores e velocidades aqui testadas. Verifica-se que as amplitudes são pouco sensíveis à variação de resistência, conforme as discussões apresentadas na seção anterior. 


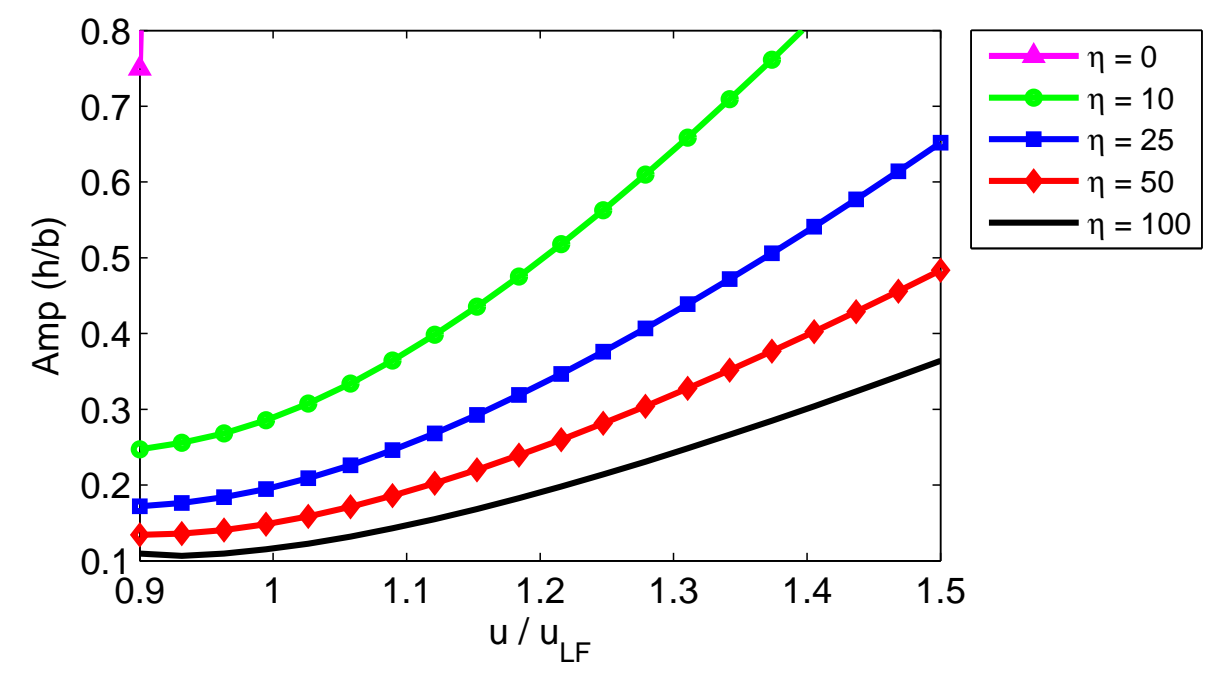

Figura 22 - Variação da amplitude de deslocamento linear com a variação da velocidade do sistema 2-GDL com não linearidade combinada para cada razão de rigidez e na condição de curto-circuito

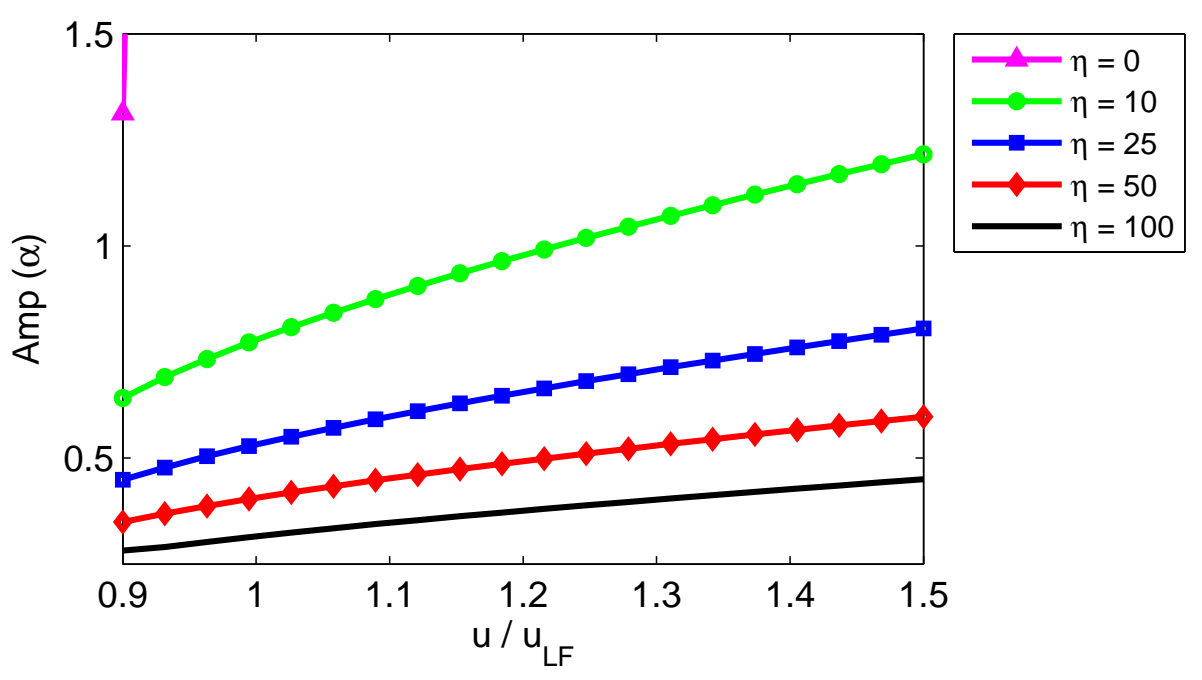

Figura 23 - Variação da amplitude de rotação com a variação da velocidade do sistema 2-GDL com não linearidade combinada para cada razão de rigidez e na condição de curtocircuito 


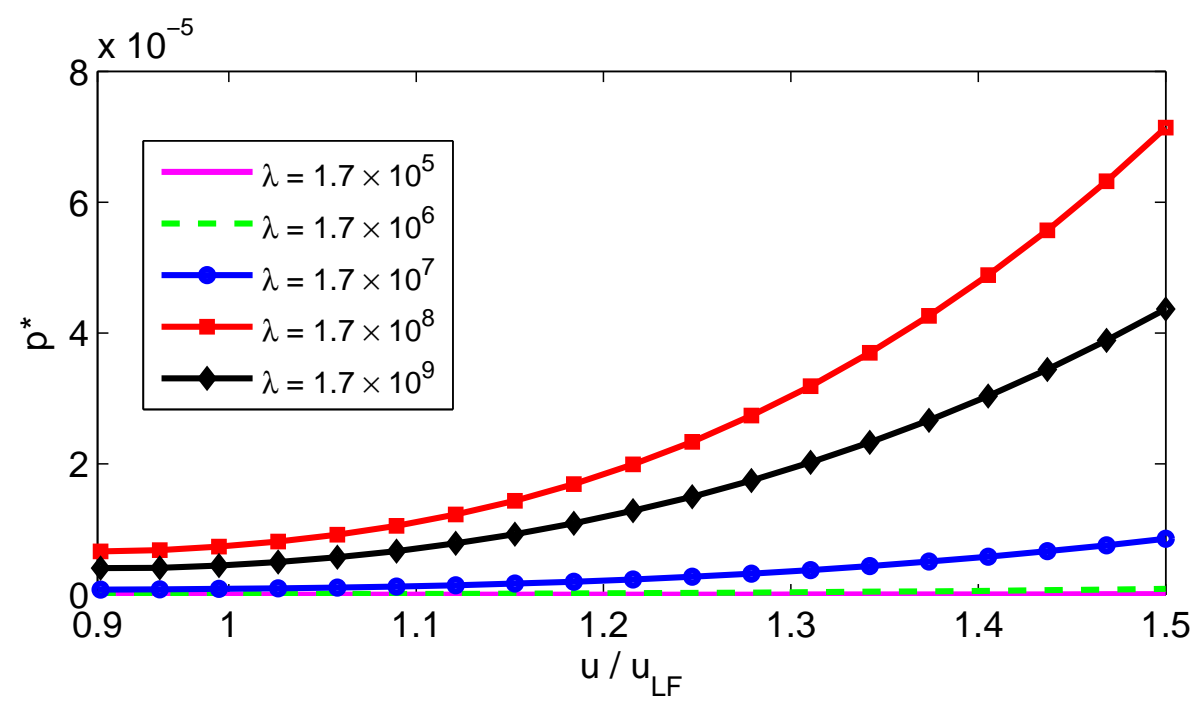

Figura 24 - Variação da potência elétrica com o aumento da velocidade do escoamento para o sistema 2-GDL com não linearidade combinada e para cada carga resistiva $(\eta=$ 100)

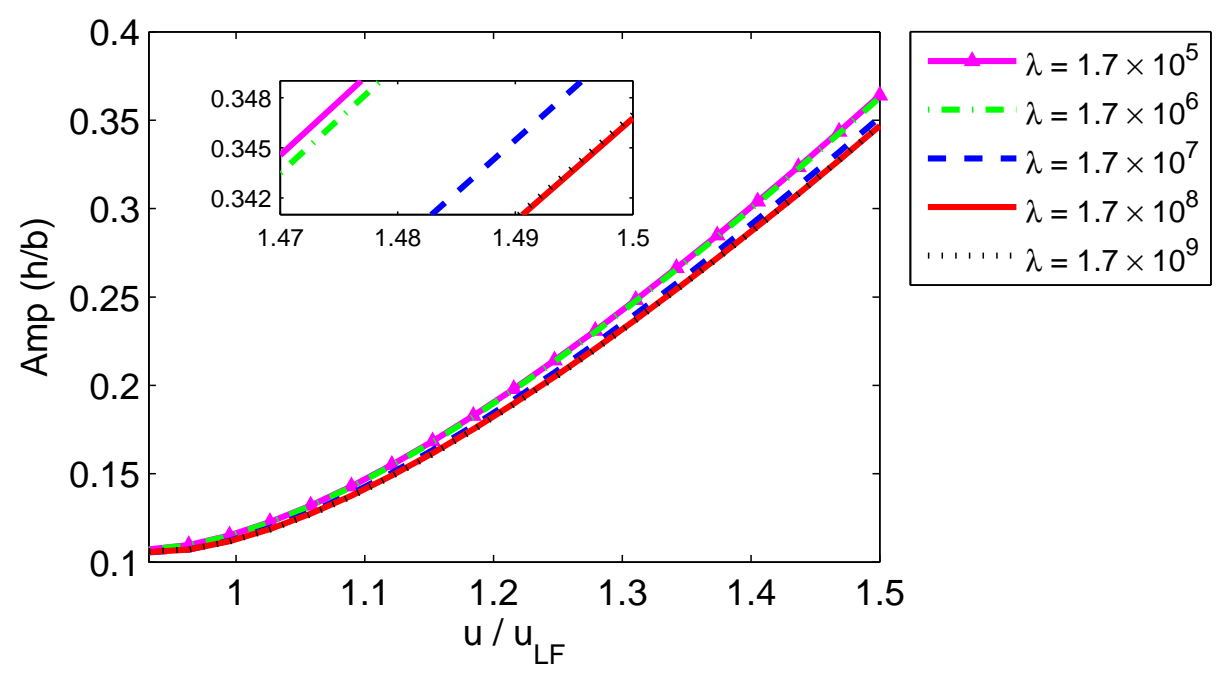

Figura 25 - Variação da amplitude de deslocamento linear com o aumento da velocidade do sistema 2-GDL com não linearidade combinada e para cada carga resistiva $(\eta=$ 100) 


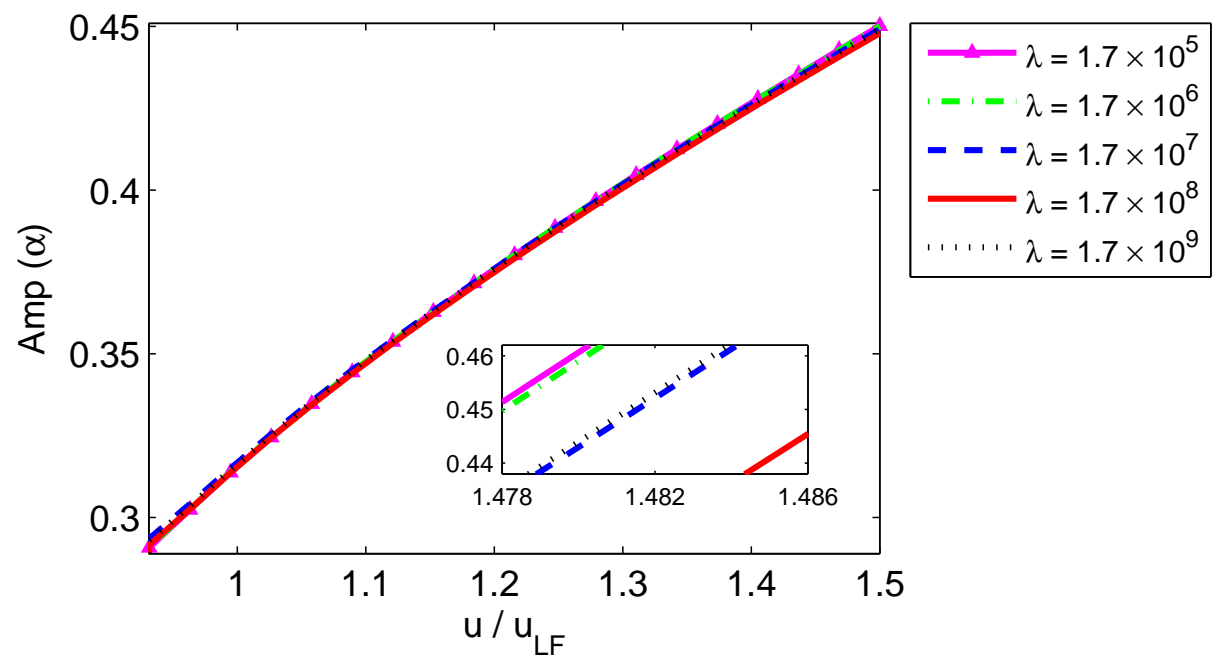

Figura 26 - Variação da amplitude de rotação com o aumento da velocidade do sistema 2-GDL com não linearidade combinada e para cada carga resistiva $(\eta=100)$ 


\subsubsection{Análise da Influência de Parâmetros sobre o Comportamento Pie- zoaeroelástico Linear}

A influência de parâmetros aeroelásticos na resposta de uma seção típica é bem estabelecida na literatura (BISPLINGHOFF; ASHLEY; HALFMAN, 1955; FUNG, 1955; HODGES; PIERCE, 2002). Os parâmetros envolvidos na conversão piezelétrica de energia a partir de vibrações aeroelásticas, por outro lado, merecem investigação. Assim sendo, apresenta-se uma análise da influência de parâmetros adimensionais (capacitância, acoplamento eletromecânico e resistência elétrica) sobre o comportamento eletroaeroelástico do gerador.

A Fig. 27 mostra a variação da velocidade linear de flutter adimensional (ou reduzida) com a variação da resistência elétrica adimensional do circuito gerador e variação do acoplamento eletromecânico adimensional. Durante as simulações a capacitância equivalente adimensional é fixada em $\psi=3.657 \times 10^{-9}$, o que corresponde a associação de duas piezocerâmicas QP-10N em paralelo. A velocidade de flutter aumenta com o aumento da acoplamento eletromecânico para as cargas resistivas considerada durante as simulações (exceto para valores de resistência muito próximos à condição de curto-circuito). Verifica-se também que para qualquer valor de acoplamento eletromecânico adimensional existe um resistor ótimo, para o qual a velocidade de flutter é máxima.

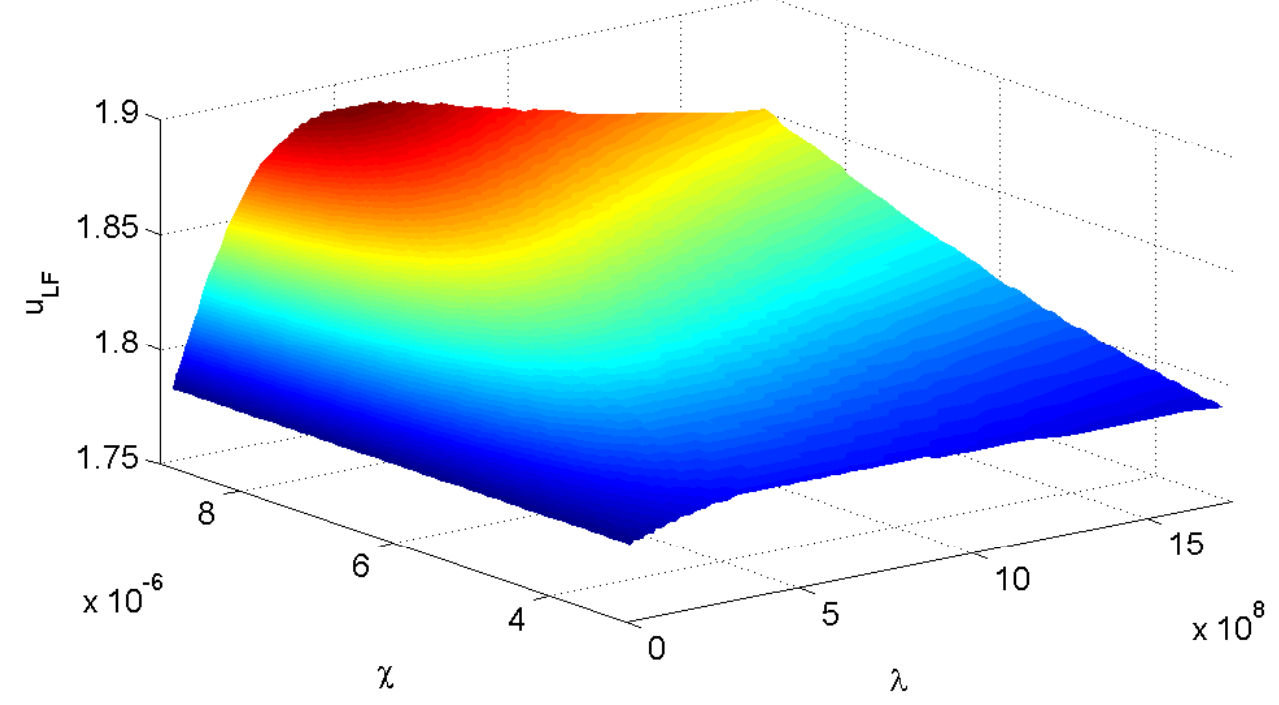

Figura 27 - Variação da velocidade linear crítica em função da carga resistiva e do acoplamento eletromecânico

A Fig. 28 mostra a variação da potência elétrica adimensional com a carga resistiva adimensional e acoplamento eletromecânico adimensional em cada velocidade linear de flutter 
(adimensional) apresentada na Fig. 27. Novamente a capacitância equivalente do sistema é mantida fixa. A potência elétrica gerada aumenta com o aumento do acoplamento eletromecânico para os valores de resistência considerados neste trabalho. Existe uma resistência ótima para cada valor de acoplamento aqui considerado. Assim como no caso da velocidade adimensional apresentado na Fig. 27, a resistência ótima varia com o acoplamento eletromecânico.

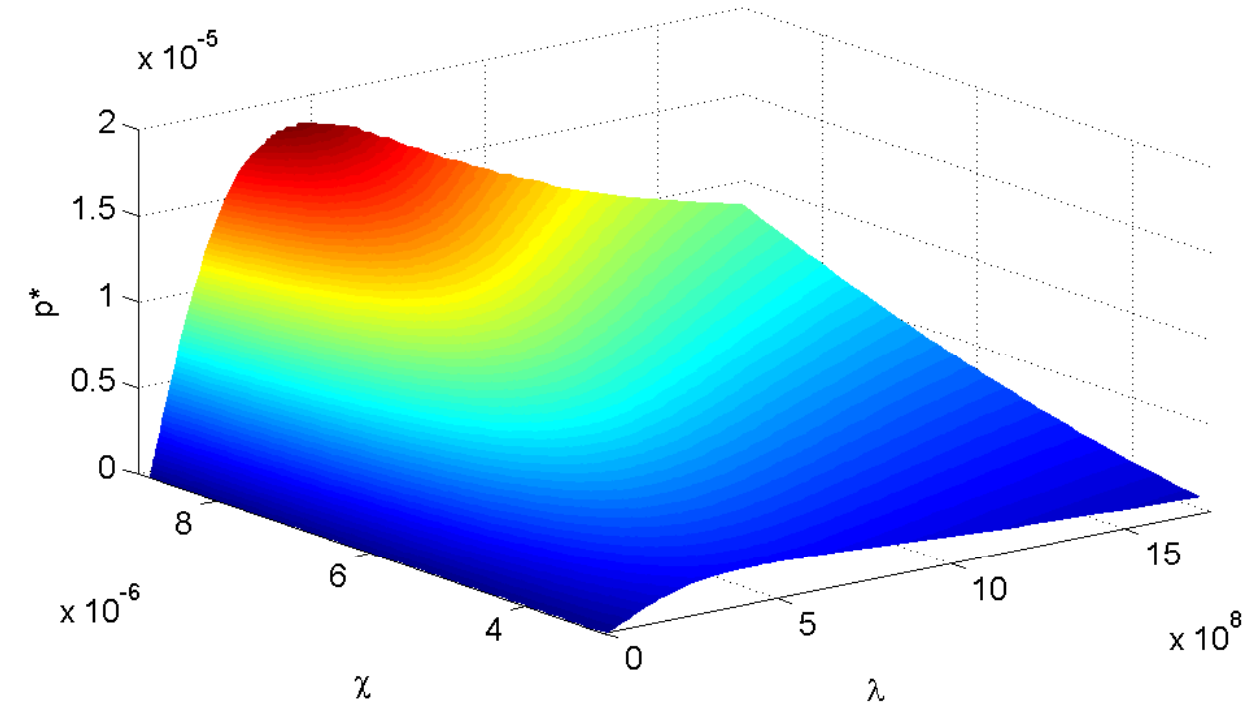

Figura 28 - Variação da potência elétrica adimensional em função da carga resistiva e do acoplamento eletromecânico

A variação da velocidade linear de flutter com a carga resistiva e com a capacitância equivalente (adimensionais) é apresentada na Fig. 29. Nestas simulações o acoplamento eletromecânico adimensional é fixado em $\chi=5.9 \times 10^{-6}$. A velocidade adimensional de flutter diminui com o aumento da capacitância equivalente do sistema para qualquer valor de carga resistiva (exceto para valores próximos ao curto circuito). É importante notar que o eixo relativo à capacitância está invertido para tornar o gráfico mais claro. Novamente, há um resistor ótimo para capacitância adimensional utilizada nas simulações.

Na Fig. 30 é apresentada a variação da potência elétrica adimensional $\left(p^{*}\right)$ com a variação da carga resistiva e capacitância adimensionais, $\lambda$ e $\psi$, respectivamente. Novamente o acoplamento eletromecânico adimensional é mantido fixo em $\chi=5.9 \times 10^{-6}$. A potência elétrica gerada diminui com o aumento da capacitância do sistema para qualquer carga resistiva (exceto para valores próximos à condição de curto circuito). A presença de uma resistência ótima (que fornece a máxima potência) para cada valor de capacitância e também a sua variação com a variação da capacitância pode ser observada na Fig. 30. 


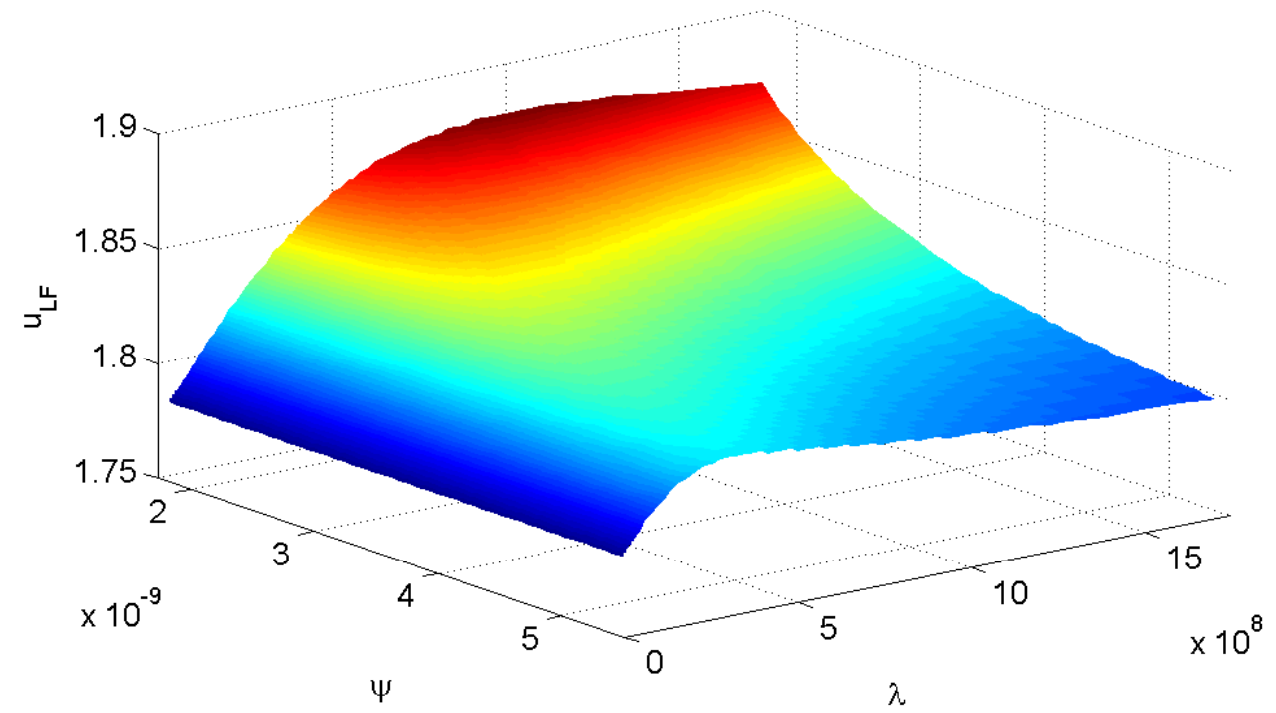

Figura 29 - Variação da velocidade linear de flutter com a carga resistiva e a capacitância equivalente

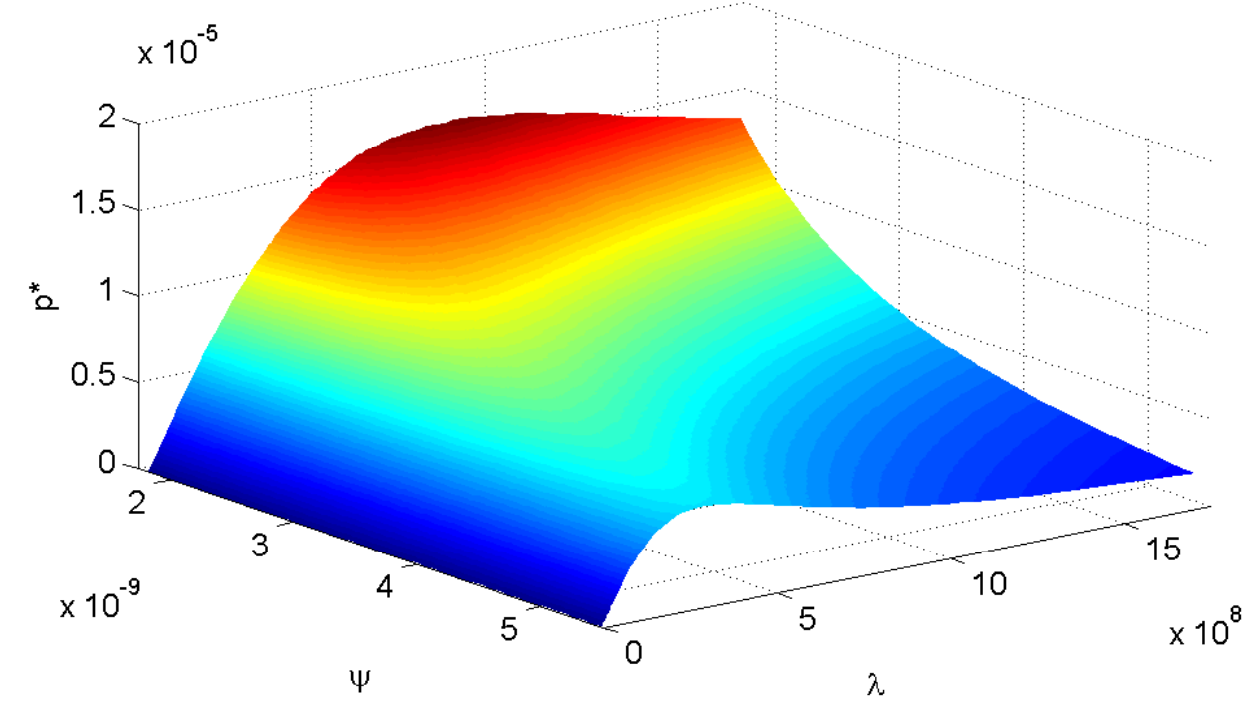

Figura 30 - Variação da potência elétrica adimensional com a carga resistiva e a capacitância equivalente 


\subsection{Seção Típica com Três Graus de Liberdade}

Nesta seção, a investigação numérica de uma seção típica eletromecanicamente acoplada e com 3-GDL é realizada. Inicialmente o caso linear é avaliado para o conjunto de resistores assumidos neste trabalho. Posteriormente, não linearidades estruturais concentradas são modeladas em diferentes GDL do sistema piezoaeroelástico. No primeiro caso, uma mola bilinear é modelada na superfície de controle. Em seguida, uma mola cúbica é considerada no GDL de rotação da seção típica ao mesmo tempo que uma mola bilinear é considerada no GDL de rotação da superfície de controle.

A Tab. 3 apresenta os parâmetros piezoaeroelásticos adimensionais do sistema com 3GDL. Estes parâmetros são os mesmos apresentados para o caso com 2-GDL (Tab. 2), além de termos adicionais devido à presença da superfície de controle. A razão de frequências $\eta_{\beta}$ foi escolhida de maneira que a amplitude de rotação da superfície de controle não viole a hipótese de pequenos deslocamentos. A influência deste parâmetro no comportamento piezoaeroelástico do sistema com 3-GDL é investigada em Sousa, D’ Assunção e De Marqui (2011).

Tabela 3 - Parâmetros adimensionais do modelo com 3-GDL

\begin{tabular}{cc}
\hline \hline Parâmetro & Valor \\
\hline$a$ & $-5 \times 10^{-1}$ \\
$c$ & $4.18 \times 10^{-1}$ \\
$\mu$ & 2.594 \\
$x_{\alpha}$ & $2.5448 \times 10^{-1}$ \\
$x_{\beta}$ & $4.9 \times 10^{-2}$ \\
$r_{\alpha}$ & 4.373 \\
$r_{\beta}$ & 1.06 \\
$\eta_{\alpha}$ & $5.1 \times 10^{-1}$ \\
$\eta_{\beta}$ & 1.86 \\
$\xi_{\alpha}$ & $4.3 \times 10^{-2}$ \\
$\xi_{\beta}$ & $2 \times 10^{-3}$ \\
$\xi_{h}$ & $1.5 \times 10^{-2}$ \\
$\chi$ & $5.905 \times 10^{-6}$ \\
$\psi$ & $3.657 \times 10^{-9}$ \\
$\lambda$ & $1.713 \times 10^{5}$ \\
\hline
\end{tabular}

\subsubsection{Análise do Comportamento Piezoaeroelástico Linear}

A Fig. 31 apresenta a variação da parte real do autovalor do GDL de deslocamento linear do sistema com 3-GDL com a velocidade do escoamento. A condição de contorno elétrica varia 
desde próximo de curto-circuito $\left(R_{l} \rightarrow 0\right)$ até próximo de circuito aberto $\left(R_{l} \rightarrow \infty\right)$.

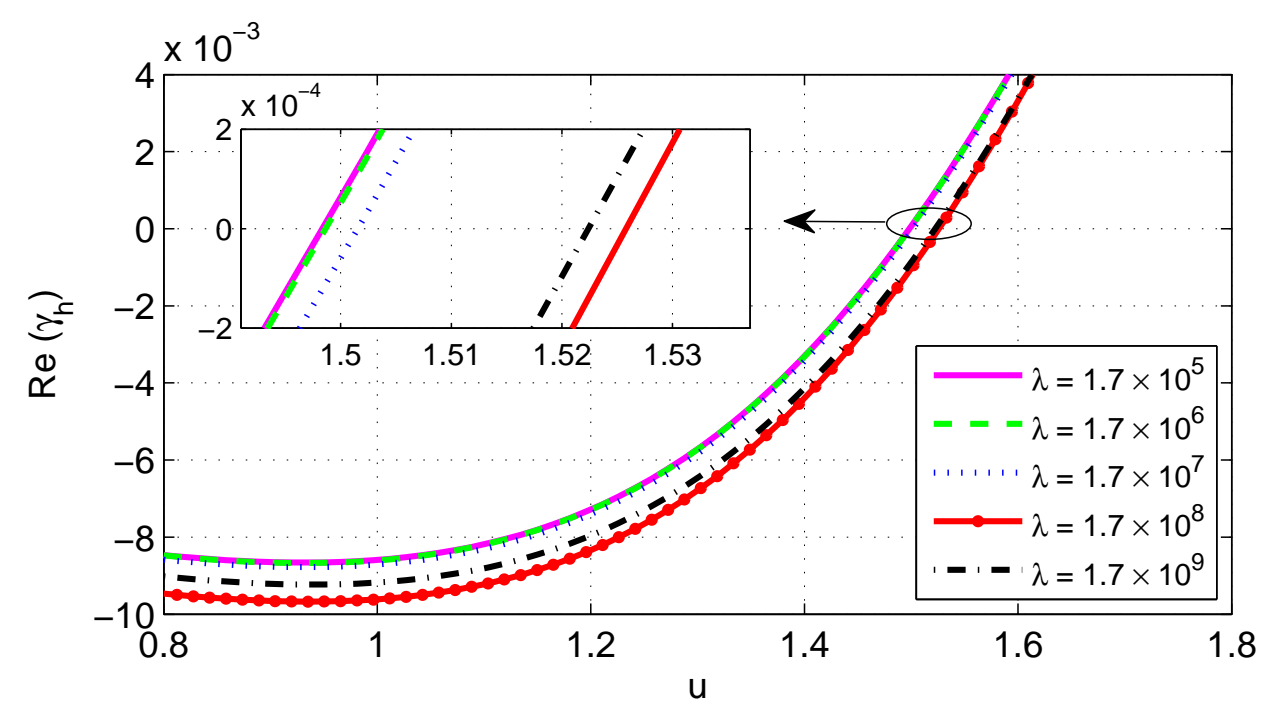

Figura 31 - Análise de estabilidade por autovalores para o sistema linear com 3-GDL nas condições de curto-circuito $\left(R_{l} \rightarrow 0\right)$ à circuito aberto $\left(R_{l} \rightarrow \infty\right)$

A velocidade linear de flutter para a condição de curto-circuito é 1.499 (ou $9.8 \mathrm{~m} / \mathrm{s}$ ). Para a carga ótima, a velocidade é 1.527 (ou 10 m/s). Em relação ao aerofólio com 2-GDL, constata-se uma redução de $18 \%$ na velocidade linear de flutter com a inclusão da superfície de controle.

As respostas no tempo obtidas na velocidade de flutter do resistor ótimo ( $\lambda=1.7 \times 10^{8}$, conforme a Fig. 31) são apresentadas nas Figs. 32 até 36. Para fins de comparação (em termos de parâmetros dimensionais), o modelo prevê cerca de $11 \mathrm{~mW}$ de potência para deslocamentos lineares iniciais em torno de $7 \mathrm{~mm}$, enquanto que no caso linear com 2-GDL a potência gerada com a resistência ótima foi de $10 \mathrm{~mW}$.

Embora a seção típica linear com 3-GDL apresente oscilações auto sustentadas em uma velocidade inferior à do modelo com 2-GDL, o envelope de operação também é limitado a uma única velocidade (velocidade linear de flutter). 


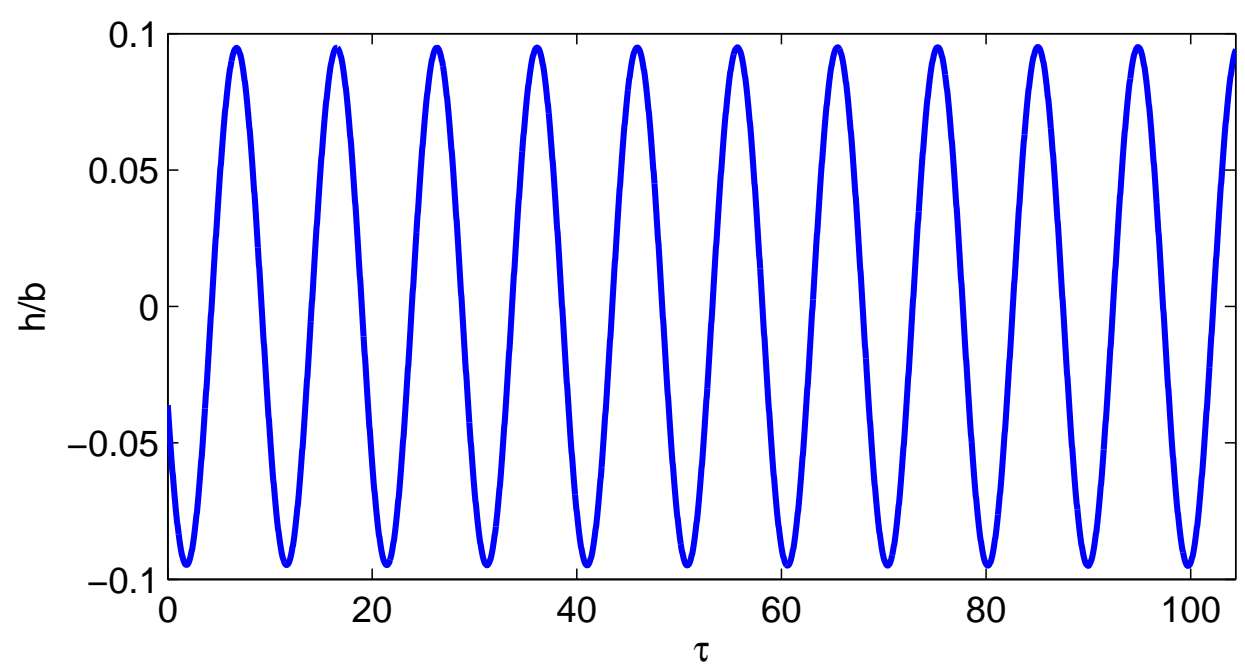

Figura 32 - Resposta no tempo (deslocamento linear) do sistema linear com 3-GDL para a carga resistiva ótima

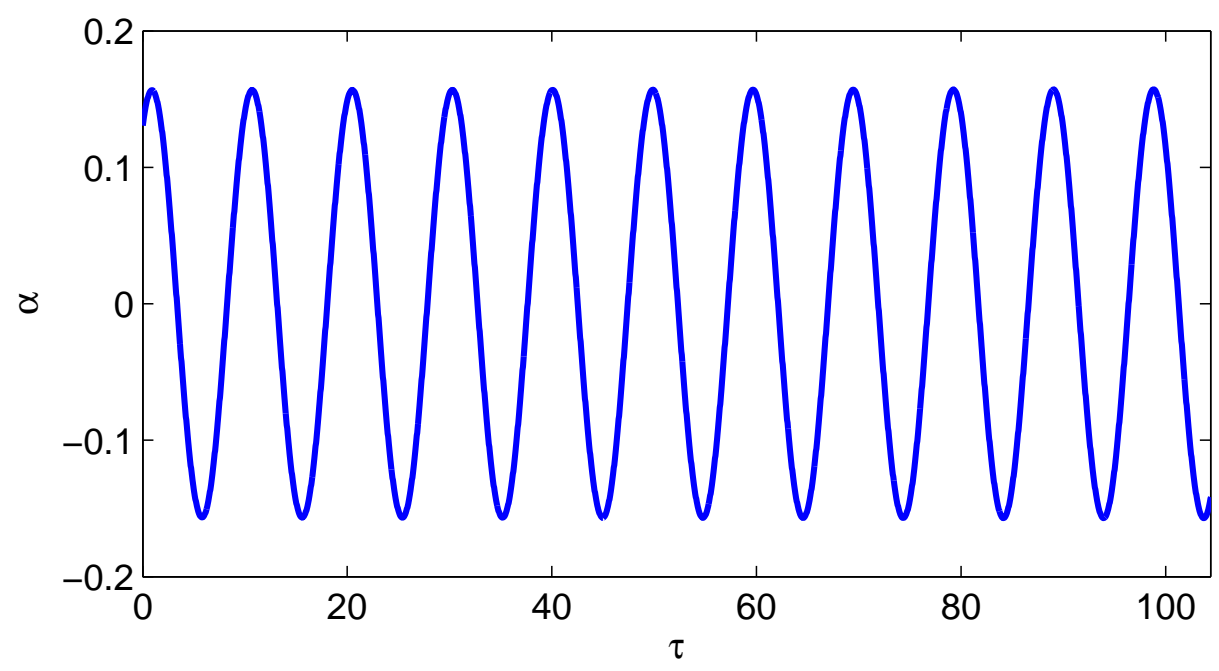

Figura 33 - Resposta no tempo (rotação da seção típica) do sistema linear com 3-GDL para a carga resistiva ótima 


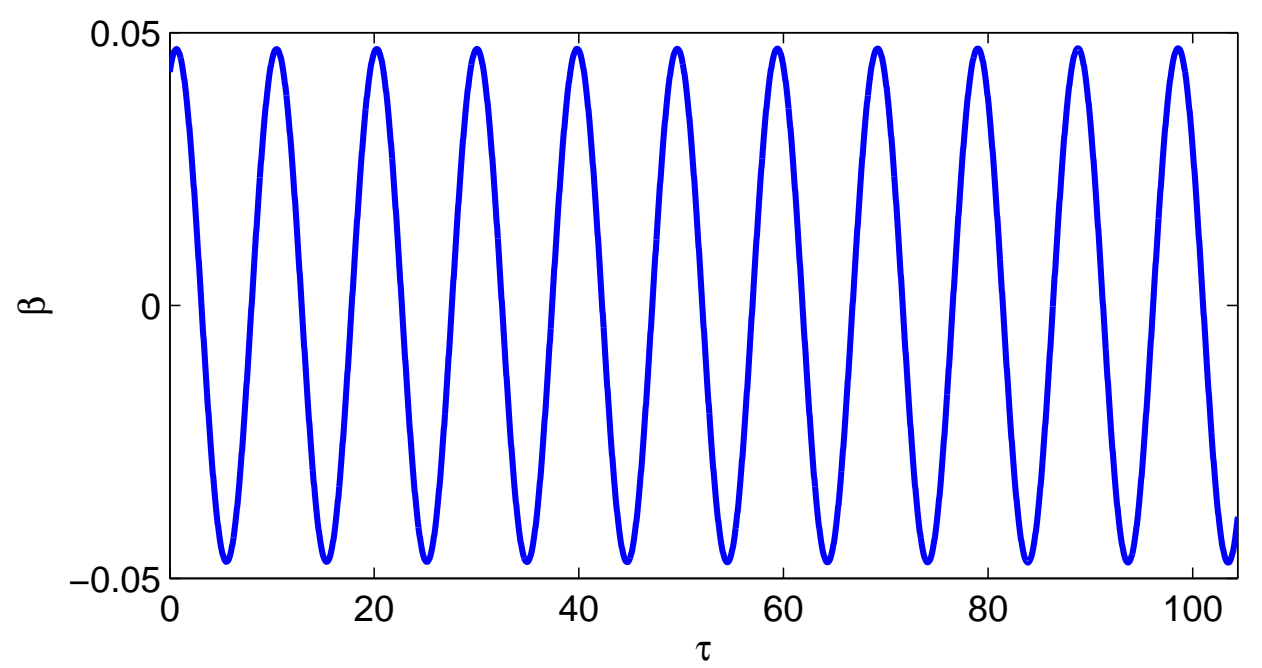

Figura 34 - Resposta no tempo (rotação da superfície de controle) do sistema linear com 3-GDL para a carga resistiva ótima

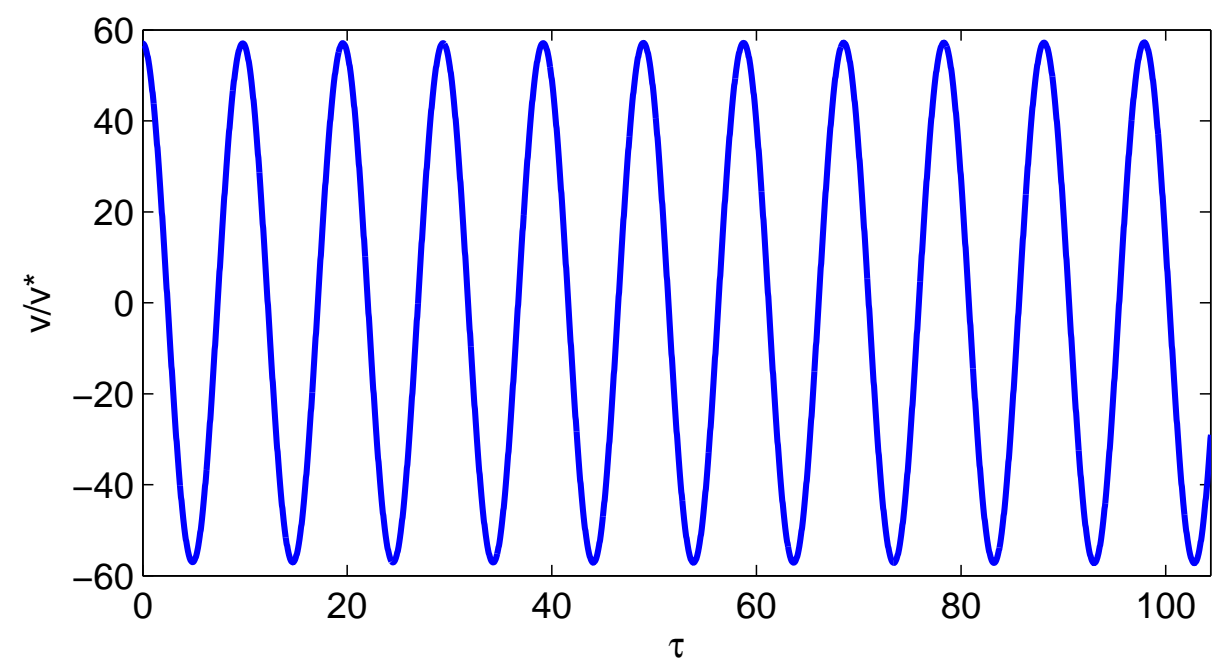

Figura 35 - Resposta no tempo (voltagem) do sistema linear com 3-GDL para a carga resistiva ótima 


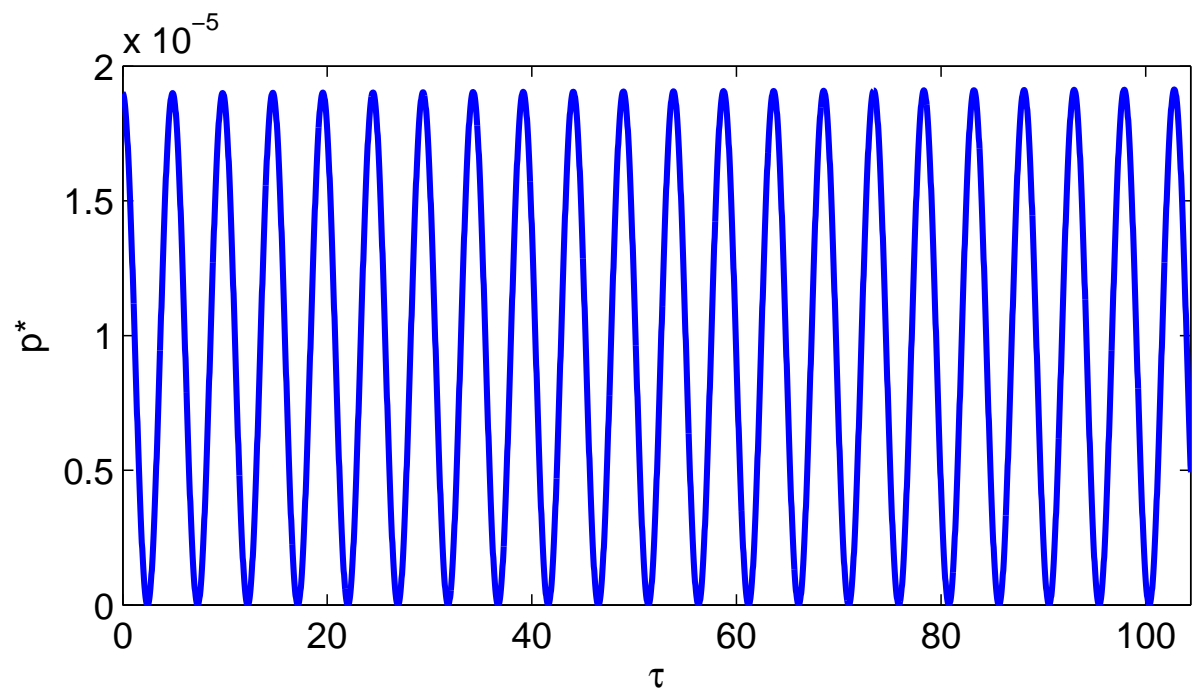

Figura 36 - Resposta no tempo (potência) do sistema linear com 3-GDL para a carga resistiva ótima 


\subsubsection{Caso Não Linear com Mola Bilinear no Grau de Liberdade de Ro- tação da Superfície de Controle}

A velocidade do escoamento na qual ocorre a primeira LCO para uma determinada perturbação inicial é 1.191 ou $78 \%$ da velocidade linear de flutter quando a carga ótima é considerada (ou $7.77 \mathrm{~m} / \mathrm{s}$ para os parâmetros dimensionais apresentados para o caso com 2-GDL). Em relação à condição de curto-circuito, esta velocidade é superior em $1.8 \%$. Vale ressaltar que a folga (nominal) considerada na superfície de controle é de $\delta_{\beta}=2.8 \pi / 180$ radianos. A amplitude das LCOs aumenta com o aumento da velocidade do escoamento. As LCOs são observadas até aproximadamente $98 \%$ da velocidade linear crítica, isto é, 1.495 (ou $9.75 \mathrm{~m} / \mathrm{s}$ ). Nesta velocidade, a amplitude de oscilação é aproximadamente igual à amplitude da perturbação inicial. Acima de $98 \%$ da velocidade crítica, o movimento oscilatório é divergente. Abaixo de $78 \%$ da velocidade crítica, qualquer perturbação inicial desaparece.

A Fig. 37 mostra a variação da potência elétrica com a variação da velocidade do escoamento (adimensionais) produzida pelo sistema não linear com 3-GDL e carga resistiva ótima. A potência adimensional varia entre $3.2 \times 10^{-9}$ e $1.9 \times 10^{-5}$ (ou entre $5.5 \mu \mathrm{W}$ e $32.6 \mathrm{~mW}$ ) para velocidades entre 1.196 (ou $78 \%$ da velocidade linear crítica) e 1.495 (ou 94\% da velocidade linear crítica). Observa-se que a potência aumenta linearmente até a velocidade 1.42, quando o sistema apresenta LCOs de pequena amplitude, e passa a aumentar rapidamente acima desta velocidade, quando o sistema apresenta LCOs com grandes amplitudes. Até a velocidade 1.495, as oscilações são persistentes e de amplitudes aceitáveis. Acima deste limiar, as amplitudes são crescentes e não aceitáveis para um sistema experimental. 


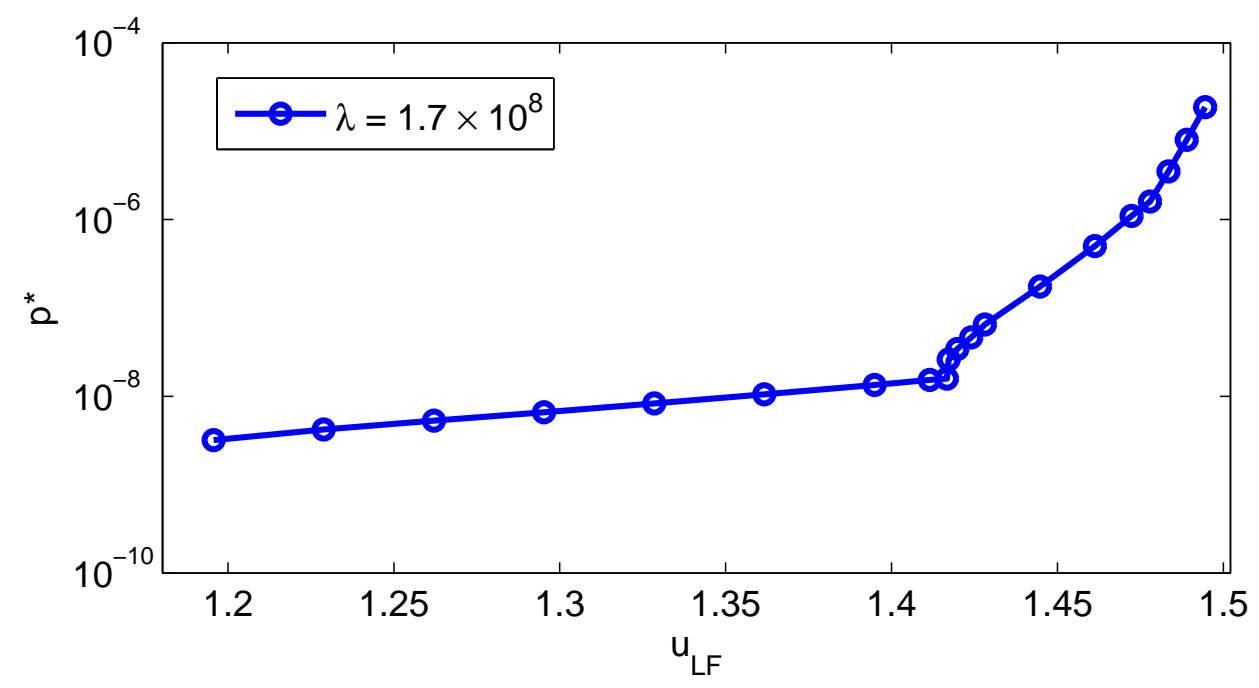

Figura 37 - Variação da potência elétrica adimensional convertida pelo sistema 3-GDL com mola bilinear na superfície de controle conforme a velocidade reduzida do escoamento e para a carga resistiva ótima

\subsubsection{Caso Não Linear com Mola Cúbica no Grau de Liberdade de Rota- ção do Aerofólio e Mola Bilinear na Superfície de Controle}

Neste estudo de caso, a mola bilinear no GDL da superfície de controle é mantida e uma não linearidade combinada (bilinear + mola cúbica) é introduzida no GDL de rotação da seção típica.

A faixa de velocidades considerada está entre $90 \%$ até $140 \%$ da velocidade linear de flutter da seção típica com 3-GDL na condição de curto-circuito ( $u=1.499$ ou $9.8 \mathrm{~m} / \mathrm{s})$. O comportamento piezoaeroelástico do sistema é investigado para diferentes razões de rigidez, definidas neste caso como sendo $\kappa=k_{\alpha c} / k_{\alpha}$. As Figs. 38 a 40 mostram a variação da amplitude dos deslocamentos linear, rotação da seção típica e rotação da superfície de controle, respectivamente, com o aumento da velocidade do escoamento (na condição de curto-circuito) e para cada razão de rigidez $\kappa$ investigada.

Observa-se na Fig. 38 que a amplitude do deslocamento linear cresce rapidamente conforme a velocidade do escoamento se aproxima da velocidade de referência (velocidade linear de flutter para a condição de curto-circuito) quando somente a não linearidade bilinear é modelada no sistema $(\kappa=0)$. Verifica-se também que a amplitude diminui com o aumento da razão de rigidez. Observa-se um comportamento semelhante no caso do ângulo de rotação da seção típica, mostrado na Fig. 39. Entretanto, existe uma tendência de saturação da amplitude com o aumento da velocidade para a maioria das razões de rigidez consideradas. Na Fig. 40 é 
apresentada a variação da amplitude de rotação da superfície de controle. Observa-se que este é o GDL mais crítico em relação ao aumento de amplitude com aumento de velocidade, o que restringe o envelope de operação (em termos de velocidade).

Observa-se pela Fig. 40 que a amplitude de rotação da superfície de controle varia mais lentamente em relação à amplitude de rotação da seção típica para razões inferiores a 100. Quando $\kappa=100$, a amplitude de rotação da seção típica é aceitável até velocidades aproximadamente $45 \%$ superiores à velocidade de referência, ao passo que o deslocamento da superfície de controle torna-se demasiado grande a uma velocidade $40 \%$ superior à de referência.

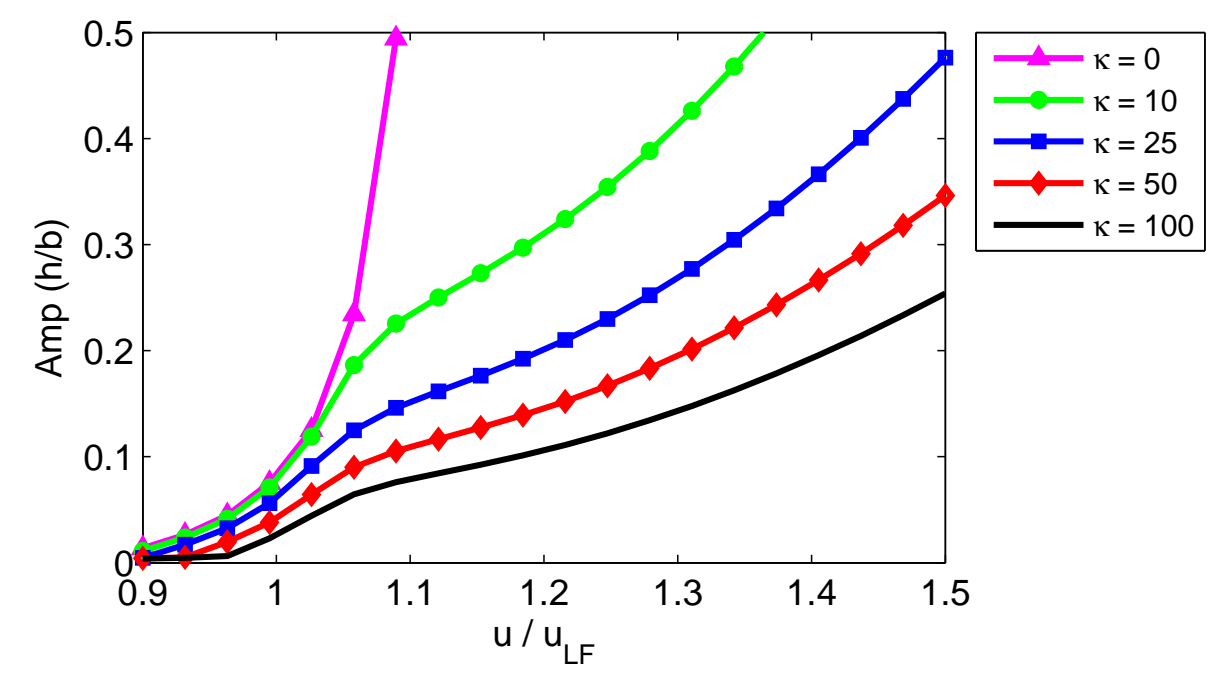

Figura 38 - Variação da amplitude de deslocamento linear com o aumento da velocidade para o sistema 3-GDL e não linearidades combinadas $\left(R_{l} \rightarrow 0\right)$

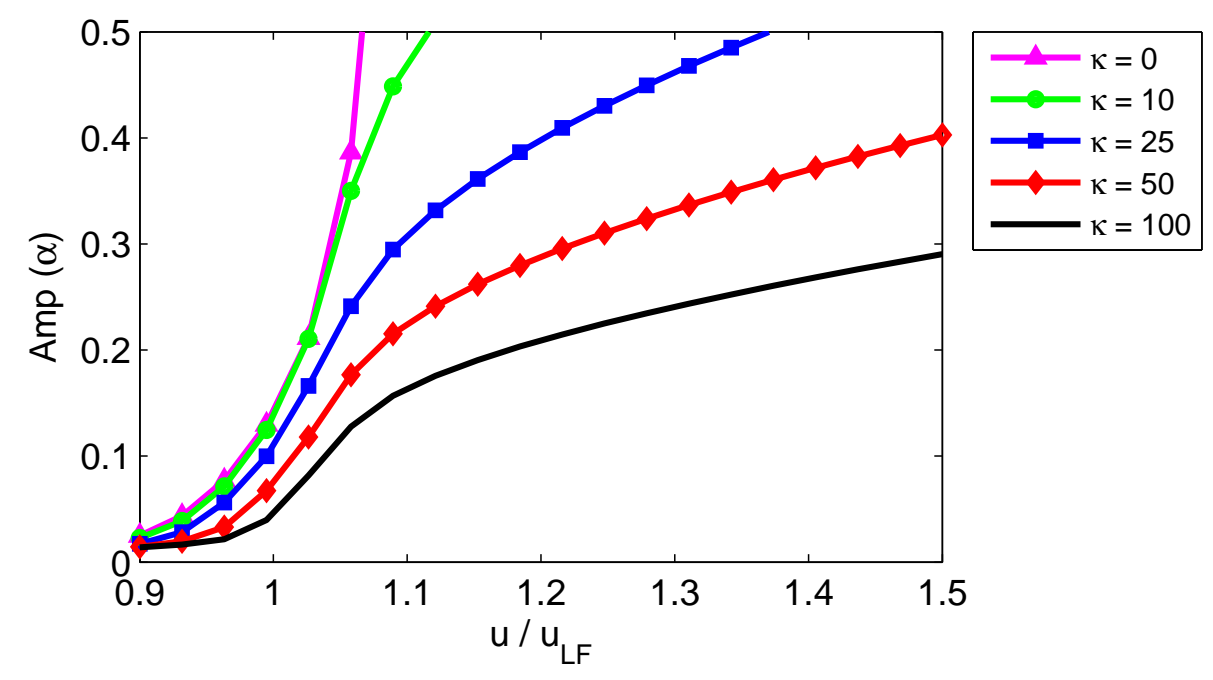

Figura 39 - Variação da amplitude de rotação da seção típica com aumento da velocidade para o sistema 3-GDL e não linearidades combinadas $\left(R_{l} \rightarrow 0\right)$ 


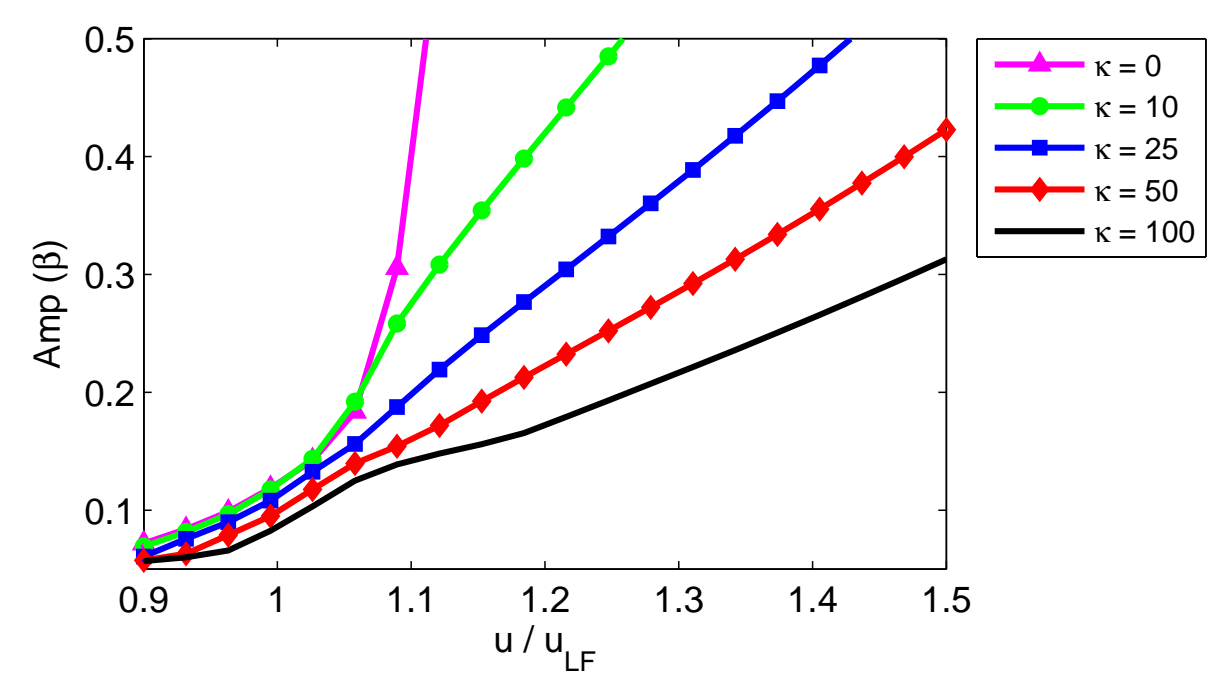

Figura 40 - Variação da amplitude de rotação da superfície de controle com aumento da velocidade para o sistema 3-GDL e não linearidades combinadas $\left(R_{l} \rightarrow 0\right)$

A Fig. 41 mostra a variação da potência elétrica para as mesmas condições anteriores (exceto que $\lambda=1.7 \times 10^{8}$ ). Novamente verifica-se o aumento da amplitude da saída elétrica com o aumento da velocidade do escoamento, assim como a redução de amplitudes com o aumento da razão de rigidez. Assim como no caso 2-GDL com não linearidade combinada, a utilização de molas não lineares cúbicas no GDL de rotação da seção típica pode garantir a limitação de amplitudes em valores aceitáveis para uma faixa de velocidades, ampliando o envelope de operações do gerador.

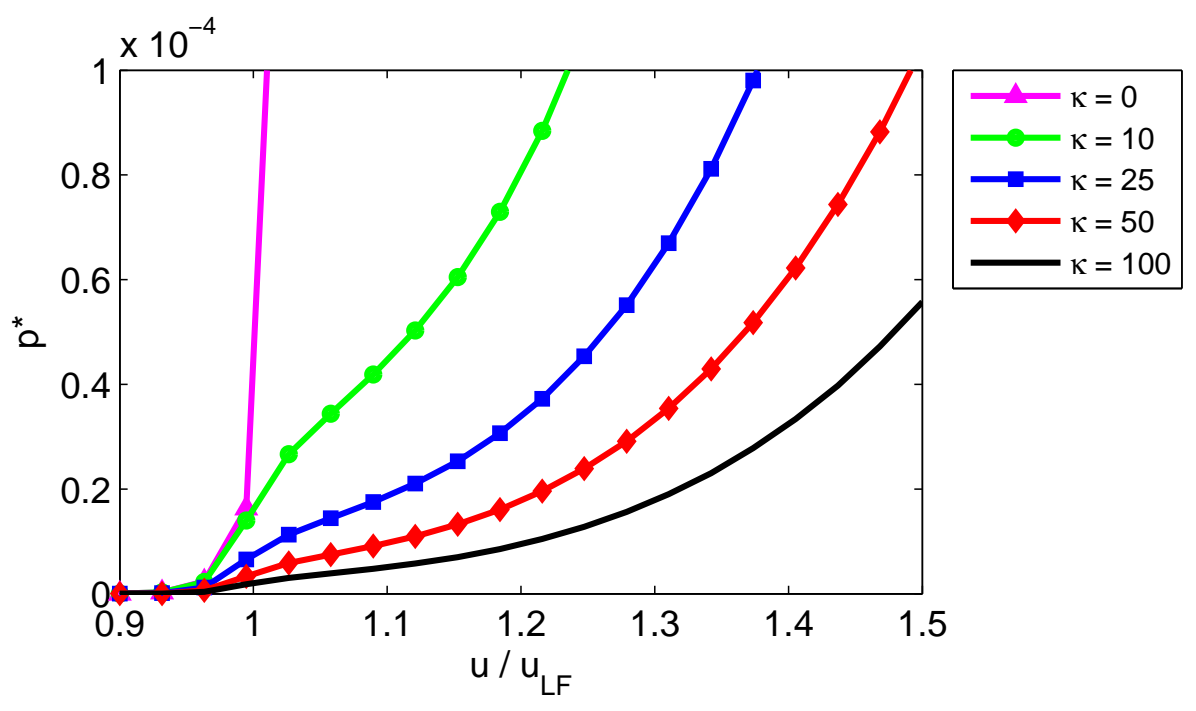

Figura 41 - Variação da potência elétrica com o aumento de velocidade para o sistema 3-GDL com não linearidades combinadas e carga resistiva ótima 


\subsubsection{Análise Comparativa dos Casos Linear, Bilinear e com Não Lineari- dade Combinada para a Seção Típica com Três Graus de Liberdade}

A Fig. 42 representa a conversão de potência elétrica a partir de oscilações persistentes para os três casos considerados (linear, bilinear e com não linearidade combinada). Uma velocidade muito específica $(10 \mathrm{~m} / \mathrm{s})$ representa o caso linear. A área entre $7 \mathrm{~m} / \mathrm{s}$ (velocidade da primeira $\mathrm{LCO}$ ) e $10 \mathrm{~m} / \mathrm{s}$ (velocidade de movimento divergente) representa o caso bilinear. A área entre $7 \mathrm{~m} / \mathrm{s}$ (primeira LCO) e $14 \mathrm{~m} / \mathrm{s}$ (movimento divergente) representa o caso com não linearidade combinada.

Observa-se que a conversão é muito limitada no caso linear, ao passo que no caso bilinear a conversão ocorre em uma faixa de velocidades (porém somente abaixo da velocidade linear de flutter). No caso com não linearidade combinada, a conversão ocorre em uma faixa mais ampla de velocidades, inclusive acima da velocidade linear de flutter.

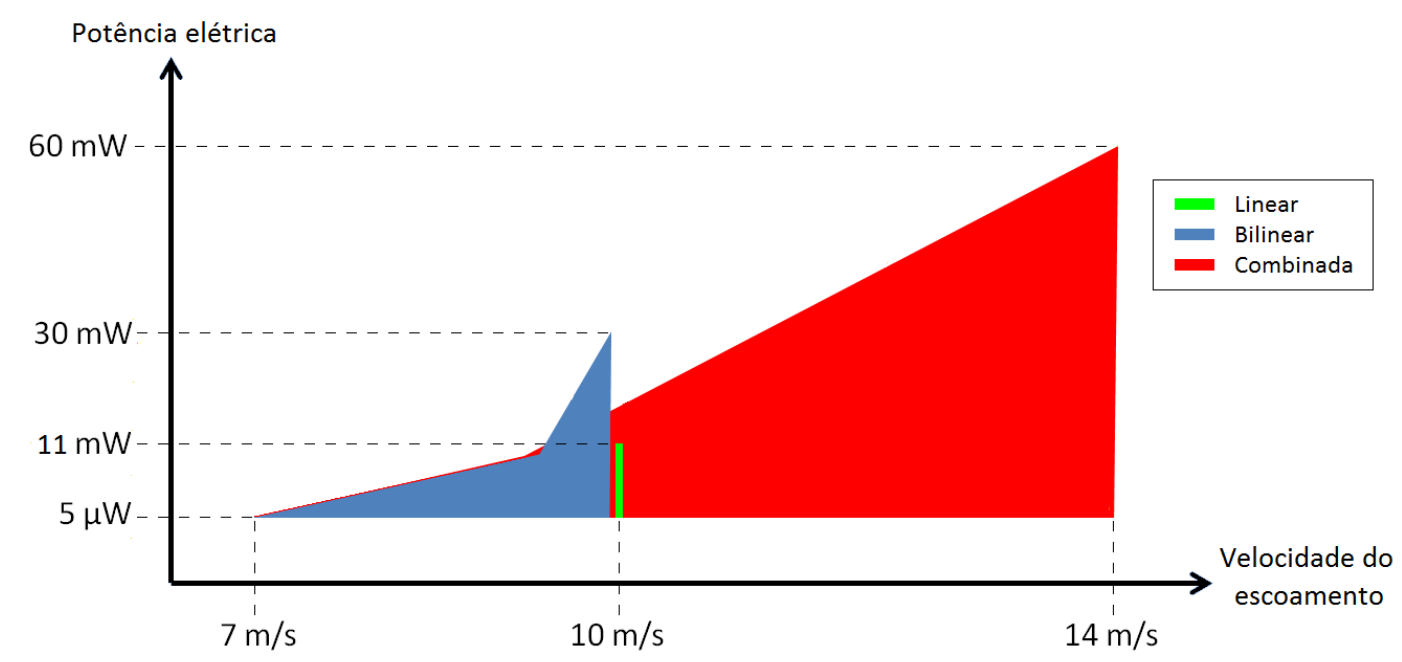

Figura 42 - Comparação da conversão de potência elétrica entre os casos linear, bilinear e com não linearidade combinada para a seção típica 3-GDL

O caso com não linearidade combinada mostra-se, portanto, o mais atraente para a conversão de energia a partir de oscilações persistentes (excitadas pelo escoamento) entre os casos aqui considerados. 


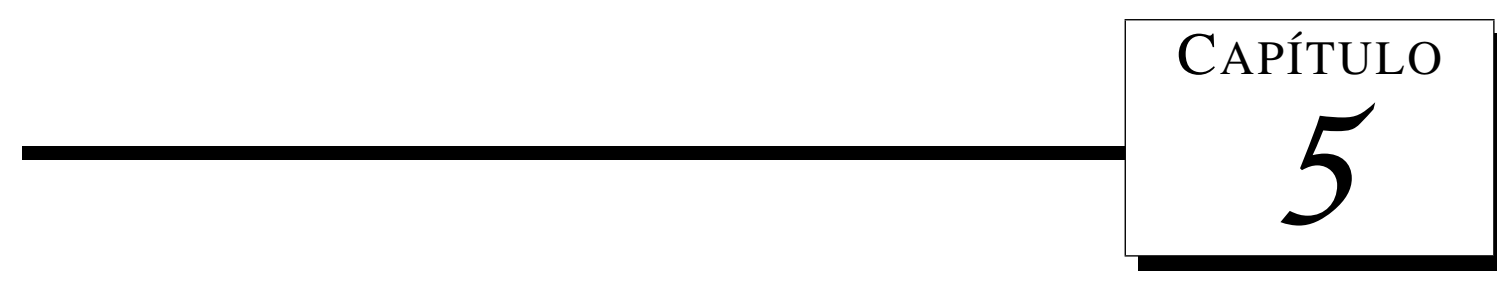

\section{Conclusões}

\subsection{Conclusões deste trabalho}

Este trabalho investigou o comportamento eletroaeroelástico linear e não linear de geradores piezelétricos de energia. Duas configurações foram consideradas: 1) uma seção típica piezoaeroelástica com 2-GDL e 2) uma seção típica piezoaeroelástica com 3-GDL. Em todos os casos, uma carga resistiva foi considerada no domínio elétrico do sistema com o objetivo de se estimar a potência elétrica gerada a partir de oscilações aeroelásticas persistentes. O acoplamento piezelétrico foi inserido no GDL de deslocamento linear enquanto diferentes não linearidades concentradas foram modeladas no GDL de rotação do aerofólio ou da superfície de controle, conforme o caso considerado.

Um modelo numérico por parâmetros concentrados eletromecanicamente acoplado foi obtido a partir do Princípio de Hamilton para corpos eletroaeroelásticos. Assim, todas as configurações de geradores foram modeladas, incluindo-se e excluindo-se convenientemente os termos das equações. A representação em espaço de estados foi apresentada para a simulação do comportamento no domínio do tempo e também para a análise de estabilidade do sistema, a partir dos autovalores da matriz de estados, para diferentes velocidades e condições de contorno elétricas. A aerodinâmica não estacionária para movimentos arbitrários de um aerofólio foi modelada com a aproximação de Jones para a função indicial de Wagner (uma aproximação para a função generalizada de Theodorsen).

A previsão numérica do comportamento piezoaeroelástico linear do sistema com 2-GDL foi verificada com sucesso a partir de resultados experimentais obtidos em ensaios em túnel de vento. Os ensaios foram realizados para diferentes resistores no domínio elétrico do problema e em velocidades próximas a fronteira de flutter do sistema. Entretanto, oscilações persistentes ocorrendo somente na velocidade linear de flutter é uma condição muito restrita para a geração 
piezoaeroelástica de energia.

Não linearidades concentradas foram modeladas no GDL de rotação do aerofólio com 2GDL e o comportamento piezoaeroelástico investigado. Quando uma mola bilinear foi modelada verificou-se a redução da velocidade onde oscilações persistentes começam ocorrer $(2 \mathrm{~m} / \mathrm{s}$ menor que a velocidade de flutter do caso linear, $12 \mathrm{~m} / \mathrm{s}$ ), o que é uma condição favorável para a geração de energia. O modelo numérico previu com sucesso o comportamento do sistema quando comparado com os resultados experimentais. A potência máxima gerada para o resistor ótimo é cerca de três vezes maior do que no caso linear. Entretanto, a faixa de velocidades onde oscilações persistentes ocorrem ainda é restrita.

Com o objetivo de se obter oscilações persistentes e com amplitudes aceitáveis em uma faixa mais ampla de velocidades, a não linearidade bilinear foi combinada com uma não linearidade cúbica. Verificou-se que a mola bilinear auxilia na redução da velocidade onde oscilações persistentes ocorrem e a não linearidade cúbica mantém as amplitudes limitadas por uma faixa ampla de velocidades do escoamento, aumentando o limite máximo de velocidade do escoamento na região de pós flutter do sistema. Assim, a utilização de não linearidades combinadas é um cenário atraente para a conversão piezoaeroelástica de energia.

O comportamento piezoaeroelástico do sistema com 2-GDL foi investigado para um conjunto de parâmetros determinados experimentalmente, tornando conveniente as comparações aqui já comentadas. Entretanto, é importante se analisar a influência da variação de parâmetros eletromecânicos sobre o comportamento do eletroaeroelástico (velocidade de flutter e potência elétrica gerada) do sistema linear com 2-GDL. Os resultados numéricos apresentados estabelecem tal influência e podem ser utilizados futuramente para o projeto e otimização de geradores piezoaeroelásticos de energia.

A previsão numérica do comportamento piezoaeroelástico de uma seção típica com 3-GDL também foi apresentada. A análise do caso linear, onde a maioria dos parâmetros do caso 2GDL foi mantida, mostrou a redução da velocidade de flutter devido à presença da superfície de controle no bordo de fuga da seção típica.

A modelagem de uma mola bilinear no GDL de rotação da superfície de controle tem um efeito positivo para a geração de energia a partir de oscilações aeroelásticas. Oscilações persistentes com amplitudes aceitáveis são observadas para uma faixa de velocidades de escoamento, permitindo a geração de energia. Neste caso, é importante observar que o sistema oscila em LCOs de pequena amplitude em uma faixa de velocidades e pode saltar para uma solução de maior amplitude a partir de uma certa velocidade, aumentando também a potência gerada. 
Por fim, uma mola cúbica foi modelada no GDL de rotação do aerofólio com 3-GDL, além da mola bilinear na superfície de controle. A análise do sistema para diferentes razões de rigidez e condições de contorno elétricas foi realizada. Verificou-se que o aumento de rigidez com aumento de ângulo de ataque propiciado pela mola cúbica limita a amplitude das oscilações persistentes em uma ampla faixa de velocidades, o que também torna o sistema mais adequado para aplicações práticas.

\subsection{Sugestões para trabalhos futuros}

Como sugestões para futuros trabalhos, vários temas podem ser sugeridos visando o aprimoramento desta dissertação e também um aprofundamento em alguns temas pouco explorados:

- Realização de experimentos em túnel de vento com não linearidades combinadas para o sistema com 2-GDL;

- Realização de experimentos em túnel de vento para um sistema com 3-GDL;

- Aplicação de técnicas para solução de problemas não lineares com o objetivo de otimizar a geração piezoaeroelástica de energia utilizando seção típica;

- Combinar diferentes mecanismos de transdução e realizar a conversão a partir de diferentes GDLs simultaneamente;

- Investigar a possibilidade da utilização de molas com memória de forma para o ajuste do comportamento aeroelástico do sistema para diferentes velocidades do escoamento;

- Investigar a possibilidade de redução de escala dos sistemas aqui estudados visando o projeto de geradores portáteis. 


\section{Referências}

ABDELKEFI, A.; NAYFEH, A.; HAJJ, M. Modeling and analysis of piezoaeroelastic energy harvesters. Nonlinear Dynamics, Springer Netherlands, v. 0, p. 1-15, 2011. ISSN 0924-090X. Disponível em: <www.springerlink.com/content/48mh108ux3165325/>.

AKAYDIN, H. D.; ELVIN, N.; ANDREOPOULOS, Y. Energy harvesting from highly unsteady fluid flows using piezoelectric materials. Journal of Intelligent Material Systems and Structures, v. 21, p. 1263-1278, 2010. Disponível em: <jim.sagepub.com/content/21/13/1263>.

ALIGHANBARI, H. Flutter analysis and chaotic response of an airfoil accounting for structural nonlinearities. Tese (Doutorado) - Department of Mechanical Engineering, McGill University, Montreal, Canada, 1995.

ALLEN, J. J.; SMITS, A. J. Energy harvesting EEL. Journal of Fluids and Structures, v. 15, n. 3-4, p. 629-640, 2001. Disponível em:

$<$ www.sciencedirect.com/science/article/pii/S0889974600903554>.

ANTON, S. R.; SODANO, H. A. A review of power harvesting using piezoelectric materials (2003-2006). Smart Materials and Structures, v. 16, n. 3, p. R1-R21, 2007. Disponível em: $<$ stacks.iop.org/0964-1726/16/i=3/a=R01 > .

ARNOLD, D. Review of microscale magnetic power generation. IEEE Transactions on Magnetics, v. 43, p. 3940-3951, 2007.

BEEBY, S. P.; TUDOR, M. J.; WHITE, N. M. Energy harvesting vibration sources for microsystems applications. Measurement Science And Technology, v. 17, p. R175-R195, 2006. Disponível em: <stacks.iop.org/MST/17/R175>.

BIBO, A.; LI, G.; DAQAQ, M. F. Electromechanical modeling and normal form analysis of an aeroelastic micro-power generator. Journal of Intelligent Material Systems and Structures, v. 22, n. 6, p. 577-592, April 2011. Disponível em: <jim.sagepub.com/content/22/6/577>.

BISPlinghOFF, R. L.; ASHLEY, H.; HALFMAN, R. L. Aeroelasticity. Cambridge, Massachussets: Addison-Wesley Publishing Company, Inc., 1955. 860 p.

BRYANT, M.; GARCIA, E. Modeling and testing of a novel aeroelastic flutter energy harvester. Journal of Vibration and Acoustics, v. 133, p. 011010 (11pp), 2011. Disponível em: $<$ http://dx.doi.org/10.1115/1.4002788>.

CHEN, S.-N.; WANG, G.-J.; CHIEN, M.-C. Analytical modeling of piezoelectric vibrationinduced micro power generator. Mechatronics, v. 16, n. 7, p. 397-387, 2006. Disponível em: $<$ sciencedirect.com/science/article/pii/S0957415806000316>. 
CONNER, M. D. Nonlinear aeroelasticity of an airfoil section with control surface freeplay. Tese (Doutorado) - Department of Mechanical Engineering and Materials Science, Duke University, 1996.

COOK-CHENNAULT, K. A.; THAMBI, N.; SASTRY, A. M. Powering MEMS portable devices - a review of non-regenerative and regenerative power supply systems with emphasis on piezoelectric energy harvesting systems. Smart Materials and Structures, v. 17, n. 4, p. 043001 (33pp), 2008. Disponível em: <stacks.iop.org/SMS/17/043001>.

DE MARQUI, C. et al. Linear and nonlinear modeling and experiments of a piezoaeroelastic energy harvester. In: Proceedings of the ASME 2010 Conference on Smart Materials, Adaptive Structures and Intelligent Systems. Philadelphia, Pennsylvania, USA: [s.n.], 2010. p. 9.

DE MARQUI, C.; ERTURK, A.; INMAN, D. J. Piezoaeroelastic modeling and analysis of a generator wing with continuous and segmented electrodes. Journal of Intelligent Material Systems and Structures, v. 21, n. 10, p. 983-993, 2010. Disponível em: $<$ jim.sagepub.com/content/21/10/983 $>$.

DE MARQUI, C. et al. Modeling and analysis of piezoelectric energy harvesting from aeroelastic vibrations using the doublet-lattice method. Journal of Vibration and Acoustics, v. 133, n. 1, p. 011003 (9pp), 2011. Disponível em: <http://dx.doi.org/10.1115/1.4002785>.

DOWELL, E. H.; EDWARDS, J.; STRGANAC, T. Nonlinear aeroelasticity. AIAA Journal of Aircraft, v. 40, p. 857-874, 2003.

DOWELL, E. H.; TANG, D. Nonlinear aeroelasticity and unsteady aerodynamics. AIAA Journal, v. 40, p. 1697-1707, 2002.

DUNNMON, J. A. et al. Power extraction from aeroelastic limit cycle oscillations. Journal of Fluids and Structures, v. 27, n. 8, p. 1182-1198, 2011. Disponível em: $<$ www.sciencedirect.com/science/article/pii/S0889974611000211 >.

DUTOIT, N. E.; WARDLE, B. L. Performance of microfabricated piezoelectric vibration energy harvesters. Integrated Ferroelectrics, An International Journal, v. 83, p. 13-32, 2006. Disponível em: < robotics.caltech.edu/ ndutoit/wiki/images/4/47/If2006.pdf $>$.

DUTOIT, N. E.; WARDLE, B. L.; KIM, S. G. Design considerations for MEMSscale piezoelectric mechanical vibration energy harvesters. Integrated Ferroelectrics, An International Journal, v. 71, p. 121-160, 2005. Disponível em: $<$ robotics.caltech.edu/ ndutoit/wiki/images/2/26/If2005.pdf $>$.

EDWARDS, J. W. Unsteady aerodynamic modeling and active aeroelastic control. Tese (Doutorado) - Department of Aeronautics and Astronautics, Stanford University, Stanford, California, 1977.

EDWARDS, J. W.; ASHLEY, H.; BREAKWELL, J. V. Unsteady aerodynamic modeling for arbitrary motions. AAIA Journal, v. 17, n. 4, p. 365-374, 1979.

ERTURK, A. et al. Piezoelectric energy harvesting from macro-fiber composites with an application to morphing wing aircrafts. In: Proceedings of the 19th International Conference of Adaptive Structures and Technologies. Ascona, Switzerland: [s.n.], 2008. Disponível em: $<$ library.eawag-empa.ch/icast_proceedings_2008_open_access/ICAST2008030.pdf > . 
ERTURK, A.; INMAN, D. J. A distributed parameter electromechanical model for cantilevered piezoelectric energy harvester plates. ASME Journal of Vibration and Acoustics, v. 130, n. 4, p. 041002 (15pp), Aug. 2008. Disponível em: <dx.doi.org/10.1115/1.2890402>.

ERTURK, A.; INMAN, D. J. Piezoelectric energy harvesting. [S.1.]: John Wiley \& Sons, Ltd., 2011.

ERTURK, A.; RENNO, J. M.; INMAN, D. J. Modeling of piezoelectric energy harvesting from an L-shaped beam-mass structure with an application to UAVs. Journal of Intelligent Material Systems and Structures, v. 20, n. 5, p. 529, 2009. Disponível em: $<$ jim.sagepub.com/content/20/5/529>.

ERTURK, A. et al. On the energy harvesting potential of piezoaeroelastic systems. Applied Physics Letters, v. 96, n. 18, p. 184103 (3pp), 2010. Disponível em: <apl.aip.org/resource/1/applab/v96/i18/p184103_s1>.

FUNG, Y. C. An introduction to the theory of aeroelasticity. [S.1.]: John Wiley \& Sons, 1955.

GIACOMELLO, A.; PORFIRI, M. Energy harvesting from flutter instabilities of heavy flags in water through ionic polymer metal composites. In: BAR-COHEN, Y.; CARPI, F. (Ed.). Electroactive Polymer Actuators and Devices (EAPAD) 2011, Proceedings of SPIE. [S.1.: s.n.], 2011. v. 7976, p. 797608 (9pp).

GLYNNE-JONES, P. et al. An electromagnetic, vibration-powered generator for intelligent sensor systems. Sensors and Actuators A, v. 110, p. 344-349, 2004.

HEMATI, N. Nondimensionalization of the equations of motion for permanent-magnet machines. Electric Machines \& Power Systems, v. 23, n. 5, p. 541-556, September 1995. Disponível em: <www.tandfonline.com/doi/abs/10.1080/07313569508955642>.

HENON, M. On the numerical computation of Poincaré maps. Physica D, v. 5, n. 2-3, p. 412-414, 1982. Disponível em: <dx.doi.org/10.1016/0167-2789(82)90034-3>.

HODGES, D. H.; PIERCE, G. A. Introduction to structural dynamics and aeroelasticity. [S.1.]: Cambridge Aerospace Series, 2002.

HU, J. Optimal design of vibration-based energy harvesting systems using magnetostrictive material (MsM). Tese (Doutorado) - Graduate Faculty of North Carolina State University, Raleigh, North Carolina, 2010.

JONES, R. T. Operational treatment of the non-uniform-lift theory in airplane dynamics. [S.1.], 1938. N.A.C.A. Technical Report 667.

JONES, R. T. The unsteady lift of a finite wing. [S.1.], 1939. N.A.C.A. Technical Report 682.

KWON, S.-D. A T-shaped piezoelectric cantilever for fluid energy harvesting. Applied Physics Letters, v. 97, p. 164102 (3pp), 2010. Disponível em: $<$ apl.aip.org/resource/1/applab/v97/i16/p164102_s1>.

LALLART, M.; GUYOMAR, D. Piezoelectric conversion and energy harvesting enhancement by initial energy injection. Applied Physics Letters, v. 97, n. 1, p. 014104 (3pp), 2010.

Disponível em: <http://apl.aip.org/resource/1/applab/v97/i1/p014104_s1>. 
LEE, B. H. K.; PRICE, S. J.; WONG, Y. S. Nonlinear aeroelastic analysis of airfoils: bifurcation and chaos. In: Progress in Aerospace Sciences. Elsevier Science Ltd., 1999. v. 35, n. 3, p. 205-334. Disponível em: <sciencedirect.com/science/article/pii/S0376042198000153>.

LI, S. G. D.; XIANG, J. Aeroelastic dynamic response and control of an airfoil section with control surface nonlinearities. Journal of Sound and Vibration, v. 329, p. 4756-4771, 2010.

LU, F.; LEE, H.; LIM, S. Modeling and analysis of micro piezoelectric power generators for micro-electromechanical-systems applications. Smart Materials and Structures, v. 13, n. 1, p. 57-63, 2004. Disponível em: <iopscience.iop.org/0964-1726/13/1/007>.

MANN, B. P.; SIMS, N. D. Energy harvesting from the nonlinear oscillations of magnetic levitation. Journal of Sound and Vibration, v. 319, n. 1-2, p. 515-530, 2009. Disponível em: $<$ sciencedirect.com/science/article/pii/S0022460X08005567 $>$.

MITCHESON, P. et al. MEMS electrostatic micro-power generator for low-frequency operation. Sensors and Actuators A, v. 115, p. 523-529, 2004.

MYERS, R. et al. Small scale windmill. Journal of Applied Physics, v. 90, n. 5, p. 054106, 2007. Disponível em: <apl.aip.org/resource/1/applab/v90/i5/p054106_s1>.

NAYFEH, A. H.; BALACHANDRAN, B. Applied nonlinear dynamics: analytical, computational, and experimental methods. New York: John Wiley \& Sons, Inc., 1995. (Wiley Series in Nonlinear Science).

OTT, E. Chaos in dynamical systems. [S.1.]: Cambridge University Press, 1993.

PENG, Z.; ZHU, Q. Energy harvesting through flow-induced oscillations of a foil. Physics of Fluids, v. 21, n. 12, p. 123602 (9pp), 2009. Disponível em: $<$ pof.aip.org/resource/1/phfle6/v21/i12/p123602_s1 >.

PETERS, D. A. Toward a unified lift model for use in helicopter rotor blade stability analyses. Journal of the American Helicopter Society, v. 30, n. 3, p. 32-43, 1985. Disponível em: $<$ ahsjournal.org/resource/1/jhesak/v30/i3/p32_s1 >.

POBERING, S.; SCHWESINGER, N. A novel hydropower harvesting device. In: Proceedings of the 2004 International Conference on MEMS, NANO and Smart Systems (ICMENS04). IEEE Computer Society, 2004. p. 480-485. Disponível em: $<$ ieeexplore.ieee.org/stamp/stamp.jsp?tp=arnumber $=1508997>$.

PRIYA, S. Advances in energy harvesting using low profile piezoelectric transducers. Journal of Electroceramics, v. 19, p. 167-184, 2007.

PRIYA, S. et al. Piezoelectric windmill: a novel solution to remote sensing. Japanese Journal of Applied Physics, v. 44, p. L104-L107, 2005. Disponível em: $<$ jjap.jsap.jp/link?JJAP/44/L104>.

RANCOURT, D.; TABESH, A.; FRECHETTE, L. G. Evaluation of centimeter-scale micro wind mills: aerodynamics and electromagnetic power generation. In: Proceedings of PowerMEMS 2007. [S.1.: s.n.], 2007. p. 93-96.

ROBBINS, W. et al. Wind-generated electrical energy using flexible piezoelectric materials. In: Proceedings of ASME IMECE 2006. Chicago, IL: [s.n.], 2006. 
ROUNDY, S.; WRIGHT, P. K.; RABAEY, J. A study of low level vibrations as a power source for wireless sensor nodes. Computers Communications, v. 23, p. 1131-1144, 2003.

SCHMIDT, V. H. Piezoelectric energy conversion in windmills. In: Ultrasonics Symposium, 1992. Proceedings., IEEE 1992. Tucson, AZ, USA: [s.n.], 1992. v. 2, p. 897-904. Disponível em: $<$ ieeexplore.ieee.org/stamp/stamp.jsp?tp=arnumber $=275842>$.

SIROHI, J.; MAHADIK, R. Piezoelectric wind energy harvester for low-power sensors. Journal of Intelligent Material Systems and S, v. 11, n. 16, p. (0), Dec. 2011. Disponível em: $<$ jim.sagepub.com/content/early/2011/11/16/1045389X11428366 >.

SODANO, H. A.; INMAN, D. J.; PARK, G. A review of power harvesting from vibration using piezoelectric materials. Shock and Vibration Digest, v. 36, n. 3, p. 197-205, 2004. Disponível em: <dx.doi.org/10.1177/0583102404043275>.

SOUSA, V. C. et al. Enhanced aeroelastic energy harvesting by exploiting combined nonlinearities: theory and experiment. Smart Materials and Structures, v. 20, p. 094007 (8pp), August 2011. Disponível em: <stacks.iop.org/SMS/20/094007>.

SOUSA, V. C.; D’ASSUNÇÃO, D.; DE MARQUI, C. Piezoaeroelastic typical section for wind energy harvesting. In: Proceedings of IMAC XXX - A Conference and Exposition on Structural Dynamics. Jacksonville, FL, USA: [s.n.], 2011.

SOUSA, V. C.; DE MARQUI, C. Modeling and analysis of a broadband piezoaeroelastic energy harvester. In: Proceedings of COBEM - Brazilian Congress of Mechanical Engineering. Natal, RN, Brazil: [s.n.], 2011.

TANG, D.; DOWELL, E. H. Aeroelastic airfoil with free play at angle of attack with gust excitation. AIAA Journal, v. 48, n. 2, p. 427-442, 2010.

TANG, D.; DOWELL, E. H.; VIRGIN, L. N. Limit cycle behavior of an airfoil with a control surface. Journal of Fluids and Structures, v. 12, p. 839-858, 1998.

TANG, L.; PAIDOUSSIS, M.; JIANG, J. Cantilevered flexible plates in axial flow: energy transfer and the concept of flutter-mill. Journal of Sound and Vibration, v. 326, n. 1-2, p. $263-$ 276, 2009. Disponível em: <sciencedirect.com/science/article/pii/S0022460X09004076>.

TAVARES, E. J. Modelo experimental para ensaios de flutter de uma seção típica aeroelástica. Dissertação (Mestrado) - Escola de Engenharia de São Carlos, Universidade de São Paulo, 2009.

TAYLOR, G. W. et al. The energy harvesting eel: a small subsurface ocean/river power generator. IEEE Journal of Oceanic Engineering, v. 26, n. 4, p. 539-547, October 2001. Disponível em: <ieexplore.ieee.org/stamp/stamp.jsp?tp=arnumber=972090 $>$.

THEODORSEN, T. General theory of aerodynamic instability and the mechanism of flutter. [S.1.], 1935.

THORBY, D. Structural dynamics and vibration in practice - an engineering handbook. 1. ed. [S.1.]: Butterworth-Heinemann, 2008. 419 p. 
TRICKEY, S. T. Global and local dynamics of an aeroelastic system with a control surface freeplay nonlinearity. Tese (Doutorado) - Department of Mechanical Engineering and Materials Science, Duke University, 2000.

WANG, L.; YUAN, F. G. Vibration energy harvesting by magnetostrictive material. Smart Materials and Structures, v. 17, n. 4, p. 045009 (14pp), 2008. Disponível em: $<$ iopscience.iop.org/0964-1726/17/4/045009>.

WILLIAMS, C. B.; YATES, R. B. Analysis of a micro-electric generator for microsystems. Sensors and Actuators A, v. 52, p. 8-11, 1996.

XU, F. J. et al. Design of a miniature wind turbine for powering wireless sensors. In: Proceedings of SPIE 7646. [S.1.: s.n.], 2010. p. 764741.

ZHAO, Y. Vibration suppression of a quadrilateral plate using hybrid piezoelectric circuits. Journal of Vibration and Control, v. 16, n. 5, p. 701-720, 2010. Disponível em: $<$ jvc.sagepub.com/content/16/5/701 $>$.

ZHU, D. et al. A novel miniature wind generator for wireless sensing applications. In: IEEE Sensors 2010. [s.n.], 2010. Disponível em: <eprints.ecs.soton.ac.uk/21682/>.

ZHU, Q. Optimal frequency for flow energy harvesting of a flapping foil. Journal of Fluids Mechanics, v. 675, p. 495-517, 2011. 


\section{APÊNDICE A - Equações de Lagrange para o Sistema Piezoaeroelástico}

A formulação das equações eletromecânicas de Lagrange apresentada a seguir seguirá os passos de Erturk e Inman (2011).

O princípio de Hamilton extendido para um sistema eletromecânico (na ausência de efeitos mecânicos dissipativos) é dado,

$$
\int_{t_{1}}^{t_{2}}\left(\delta T-\delta U+\delta W_{i e}+\delta W_{n c}\right) d t=0
$$

onde $\delta T, \delta U$ e $\delta W_{i e}$ são, respectivamente, a primeira variação da energia cinética total, da energia potencial total e da energia elétrica interna; $W_{n c}$ é o trabalho virtual das componentes não-conservativas de força mecânica e carga elétrica.

A energia cinética total pode ser expressa em função de coordenadas generalizadas e de suas respectivas derivadas no tempo,

$$
T=T\left(q_{1}, q_{2}, \ldots, q_{n}, \dot{q}_{1}, \dot{q}_{2}, \ldots, \dot{q}_{n}\right)
$$

ao passo que a energia potencial total e a energia elétrica interna são funções das coordenadas generalizadas apenas,

$$
\begin{gathered}
U=U\left(q_{1}, q_{2}, \ldots, q_{n}\right) \\
W_{i e}=W_{i e}\left(q_{1}, q_{2}, \ldots, q_{n}\right)
\end{gathered}
$$

onde $q_{k}$ representa cada uma das $n$ coordenadas do sistema considerado.

A primeira variação de $T, U$ e $W_{i e}$ é, respectivamente,

$$
\begin{gathered}
\delta T=\sum_{k=1}^{n}\left(\frac{\partial T}{\partial q_{k}} \delta q_{k}+\frac{\partial T}{\partial \dot{q}_{k}} \delta \dot{q}_{k}\right) \\
\delta U=\sum_{k=1}^{n} \frac{\partial U}{\partial q_{k}} \delta q_{k}
\end{gathered}
$$




$$
\delta W_{i e}=\sum_{k=1}^{n} \frac{\partial W_{i e}}{\partial q_{k}} \delta q_{k}
$$

e o trabalho virtual $W_{n c}$ é,

$$
\delta W_{n c}=\sum_{k=1}^{n} Q_{k} \delta q_{k}
$$

onde $Q_{k}$ são as forças não-conservativas.

O princípio de Hamilton extendido, Eq. (A.1), se torna, então,

$$
\int_{t_{1}}^{t_{2}} \sum_{k=1}^{n}\left[\left(\frac{\partial T}{\partial q_{k}}-\frac{\partial U}{\partial q_{k}}+\frac{\partial W_{i e}}{\partial q_{k}}+Q_{k}\right) \delta q_{k}+\frac{\partial T}{\partial \dot{q}_{k}}\right] d t=0
$$

assumindo que $\delta q_{k}=0$ quando $t=t_{1}$ e $t=t_{2}$.

Fazendo-se a integração por partes do último termo da equação anterior, o princípio de Hamilton extendido pode, portanto, ser expresso como,

$$
\int_{t_{1}}^{t_{2}} \sum_{k=1}^{n}\left[\frac{\partial T}{\partial q_{k}}-\frac{\partial U}{\partial q_{k}}+\frac{\partial W_{i e}}{\partial q_{k}}+Q_{k}-\frac{d}{d t}\left(\frac{\partial T}{\partial \dot{q}_{k}}\right)\right] \delta q_{k} d t=0
$$

Para deslocamentos virtuais arbitrários, a Eq. (A.10) se reduz às equações eletromecânicas de Lagrange,

$$
\frac{d}{d t}\left(\frac{\partial T}{\partial \dot{q}_{k}}\right)-\frac{\partial T}{\partial q_{k}}+\frac{\partial U}{\partial q_{k}}-\frac{\partial W_{i e}}{\partial q_{k}}=Q_{k}
$$

e os efeitos mecânicos dissipativos podem, então, ser introduzidos como forças não-conservativas. 


\section{APÊNDICE B - Submatrizes do Modelo Aerodinâmico}

As contribuições não circulatórias são (EDWARDS, 1977),

$$
\begin{gathered}
\mathbf{M}_{n c}=\left[\begin{array}{ccc}
-\pi\left(\frac{1}{8}+a^{2}\right) & -2 T_{13} & \pi a \\
-2 T_{13} & \frac{T_{3}}{\pi} & T_{1} \\
\pi a & T_{1} & -\pi
\end{array}\right] \\
\mathbf{K}_{n c}=\left[\begin{array}{ccc}
0 & -\left(T_{10}+T_{4}\right) & 0 \\
0 & \frac{1}{\pi}\left(T_{4} T_{10}-T_{5}\right) & 0 \\
0 & 0 & 0
\end{array}\right] \\
\mathbf{B}_{n c}=\left[\begin{array}{ccc}
\pi\left(a-\frac{1}{2}\right) & 2 p+\left(\frac{1}{2}-a\right) T_{4} & 0 \\
-p+T_{1}+\frac{T_{4}}{2} & \frac{T_{11} T_{4}}{2 \pi} & 0 \\
-\pi & T_{4} & 0
\end{array}\right]
\end{gathered}
$$

e as contribuições circulatórias são,

$$
\begin{aligned}
& \mathbf{R}=\left[\begin{array}{c}
2 \pi\left(a+\frac{1}{2}\right) \\
-T_{12} \\
-2 \pi
\end{array}\right] \\
& \mathbf{S}_{1}=\left[\begin{array}{lll}
1 & \frac{T_{10}}{\pi} & 0
\end{array}\right] \\
& \mathbf{S}_{2}=\left[\begin{array}{lll}
\left(\frac{1}{2}-a\right) & \frac{T_{11}}{2 \pi} & 1
\end{array}\right] \\
& \mathbf{S}_{\mathbf{3}}=\left[\begin{array}{ll}
0.006825\left(\frac{U}{b}\right)^{2} & 0.10805\left(\frac{U}{b}\right)
\end{array}\right]
\end{aligned}
$$

As matrizes que constituem as duas equações diferenciais adicionais associadas à aproximação de aerodinâmica não-estacionária para movimentos arbitrários de aerofólio no tempo adimensional são uma modificação das matrizes apresentadas em Edwards (1977), e são definidas a seguir. 


$$
\begin{gathered}
\tilde{\mathbf{D}}=\frac{1}{\omega_{h}^{2}} \mathbf{D} \\
\tilde{\mathbf{E}}_{1}=\frac{1}{\omega_{h}^{2}}\left(\frac{U}{b}\right)\left[\begin{array}{c}
\mathbf{0} \\
\mathbf{S}_{1}
\end{array}\right] \\
\tilde{\mathbf{E}}_{2}=\frac{1}{\omega_{h}}\left[\begin{array}{c}
\mathbf{0} \\
\mathbf{S}_{2}
\end{array}\right] \\
0 \\
\tilde{\mathbf{F}}_{p}=\frac{1}{\omega_{h}^{2}}\left[\begin{array}{cc}
0.01365\left(\frac{U}{b}\right)^{2} & -0.3455\left(\frac{U}{b}\right)
\end{array}\right]
\end{gathered}
$$




\section{APÊNDICE C - Constantes de Theodorsen}

$$
\begin{gathered}
T_{1}=-\frac{1}{3} \sqrt{1-c^{2}}\left(2+c^{2}\right)+c \cos ^{-1} c \\
T_{2}=c\left(1-c^{2}\right)-\sqrt{1-c^{2}}\left(1+c^{2}\right) \cos ^{-1} c+c\left(\cos ^{-1} c\right)^{2} \\
T_{3}=-\left(\frac{1}{8}+c^{2}\right)\left(\cos ^{-1} c\right)^{2}+\frac{1}{4} \sqrt{1-c^{2}} \cos ^{-1} c\left(7+2 c^{2}\right)-\frac{1}{8} c\left(1-c^{2}\right)\left(5 c^{2}+4\right) \\
T_{4}=-\cos ^{-1} c+c \sqrt{1-c^{2}} \\
T_{5}=-\left(1-c^{2}\right)-\left(\cos ^{-1} c\right)^{2}+2 c \sqrt{1-c^{2}} \cos ^{-1} c \\
T_{6}=T_{2} \\
T_{7}=-\left(\frac{1}{8}+c^{2}\right) \cos ^{-1} c+\frac{1}{8} c \sqrt{1-c^{2}}\left(7+2 c^{2}\right) \\
T_{8}=-\frac{1}{3} \sqrt{1-c^{2}}\left(2 c^{2}+1\right)+c \cos ^{-1} c \\
T_{9}=\frac{1}{2}\left[\frac{1}{3}\left(\sqrt{1-c^{2}}\right)^{3}+a T_{4}\right] \\
T_{10}=\sqrt{1-c^{2}}+\cos ^{-1} c \\
T_{11}=\cos ^{-1} c(1-2 c)+\sqrt{1-c^{2}}(2-c) \\
T_{12}=\sqrt{1-c^{2}}(2+c)-\cos ^{-1} c(2 c+1) \\
T_{13}=\frac{1}{2}\left[-T_{7}-(c-a) T_{1}\right] \\
T_{14}=\frac{1}{16}+\frac{1}{2} a c
\end{gathered}
$$




\section{Publicações decorrentes deste trabalho}

- SOUSA, V. C.; ANICÉZIO, M. M.; DE MARQUI JR., C.; ERTURK, A.

Enhanced aeroelastic energy harvesting by exploiting combined nonlinearities: theory and experiment. Smart Materials and Structures, v.20, p.094007 (8pp), August 2011. DOI: 10.1088/0964-1726/20/9/094007. Disponível em: <stacks.iop.org/SMS/20/094007>

- SOUSA, V. C.; DE MARQUI JR., C.

Modeling and analysis of a broadband piezoaeroelastic energy harvester. In: Proceedings of COBEM, Brazilian Congress of Mechanical Engineering. Oct. 24-28 - Natal, RN, Brazil, 2011.

- SOUSA, V. C.; D’ASSUNÇÃO, D.; DE MARQUI JR., C.

Piezoaeroelastic typical section for wind energy harvesting. In: Proceedings of IMAC XXX, A Conference and Exposition on Structural Dynamics. Jan. 30-Feb. 2 - Jacksonville, FL, USA, 2012. 